\title{
On the Interpretation of Results from Small Punch Creep Tests
}

\author{
T H Hyde*, S Miroslav, W Sun and C J Hyde \\ Department of Mechanical, Materials and Manufacturing Engineering \\ University of Nottingham, Nottingham NG7 2RD UK \\ * Corresponding Author: Thomas.hyde@nottingham.ac.uk
}

\begin{abstract}
The small punch creep testing method is highly complex and involves interactions between a number of nonlinear processes. The deformed shapes which are produced from such tests are related to the punch and specimen dimensions and to the elastic, plastic and creep behaviour of the test material, under contact and large deformation conditions, at elevated temperature. Due to its complex nature, it is difficult to interpret the small punch test creep data in relation to the corresponding uniaxial creep behaviour of the material. One of the aims of this paper is to identify the important characteristics of the creep deformation resulting from "localised" deformations and from the "overall" deformation of the specimen. Following this, the results of approximate analytical and detailed finite element analyses of small punch tests are investigated. It is shown that the regions of the uniaxial creep test curves dominated by primary, secondary and tertiary creep, are not those which are immediately apparent from the displacement versus time records produced during a small punch test. On the basis of the interpretation of the finite element results presented, a method based on a reference stress approach is proposed for interpreting the results of small punch test experimental data. Future work planned for the interpretation of small punch tests data is briefly addressed.
\end{abstract}

Keywords: $\quad$ Small punch test; Creep; Norton's law; Kachanov damage model; Finite element analysis; Data interpretation

\section{NOTATION}

$\begin{array}{ll}\mathrm{a}_{\mathrm{p}}, \mathrm{R}_{\mathrm{s}}, \mathrm{t}_{\mathrm{o}} & \text { Dimensions of small punch test specimen } \\ \mathrm{B}, \mathrm{n} & \text { Constants in Norton's creep law } \\ \mathrm{BM}, \mathrm{HAZ}, \mathrm{WM} & \text { Base material, heat-affected zone and weld metal, respectively } \\ \mathrm{D} & \text { Reference multiplier } \\ \mathrm{FE} & \text { Finite element } \\ \mathrm{K}_{\mathrm{S}} & \text { Correction factor for membrane stress } \\ \mathrm{M}, \phi & \text { Constants in the Kachanov damage model } \\ \mathrm{P}, \mathrm{P}_{\mathrm{L}} & \text { Load and limit load } \\ \mathrm{SCF} & \text { Stress concentration factor } \\ \mathrm{SPT} & \text { Small punch test } \\ \mathrm{t}, \mathrm{t}_{\mathrm{f}} & \text { Time and failure time } \\ \alpha & \text { Reference stress scaling factor or material constant in Kachanov } \\ \beta, \eta & \text { damage model } \\ \Delta & \text { Reference conversion parameters } \\ \dot{\Delta}, \dot{\Delta}_{\min } & \text { Displacement } \\ & \text { Displacement rate and minimum displacement rate }\end{array}$




$\begin{array}{ll}\varepsilon, \varepsilon^{\mathrm{c}}, \varepsilon_{\mathrm{eng}}, \varepsilon_{\mathrm{eq}}^{\mathrm{c}}, \varepsilon_{\mathrm{m}} & \begin{array}{l}\text { Strain, creep strain, engineering strain, equivalent creep strain and } \\ \text { mean strain, respectively }\end{array} \\ \dot{\varepsilon}, \dot{\varepsilon}_{\mathrm{min}}^{\mathrm{c}}, \dot{\varepsilon}\left(\sigma_{\mathrm{ref}}\right) & \begin{array}{l}\text { Strain rate, minimum creep strain rate and strain rate at reference } \\ \text { stress, respectively }\end{array} \\ \chi & \text { Constant in the Kachanov damage model } \\ \sigma, \sigma_{\mathrm{m}}, \sigma_{\mathrm{y}} & \text { Stress, meridional membrane stress and yield stress, respectively } \\ \sigma_{1}, \sigma_{\mathrm{eq}} & \text { Maximum principle stress and von-Mises equivalent stress } \\ \sigma_{\text {nom }}, \sigma_{\mathrm{o}} & \text { Nominal stress and initial (nominal) stress } \\ \sigma_{r e f}, \sigma_{r e f}^{R} & \text { Reference stress and rupture reference stress } \\ \theta & \text { Cone angle } \\ \omega, \dot{\omega} & \text { Damage variable and damage rate in Kachanov damage model }\end{array}$

\section{INTRODUCTION}

Many components in conventional and nuclear power plant, chemical plant and aeroengines, for example, operate at temperatures high enough for such things as creep strains, creep damage, microstructure degradation, etc. to occur [1]. These phenomena may result in the premature failure of components [2]. Hence, non-destructive testing is often carried out as part of remaining plant life assessment processes [3]. For some components it is possible to extract small samples of material without significantly reducing the integrity of the structure from which the material is taken [3]. Also, in some regions, such as the heat-affected zones of welds [4], the amount of material which exists may be small. Similarly, when new alloys are being developed, it may only be viable to manufacture small quantities of the material. As a result, a number of attempts have been made to devise small specimen tests for determining engineering properties from small material samples [5]. Three specimen types have mainly been used for determining creep properties from small material samples. These are miniature tensile creep specimens [e.g. 3], impression creep specimens [6] and small punch test specimens [e.g. 7]; Figs. 1(a) to 1(c) show a typical conventional uniaxial creep test specimen and a typical set of uniaxial creep and creep rupture test data. Figs. 2(a) - 2(c) show the small specimens mentioned above. More recently an alternative small, creep test specimen, which enables a relatively large equivalent gauge length to be achieved, has been proposed [8]. The processing and interpretation of the results from miniature tensile creep specimens is the same as that used for conventional uniaxial creep tests [9]. Also, a mechanics-based procedure has been developed [6] for interpretation of the results from impression creep tests. In general, only the primary and secondary creep properties can be determined from impression creep tests; see Fig. 1(b) for typical uniaxial creep behaviour curves showing the primary, secondary and tertiary regions. The small punch creep specimen test procedure has also been used to estimate creep properties [7] related to the secondary and tertiary ranges of creep. However, although a code of practise for performing small punch tests has been produced [10] and is becoming generally accepted, there is still a need for a mechanics based approach to explain how the failure time, stress and strain rate from uniaxial tests correspond to the small punch test specimen data.

This paper contains the results of approximate analytical and detailed finite element (FE) analyses of small punch creep tests. It is shown that the regions of the test data dominated by primary, secondary and tertiary creep are not those which are immediately apparent from the 
displacement versus time records produced during the small punch tests. On the basis of the interpretation of the FE results presented, a method is proposed for interpreting the results of experimental small punch creep tests.

\section{GENERAL DESCRIPTION OF SMALL PUNCH TEST SPECIMEN BEHAVIOUR}

\section{1 "Problem Definition"}

A small punch test (SPT) setup is shown schematically in Fig. 3(a). A typical SPT specimen has the following dimensions: $a_{p}=2 \mathrm{~mm}, \mathrm{R}_{\mathrm{S}}=1.25 \mathrm{~mm}$ and $\mathrm{t}_{\mathrm{o}}=0.5 \mathrm{~mm}$. The form of the displacement versus time output obtained from a small punch creep test is shown schematically in Fig. 3(b). The output (typically) includes an initially high, but rapidly decreasing, displacement rate which reduces to a minimum value, which persists for a relatively long time, before accelerating towards the end of the test, leading to fracture. Fig. 3 (b) is shown to indicate the relative durations and the extents of the deformations which occur at the various stages of a typical test. Typical test curves are shown in Fig. 3(c), where $\mathrm{BM}, \mathrm{HAZ}$ and WM refer to the base material, the heat-affected zone and the weld metal of the weld, respectively.

The small punch test is highly complex and involves the interactions between a number of nonlinear processes. These include:

(i) Contact: the contact area between the specimen and the punch increases as the "constant load" creep test progresses (the friction conditions may also be important).

(ii) Non-linear material: in general the elastic-plastic and the creep strains are non-linearly related to the stress state (the simplest constitutive equations that demonstrate this are the elastic-perfectly plastic model and the Norton creep equation [1], i.e. $\dot{\varepsilon}^{\mathrm{c}}=\mathrm{B} \sigma^{\mathrm{n}}$ ).

(iii) Large deformation: the specimen starts as a flat plate and ends up being approximately conical in shape with a part-spherical shaped end, as indicated in Fig. 3(a).

(iv) Large strains: for most engineering materials, which have been tested using the small punch test method [e.g. 11], the failure strains obtained from uniaxial tests are in excess of 25\% (see Fig. 1(b)) and for SPT specimens, there is often evidence of localised "necking" at or near the edge of contact between the specimen and the punch [12], at which position the strains are significantly greater than the general strain level in the specimen as a whole.

Taking into account the highly non-linear behaviours experienced during a test, it is hardly surprising that the interpretation of the results is difficult.

\subsection{Approximate Theoretical Models}

The most comprehensive theoretical study which is relevant to the SPT setup is that of Chakrabarty [13]. However, there are a number of restrictions which limit its direct applicability to the SPT specimen behaviour. These include (i) the requirement that the specimen thickness is small compared to the punch radius and (ii) the analysis is strictly only 
applicable to a specific material behaviour model (rigid plastic) which is assumed in the analysis. Notwithstanding these, and other limitations, the analysis provides some very useful insights into the likely creep behaviour of a SPT specimen. In particular, Yang and Wang [12] have used the Chakrabarty model to derive equations relating (i) the equivalent strain, $\varepsilon_{\text {eq }}$, at the edge of contact between the specimen and the sphere to the overall displacement, $\Delta$, and (ii) the membrane stress, $\sigma_{m}$, for an applied force, $\mathrm{P}$, to the displacement. For a specimen with $\mathrm{a}_{\mathrm{p}}=2 \mathrm{~mm}, \mathrm{R}_{\mathrm{S}}=1.25 \mathrm{~mm}$ and $\mathrm{t}_{\mathrm{o}}=0.5 \mathrm{~mm}$, the relationships are:

$$
\begin{gathered}
\varepsilon_{e q}=0.17959 \Delta+0.09357 \Delta^{2}+0.0044 \Delta^{3} \\
\frac{P}{\sigma_{m}}=1.72476 \Delta-0.05638 \Delta^{2}-0.17688 \Delta^{3}
\end{gathered}
$$

Yang and Wang also derived an equation relating the equivalent strain at the disc centre to the deflection [12]. There is a maximum value for $P / \sigma_{m}[\mathbf{1 0 , 1 3}]$ and this has been related to $a_{p}, R_{S}$ and $t_{0}[\mathbf{1 0}]$, i.e.

$$
\left(\frac{\mathrm{P}}{\sigma_{\mathrm{m}}}\right)=3.33 \mathrm{~K}_{\mathrm{S}} \mathrm{a}_{\mathrm{p}}{ }^{-0.2} \mathrm{R}_{\mathrm{S}}{ }^{1.2} \mathrm{t}_{0}
$$

where $\mathrm{K}_{\mathrm{s}}$ is a non-dimensional correction factor, determined empirically for the particular material. The $\mathrm{K}_{\mathrm{S}}$ factor is used to take into account the localised "necking" effect of the specimen during the "coning" deformation process which is believed to be material dependant [10].

\subsection{Estimate of "General" Strain Levels and Membrane Stresses in a SPT Specimen}

Experimental observations show that high strain levels and near failure necking occur in the specimen at a position close to the edge of the contact with the sphere [14]. The severe strain variations can make it difficult to interpret the overall behaviour of the specimen. In this section, an approximate analysis is carried out which allows the "general" strain levels to be estimated.

In order to estimate the "general" strain levels, it is assumed that as deformation occurs, at a given time, the specimen thickness reduces, but remains the same for all positions within the specimen, as indicated in Fig. 4. It is also assumed that the thickness, $t$, is small compared with $\mathrm{R}_{\mathrm{S}}, \mathrm{a}_{\mathrm{p}}$ and $\Delta$.

The surface area of the cone with centre line OO' and cone surface ED is given by:

$$
A_{\text {s, one }}=\pi a_{p} L
$$

where the differences in area between the assumed conical (FD) and actual spherical (FC) end of the specimen is neglected. 
Also,

$$
\tan \theta=\frac{a_{p}}{h}
$$

Assuming constant volume during deformation gives:

Therefore

$$
\begin{gathered}
\pi a_{p} \sqrt{h^{2}+a_{p}{ }^{2}} t=\pi a_{p}{ }^{2} t_{0} \\
\frac{t}{t_{0}}=\frac{1}{\sqrt{1+\left(\frac{h}{a_{p}}\right)^{2}}}=\frac{1}{\sqrt{1+\frac{1}{\tan ^{2} \theta}}}
\end{gathered}
$$

The length

$$
\mathrm{AB}^{\prime} \mathrm{C}^{\prime}=\mathrm{ED}-\mathrm{BD}+\mathrm{B}^{\prime} \mathrm{C}^{\prime} \approx \frac{\mathrm{a}_{\mathrm{p}}}{\sin \theta}-\frac{\mathrm{R}_{\mathrm{S}}}{\tan \theta}+\mathrm{R}_{\mathrm{S}}\left(\frac{\pi}{2}-\theta\right)
$$

The "general" strain level

$$
\begin{gathered}
\bar{\varepsilon}_{m}=\ln \left(\frac{\frac{a_{p}}{\sin \theta}-\frac{R_{S}}{\tan \theta}+R_{S}\left(\frac{\pi}{2}-\theta\right)}{a_{p}}\right) \\
\bar{\varepsilon}_{\mathrm{m}}=\ln \left(\frac{1}{\sin \theta}-\frac{\mathrm{R}_{\mathrm{S}}}{\mathrm{a}_{\mathrm{p}} \tan \theta}+\frac{\mathrm{R}_{\mathrm{S}}}{\mathrm{a}_{\mathrm{p}}}\left(\frac{\pi}{2}-\theta\right)\right)
\end{gathered}
$$

Similarly, an expression for the displacement, $\Delta$, in terms of cone angle, $\theta$, can be obtained,

i.e.

$$
\Delta \approx F D-O^{\prime} D+R_{S}
$$

i.e.

$$
\frac{\Delta}{a_{p}} \approx \frac{1}{\tan \theta}-\frac{R_{S}}{a_{p}}\left(\frac{1}{\sin \theta}-1\right)
$$

The variation of $t / t_{0}$ with $\theta$ (Equ. (7), $t / t_{0}$ with $\Delta / a_{p}$ (Equs. (7) and (12)), $\Delta / a_{p}$ with $\theta$ (Equ (12), $\bar{\varepsilon}_{m}$ with $\theta$ (Equ (10) and $\bar{\varepsilon}_{m}$ with $\Delta / a_{p}$ (Equs. (10) and (12)) are given in Figs. 5 - 9.

The meridional, membrane stress, $\sigma_{\mathrm{m}}$, at a position defined by radius $\mathrm{r}$ (see Fig. 4 ) is given by :

$$
\sigma_{m}=\frac{P}{2 \pi r t \cos \theta}
$$

Using Equ. (7) gives: 


$$
\sigma_{m}=\frac{P}{2 \pi r t_{0}} \frac{\sqrt{1+\frac{1}{\tan ^{2} \theta}}}{\cos \theta}
$$

Taking the maximum membrane stress, $\hat{\sigma}_{m}$, to be that at the edge of contact between the specimen and the sphere, where $r=R_{S} \cos \theta$ (position BB' in Fig. 4), as indicated by experimental observation [e.g. 10], then:

$$
\sigma_{m}=\frac{P}{2 \pi R_{s} t_{0}} \frac{\sqrt{1+\frac{1}{\tan ^{2} \theta}}}{\cos ^{2} \theta}
$$

The predicted variation of

$$
\sigma_{m} / \frac{P}{2 \pi R_{S} t_{0}} \text { with } \theta \text { and } \sigma_{m} / \frac{P}{2 \pi R_{S} t_{0}} \text { with } \Delta / a_{p} \text { are given in Figs. }
$$

10 and 11 , respectively.

Equations (1), (2 and (3) are applicable to a specific position in the specimen, whereas equations (4) to (15) provide a measure of stress and strain which characterises the "general" states of stress and strain within the specimen. This is based on a very much simpler analysis to obtain the relationships between the "general" states of stress, strain and deformation which exist in the specimen; a clear statement of the assumptions made in the derivation of the "simpler" equations is provided. The assumption which causes the most significant difference between the derivations by Chakrabarty and that in the simplified analysis is that in the present derivation the specimen thickness is allowed to vary with deformation but it is assumed to be the same at every position within the conical and spherical zones, at any particular time.

The predicted variations of $\mathrm{P} / \sigma_{\mathrm{m}}$ and $\varepsilon_{\mathrm{m}}$ with normalised displacement, $\Delta / \mathrm{a}_{\mathrm{p}}$, are given in Fig. 12(a) and 12(b); $\varepsilon_{\mathrm{m}}$ is the meridional strain in the conical section at the edge of contact between the specimen and the punch and $\sigma_{\mathrm{m}}$ is the corresponding meridional membrane stress. It can be seen that the predictions for the membrane stress are in reasonably good agreement (Fig. 12(b)). However, although the predictions of membrane strain have similar trends (Fig. 12(a)) there is a factor of about 2 times difference for $\Delta / a_{p} \geq 0.3$. This is explicable by the fact that the present model assumes the thickness to be constant (at any given instant), whereas Chakrabarty's model [13] allows the thickness to vary. Hence the Chakrabarty model would be expected to result in higher strains at the "edge of contact" than the present model. Both models consider membrane behaviour only. Hence, neither model is applicable for low $\Delta / a_{p}$ values (i.e. $\Delta / a_{p}<0.3$ ). An important observation is that in a typical test [e.g. 15] the constant displacement rate region of the curve does not occur until $\Delta / a_{p} \geq$ 0.5 , by which time the general strain levels in the specimen (as indicated by the model described in this section) are between 10 and 15\% and the peak strains (as indicated by the Chakrabarty model) are about 30\%, see Fig. 12(a). These strain levels are way beyond the strain levels normally associated with primary and secondary creep and, usually these would only be expected to occur well into the tertiary region, close to failure. Of the four types of 
"non-linear" behaviour described in section 2.1, the relationship between contact area (a function of $\theta$, see Fig. 4) and displacement, $\Delta$, is not likely to be greatly affected by the precise details of the material behaviour model; this is implied by Equ. (12). Also, the strain distribution (expected near to failure) is not strongly affected by the precise material behaviour for a given displacement, $\Delta$, as Equs. (1) and (10) indicate. However, the material behaviour model will have a direct effect on the displacement, $\Delta$, versus time for a given load, and on the displacement rate, $\dot{\Delta}$, versus load, for a given deformation value. Hence, the material behaviour model and the failure criterion seem to be the most important parameters which affect the behaviour observed in a small punch test.

\subsection{Two Simple Material Behaviour Models}

Relatively simple material behaviour models, e.g. a Norton secondary creep law [1] and a Kachanov damage mechanics model [e.g. 16], are capable of describing tertiary creep leading to ductile failure in the case of a Norton behaviour model (see section 2.4.1) and tertiary creep leading to brittle failure in the case of a damage mechanics model (see section 2.4.2); these two cases are typical of the main types of creep behaviour models currently used to predict the creep behaviour of components [e.g. 4].

\subsubsection{Ductile Failure of a Uniaxial Specimen Obeying a Norton Creep Law}

In the case of creep ductile failure, a large deformation analysis is required. Norton's creep law relates the uniaxial strain rate to the stress via the equation:

$$
\dot{\varepsilon}=B \sigma^{n}
$$

For a specimen with an initial cross-section area of $\mathrm{A}_{0}$, and initial gauge length of $\mathrm{L}_{0}$, subjected to a constant load $\mathrm{P}$, the gauge length will increase (instantaneous value $\mathrm{L}$ ) and the cross section area will decrease (instantaneous value A). Assuming creep occurs under constant volume conditions, then:

$$
L A=L_{0} A_{0}
$$

Hence

$$
A \frac{d L}{d t}+L \frac{d A}{d t}=0
$$

The instantaneous stress, $\sigma$, is given by:

$$
\sigma=\frac{P}{A}
$$

From Equ. (18) it follows that: 


$$
\frac{\mathrm{dL} / \mathrm{dt}}{\mathrm{L}}=-\frac{\mathrm{dA} / \mathrm{dt}}{\mathrm{A}}
$$

Hence

$$
\dot{\varepsilon}=-\frac{1}{A} \frac{d A}{d t}
$$

Substituting Equ. (19) into (16) and using (21) gives:

$$
B \frac{P^{n}}{A^{n}}=-\frac{1}{A} \frac{d A}{d t}
$$

For a ductile material, failure occurs as $A \rightarrow 0$. Therefore, the failure time, $\mathrm{t}_{\mathrm{f}}$, is obtained from Equ. (22) as:

$$
B P^{n} \int_{0}^{t} d t=-\int_{A_{0}}^{0} A^{n-1} d A
$$

and since $\sigma_{0}=\frac{P}{A_{0}}$, then:

$$
t_{f}=\frac{1}{n B \sigma_{0}{ }^{n}}
$$

For intermediate times, integration of Equ. (23) between 0 to $t$ and $\mathrm{A}_{0}$ to $\mathrm{A}$ gives:

$$
\varepsilon_{\text {eng }}=\left(1-\frac{t}{t_{f}}\right)^{-\frac{1}{n}}-1
$$

Typical ductile creep curves, for different n-values, are shown in Fig. 13.

Creep rupture is often presented as $\log \left(\sigma_{0}\right)$ versus $\log \left(t_{f}\right)$; Equ. (25) implies that this would have a gradient of $-1 / \mathrm{n}$ (see Fig. 14).

Figs. 13 and 14 show, schematically, the creep strain and creep rupture behaviours predicted by these equations.

\subsubsection{Brittle Failure of a Uniaxial Specimen Obeying a Norton Creep Law and Kachanov Damage Model}

In the case of creep brittle failure, the simplest damage mechanics model is that of Kachanov [16]. The Kachanov, single damage parameter creep law relates strain rate and damage rate to the stress via the equations:

$$
\dot{\varepsilon}^{\mathrm{c}}=\mathrm{B}\left(\frac{\sigma}{1-\omega}\right)^{\mathrm{n}}
$$


where

$$
\dot{\omega}=M \frac{\sigma^{\chi}}{(1-\omega)^{\phi}}
$$

The damage parameter, $\omega$, varies for 0 (initially) to 1 (at fracture). Hence, from Equ. (27):

Therefore,

$$
\begin{gathered}
\int_{0}^{1}(1-\omega)^{\phi} \mathrm{d} \omega=\mathrm{M} \sigma^{\chi} \int_{0}^{\mathrm{t}_{\mathrm{f}}} \mathrm{dt} \\
\mathrm{t}_{\mathrm{f}}=\frac{1}{\mathrm{M}(\phi+1) \sigma^{\chi}}
\end{gathered}
$$

At intermediate times, $t$, when the damage is $0<\omega<1$ :

$$
\omega=1-\left(1-\frac{t}{t_{f}}\right)^{\frac{1}{\phi+1}}
$$

Substituting Equ. (30) into Equ. (26) and integrating leads to:

$$
\varepsilon^{c}=\frac{A \sigma^{n-\chi}}{B(n-\phi-1)}\left\{\left[1-\frac{t}{t_{f}}\right]^{\frac{\phi+1-n}{\phi+1}}-1\right\}
$$

A typical brittle creep curve is shown in Fig. 15.

Equ. (29) implies that a plot of $\log \left(\sigma_{0}\right)$ versus $\log \left(t_{f}\right)$ would have a gradient of $-1 / \chi$, as indicated in Fig. 16.

Figs. 15 and 16 show, schematically, the creep strain and creep rupture behaviours predicted by these equations.

\subsection{A Qualitative Explanation for the Shape of a SPT Creep Curve}

A schematic diagram (approximately to scale), showing the variation of displacement with time, from a small punch creep test, is shown in Fig. 3(b).

According to Eqn. (1) the strain levels related to position 1 (see Fig. 3(b)) would typically be about $25 \%$ and the "general" strain level would be more than $10 \%$ (Fig. 12(a)), according to Eqn. (10). By comparison with typical uniaxial data for P91 (Fig. 1(b)) it can be seen that the beginning of tertiary creep occurs at strains of about 1 to $3 \%$. Hence, it is likely that primary and secondary creep are over well before the time associated with position 1 (Fig. 3(b)) is reached.

By the time that position 2 (Fig. 3(b)) is reached, the strains at the edge of contact are estimated to be greater than 30\% (Eqn. (1) and Fig. 12(a)) and the general strains are about 15\% (Eqn. (10 and Fig. 12(a)). By comparison with typical uniaxial data (Fig. 1(b)) it can be seen that the strains at position 2 would be well into the tertiary creep region (tertiary creep 
seems to start at about 3 to $4 \%$ strain). From these comparisons of uniaxial and small punch creep test data, the question arises "What is happening during the minimum deflection rate portion (positions 1 to 2) of the SPT curves if it is not associated with secondary creep?"

A tentative, qualitative explanation of the behaviour (quantitative confirmation is given in Section 3) is that the early part of the region between 0 and 1 (indicated in Fig. 3(b)) is predominantly primary and secondary creep. However, the deformation rate continues to decrease, even though the tertiary creep region is being entered; this is due to the "stiffening effect" caused by the deformation entering the "membrane loading" phase, compared with the relatively "flexible situation" associated with the plate bending effect which occurs at an earlier stage. The minimum deformation rate portion (positions 1 to 2 in Fig. 3(b)) is a balance between the increasing deformation rate that would result from the combined effect of the tertiary creep behaviour and specimen thinning (large deformation) effects and opposing these effects, the reducing deformation rate that would result from the increased stiffening which occurs as a result of the cone angle, $\theta$ (Fig. 4), becoming smaller for higher deformations. The region between 2 and 3, in Fig. 3(b), is the acceleration in deformation rate associated with the final necking and/or the high damage accumulated in the local regions for the material. Section 3 contains the results of detailed FE analyses which are used to attempt to verify the above explanation.

\section{FINITE ELEMENT MODELLING}

Section 2.4.1 shows how the inclusion of large deformation and large strains can result in a tertiary - like creep behaviour leading to a clearly defined rupture time, even for a material obeying a simple Norton creep law. Section 2.4.2 shows how the further direct inclusion of a tertiary creep component (using a pair of coupled strain rate/damage equations) in the creep law can lead to similar strain versus time behaviour (see Figs. 13 and 15) but a different dependence of rupture time on applied stress (see Figs. 14 and 16); for the Norton law, $t_{f} \propto \sigma^{-n}$, and for the damage model, $t_{f} \propto \sigma^{-\chi}$, both of which produce straight lines when $\log \left(t_{f}\right)$ is plotted against $\log (\sigma)$. It can be seen that the ductile model results in the same gradient (equal to n), for $\log (\dot{\varepsilon})$ versus $\log (\sigma)$ at all strain levels, see Fig. 17, whereas the gradient varies when a damage model is used, but at each strain level a straight line fits, reasonably well, the $\log (\dot{\varepsilon})$ versus $\log (\sigma)$ data, see Figs. 18 and 19. Ductile and damage mechanics material behaviour models have been used in FE analyses, with large deformations, to investigate whether the behaviour observed in small punch creep test components can be explained using the two types of material models.

\subsection{Finite Element Analysis Details}

The geometry chosen for the FE analyses is $a_{p}=2 \mathrm{~mm}, R_{S}=1.25 \mathrm{~mm}$ and $t_{o}=0.5 \mathrm{~mm}$; the mesh and boundary conditions are shown in Fig. 20. The specimen mesh consists of eight noded, isoparametric, axisymmetric elements [17]. The indenter sphere and support are represented by rigid shell elements [17]. 
All of the analyses were performed under elastic - creep conditions. The creep behaviour was represented by a Norton's law [1] and a single parameter damage model [16] as expressed by Equation (16) and equations (26) and (27), respectively.

\subsection{Elastic-Creep Behaviour}

\subsubsection{Norton creep model}

Typical predictions of displacement versus time are shown in Fig. 21, from which it can be seen that although the material behaviour model describes secondary creep only, the displacement versus time results contain an initial reducing displacement rate portion, an almost constant displacement rate, which lasts for the majority of the time, followed by an accelerating region leading to failure. The effect is similar to that described in section 2.4.1 for a simple uniaxial specimen undergoing large deformation.

The variations of $\varepsilon_{m}$ with $\Delta$ at the apex (inside, i, middle, $\mathrm{m}$, and outside, o), position $\mathrm{A}$ in Fig. 3(a), at the edge of contact (i, $\mathrm{m}$ and o), position B in Fig. 3(a) and in the cone section (i, $\mathrm{m}$ and o), position $\mathrm{C}$ in Fig. 3(a), are shown in Figs. 22(a), 22(b) and 22(c) for $n=6$. Also shown in Fig. 22 are the predictions based on Chakrabarty`s model. It can be seen that the general trends for the results based on Chakrabarty's model are in good agreement with the FE predictions, especially for $\Delta \geq 0.3 \mathrm{~mm}$. Similarly, the agreement between $\mathrm{P} / \sigma_{\mathrm{m}}$ versus $\Delta$ obtained from the FE analysis and from both the Chakrabarty model and present model (see section 2.3), is good for $\Delta \geq 0.3 \mathrm{~mm}$, as indicated in Fig. 23. Also, although the peaks occur at different displacement values, the peak value of $\mathrm{P} / \sigma_{\mathrm{m}} \approx 1.82$, obtained from the FE analyses, is in good agreement with the published peak value of 1.89 [15]. Similar results to those shown in Figs. 22 and 23 were obtained for other n-values; the results are given in Figs. 24 and 25 .

For each n-value, calculations were performed with different load levels. From these FE analyses the plots of $\log \left(\dot{\Delta}_{\text {min }}\right)$ versus $\log (\mathrm{P})$ and $\log (\mathrm{P})$ versus $\log \left(\mathrm{t}_{\mathrm{f}}\right)$, shown in Figs. 26 and 27, respectively, were produced. An important observation from Fig. 26 is that all the log $\left(\dot{\Delta}_{\text {min }}\right)$ versus $\log (\mathrm{P})$ plots have gradients equal to their respective n-values. Also, the gradients in Fig. 27 are equal to $-1 / n$ for all three $n$-values. Plots of $\Delta / a_{p}$ versus $t / t_{\mathrm{f}}$ (Fig. 21) are similar in appearance to those shown in Fig. 13, showing the effect of the n-value on the $\varepsilon$ versus $\mathrm{t} / \mathrm{t}_{\mathrm{f}}$ plots. Comparison of the results shown in Figs. 22(b), 24(a) and 25(a) and those shown in Figs. 23, 24(b) and 25(b) confirm that the $\varepsilon_{\mathrm{m}}$ versus $\Delta$ and $\mathrm{P} / \sigma_{\mathrm{m}}$ versus $\Delta$ plots are not greatly sensitive to the exponent, $\mathrm{n}$, in the Norton equation (Equ. (16)). Hence, the large deformation, large strain behaviour of a uniaxial specimen, with a Norton creep law, as indicated by Equs. (24) and (25) is mirrored in the much more complex large deformation, large strain behaviour which occurs in the SPT specimen.

From the FE results, displacement rates, $\dot{\Delta}$, were determined for a series of $\Delta$-values; plots of $\log (\dot{\Delta})$ versus $\log (\mathrm{P})$ at each value of $\Delta$ (Fig. 28) were similar in appearance to those for $\log \left(\dot{\Delta}_{\text {min }}\right)$ versus $\log (\mathrm{P})$, shown in Fig. 26. The gradients of these plots are shown plotted against $\Delta$ in Fig. 29. It can be seen that as is the case for $\dot{\Delta}_{\min }$, the gradient at each value of $\Delta$ is close to the $n$-value used in the calculations.

\subsubsection{Single damage - parameter creep model}


Real materials do not obey Norton's law from initial loading right up to final fracture. A more realistic model is the Kachanov single damage - parameter model (Equs. (26) and (27), $[16]$.

Elastic-creep analyses were performed for a damage model with $B=1.09 \times 10^{-20}, n=8.462$, $\chi=6.789, M=3.5367 \times 10^{-17}$ and $\phi=7.3457$. The $\Delta$ versus $t$ prediction obtained using the Kachanov model is shown in Fig. 30. Also, shown in Fig. 30 is the corresponding data obtained for a Norton material model with the same $n$-value, from which it can be seen that the predictions (when compared on the bases of $t / t_{f}$ ) are in reasonably good agreement.

The $\varepsilon_{\mathrm{m}}$ versus $\Delta / \mathrm{a}_{\mathrm{p}}$ and $\mathrm{P} / \sigma_{\mathrm{m}}$ versus $\Delta / \mathrm{a}_{\mathrm{p}}$ obtained with the Kachanov model are compared with those for the Norton behaviour in Figs. 31 and 32, respectively. There is a remarkable level of agreement obtained between the two sets of results for the Kachanov and Norton models.

The rupture data obtained from the damage calculations are shown in Fig. 33 plotted as log (P) versus $\log \left(t_{f}\right)$. The gradient of the fit to this data is $-1 / 5.57$; unlike those for the Norton model this value does not correspond to either the $n$-value or the $\chi$-value used in the damage model. The gradients of $\log (\dot{\Delta})$ versus $\log (P)$, at various $\Delta$-values, shown in Fig. 34 are not constant, varying from approximately " $n$ " for the lower deflections to approximately " $\chi$ " for the higher deflections; the gradients, plotted against displacement, in Fig. 35, clearly show this behaviour.

\section{APPLICATION OF THE REFERENCE STRESS METHOD}

\subsection{Basis of the Reference Stress Method}

The reference stress method was developed to allow the creep deformation of a component at a particular load level to be related to the strains obtained from a single uniaxial creep test [e.g., 1, 18]. For some components it is possible to obtain an analytical solution which relates the displacement rate (at a point of interest in the component) to the load, material properties and geometry, e.g., for a component made from a Norton material,

$$
\dot{\Delta}=f(P, B, n, \text { dimensions })
$$

Inspection of analytical solutions show that they are of the form:

$$
\dot{\Delta}=f_{1}(n) f_{2}(\text { dimensions }) B\left(\sigma_{\text {nom }}\right)^{n}
$$

The basis of the reference stress method is that a constant, $\alpha$, can be chosen such that $f_{1}(n) / \alpha^{n}$ is practically independent of $n$. Hence, Equ. (33) can be written as:

$$
\dot{\Delta}=\operatorname{DB}\left(\alpha \sigma_{\text {nom }}\right)^{\mathrm{n}}=\mathrm{D} \dot{\varepsilon}\left(\sigma_{\text {ref }}\right)
$$


The quantity $\alpha \sigma_{\text {nom }}$ is the so-called reference stress, $\sigma_{r e f}$, and hence $B\left(\alpha \sigma_{n o m}\right)^{n}=B\left(\sigma_{r e f}\right)^{n}$ is the creep strain rate produced in a uniaxial specimen subjected to a stress of $\sigma_{r e f}$. The quantity $\mathrm{D}$ is a constant $\left(=\mathrm{f}_{1}(\mathrm{n}) \mathrm{f}_{2}(\operatorname{dim}) / \alpha^{\mathrm{n}}\right)$ which has the units of "length" if $\dot{\Delta}$ is a displacement rate. If an analytical solution does not exist for the particular component of interest, a series of FE solutions with different $n$-values can be used to determine the reference stress, $\sigma_{r e f}$, and references multiplier, D [e.g., 6]. Alternatively, approximate reference stresses and multipliers can be obtained from limit load and linear elastic solutions for the component [e.g. 1], i.e.,

and

$$
\begin{gathered}
\sigma_{r e f} \approx \frac{P}{P_{L}} \sigma_{y} \\
D \approx \frac{\Delta^{e}}{\left(\sigma_{r e f} / E\right)}
\end{gathered}
$$

For creep ductile materials the rupture reference stress, $\sigma_{r e f}^{R}$, which relates the failure time of a component to a uniaxial stress, is directly related to the deformation reference stress, given by $\alpha \sigma_{\text {nom }}$, in Equ. (34), or approximately $P \sigma_{\mathrm{y}} / \mathrm{P}_{\mathrm{L}}$ in Equ. (35). Ductile creep behaviour has been defined [19] as creep in which final elongation, $\varepsilon_{\mathrm{f}}$, is greater than five times the product of the minimum creep strain rate and the time to rupture, see Fig. 1. The rupture reference stress for a ductile material is given by [19]:

$$
\sigma_{\text {ref }}^{\mathrm{R}}=(1+0.13(\mathrm{SCF}-1)) \sigma_{\text {ref }}
$$

For materials which do not satisfy the ductility requirement, the rupture reference stress is given by [19]:

$$
\sigma_{\text {ref }}^{\mathrm{R}}=\left(1+\frac{1}{\mathrm{n}}(\mathrm{SCF}-1)\right) \sigma_{\text {ref }}
$$

In Equs. (37) and (38), SCF, is the "stress concentration factor", for adjustment of the reference stress, which is given by:

$$
\mathrm{SCF}=\frac{\bar{\sigma}_{\mathrm{E}, \text { max }}}{\sigma_{\text {ref }}}
$$

where $\bar{\sigma}_{\mathrm{E}, \max }$ is the maximum elastically calculated value of the equivalent value of stress in the structure or feature for the same set of loadings that were used to calculate $\sigma_{\text {ref }}[19]$. This evaluation is considered to be acceptable [19] for SCF $\leq 4.0$; if SCF $>4.0$ it should be treated as a crack. For the SPT it is difficult to define an appropriate SCF - value; suggestions for the choice of an appropriate value for SCF are given in the Discussion section.

\subsection{Inferring Uniaxial Behaviour from Small Punch Specimen Tests}


Rather than being used to predict the deformation rate for a component, $\dot{\Delta}$, related to the creep strain rate, $\dot{\varepsilon}\left(\sigma_{\text {ref }}\right)$, from a uniaxial creep test, Equ. (34) can be re-written as:

$$
\dot{\varepsilon}\left(\sigma_{r e f}\right)=\frac{\dot{\Delta}}{D}
$$

Equ. (40) infers that the uniaxial creep strain rate at a stress level equal to $\sigma_{\text {ref }}$ can be obtained by measuring (experimentally) the displacement rate of the component (a small punch test specimen in the present case) and dividing it by the reference multiplier, D, which is in effect the equivalent gauge length of a uniaxial specimen. Hence, the use of small specimen tests to predict corresponding uniaxial creep data requires the reference stress, $\sigma_{r e f}\left(=\alpha \sigma_{n o m}\right)$, and reference multiplier, D, to be determined. Essentially, this requires the determination of the appropriate $\alpha$-value. This approach has been used to interpret the data obtained from impression creep tests [6]. There is an additional complication which arises when using this technique to interpret the data from SPTs. Because the geometry changes progressively during the tests, the reference stress and reference multiplier will also change during the test as a result of this.

\subsection{Reference Stress, $\sigma_{\text {ref, }}$ and Multiplier, D, Related to the Minimum Displacement Rate, $\dot{\Delta}_{\min }$, in a SPT}

The minimum displacement rates, $\dot{\Delta}_{\text {min }}$, for a particular material occurs at about the same value of $\Delta$, irrespective of load level. FE solutions have been obtained for various $n$-values. By plotting $\log \left(\dot{\Delta}_{\min } / B\left(\alpha \sigma_{\text {nom }}\right)^{n}\right)$ versus $n$ for various values of $\alpha$, the value of $\alpha$ which produces a horizontal line (see Fig. 36) enables the $\alpha$-value related to the reference stress to be identified, while the intercept on the vertical axis, which is $\log (\mathrm{D})$, allows the reference multiplier to be determined. The $\sigma_{\text {nom }}$ value can be arbitrarily chosen; in the present case, for convenience, it is taken to be:

$$
\sigma_{\text {nom }}=\frac{\mathrm{P}}{2 \pi \mathrm{a}_{\mathrm{p}} \mathrm{t}_{\mathrm{o}}}
$$

From Fig. 36, it can be seen that the required $\eta$ (the specific value of $\alpha$ at the reference stress) value is 3.08 and $\mathrm{D}=2.82$. Normalising $\mathrm{D}$ with respect to $\mathrm{a}_{\mathrm{p}}$, such that $D=\beta a_{p}$, gives $\beta=1.41$.

\subsection{Variation of $\eta$ and $\beta$ with $\Delta / a_{p}$}

Applying the same technique as that described in Section 4.3 to other values of $\Delta$ allows the variation of $\eta$ and $\beta$ with $\Delta / a_{p}$ to be obtained, see Figs. 37 and 38. The justification for choosing constant $\Delta$ values as the basis for determining the reference parameters is that, to a first order of approximation, the overall shape of the SPT specimen is characterised by the displacement, $\Delta$, of the apex.

From the variations of $\eta$ and $\beta$ with $\Delta$ which are shown in Fig. 38, it can be seen that: 
(i) the $\beta$-value reduces continuously with increasing displacement, i.e., the effective gauge length reduces with increasing displacement;

(ii) there is a minimum value of $\eta$ which occurs when $\dot{\Delta}$ is a minimum, i.e. $\eta_{\min }=3.08$. Rearranging Equ. (41) and using $\sigma_{\text {ref }}=\eta \sigma_{\text {nom }}$ gives:

$$
\frac{\mathrm{P}}{\sigma_{\text {ref }}}=\frac{2 \pi \mathrm{a}_{\mathrm{p}} \mathrm{t}_{\mathrm{o}}}{\eta}
$$

Taking $a_{p}=2 \mathrm{~mm}$ and $\mathrm{t}_{\mathrm{o}}=0.5 \mathrm{~mm}$ gives $\mathrm{P} / \sigma_{\text {ref }}=6.28 / \eta$; using the variation of $\eta$ with $\Delta / \mathrm{a}_{\mathrm{p}}$ (Fig. 38), the variation of $\mathrm{P} / \sigma_{\text {ref }}$ with $\Delta / \mathrm{a}_{\mathrm{p}}$ is obtained (see Fig. 39). The maximum value of $\mathrm{P} / \sigma_{\text {ref }}$, which occur at $\Delta / \mathrm{a}_{\mathrm{p}} \approx 0.7$ is $2.04 \mathrm{~mm}^{2}$. This is close to the maximum $\mathrm{P} / \sigma_{\text {ref }}(=1.89$ $\mathrm{mm}^{2}$ ) and $\Delta / \mathrm{a}_{\mathrm{p}}$ value $(0.8)$ predicted on the basis of the Chakrabarty membrane model (Equ. (2)).

It should be noted that although the reference parameters ( $\eta$ and $\beta$ ) were obtained using a Norton creep model, the results are not restricted to there having to be used in the secondary creep behaviour region governed by Norton`s law. The material behaviour model is simply a convenient vehicle for obtaining the reference parameters $[\mathbf{1 , 1 8}]$.

\section{DISCUSSION}

In order to relate the $\Delta$ versus $t$ and $t_{\mathrm{f}}$ versus $\mathrm{P}$ data obtained from SPTs to the corresponding data from uniaxial creep tests, i.e., $\varepsilon^{c}$ versus $t$ and $t_{f}$ versus $\sigma$, it is necessary to define a stress corresponding to a SPT as a function of $\mathrm{P}, \mathrm{a}_{\mathrm{p}}, \mathrm{R}_{\mathrm{s}}$ and $\mathrm{t}_{0}$, which is equivalent to a uniaxial creep test, and to determine a method for converting the creep displacement, $\Delta^{\mathrm{c}}$, from a SPT to an equivalent uniaxial creep strain, $\varepsilon^{\mathrm{c}}$, obtained from the corresponding equivalent uniaxial creep test.

\subsection{The Equivalent Uniaxial Stress}

Attempts have been made to determine an appropriate stress to relate the minimum displacement rate, $\dot{\Delta}_{\min }$, and failure time, $\mathrm{t}_{\mathrm{f}}$, obtained from small punch tests, to the corresponding uniaxial data (e.g.[15]). Equ. (3) seems to be the most widely accepted for relating $\sigma_{m}$ to $\mathrm{P}, a_{p}, t_{0}$ and $\mathrm{R}_{\mathrm{S}}$, which leads to:

$$
\sigma_{m}=\frac{P}{3.33 K_{S} a_{p}^{-0.2} R_{S}^{1.2} t_{0}}
$$

Using the dimensions $a_{p}=2 \mathrm{~mm}, R_{S}=1.25 \mathrm{~mm}$ and $t_{0}=0.5 \mathrm{~mm}$ results in the relationship:

$$
\sigma_{m}=\frac{0.528}{K_{S}} P
$$


The correction factor, $\mathrm{K}_{\mathrm{S}}$, which is a material dependent parameter, is usually found to be in the range 1 to 1.3 .

The deformation reference stress, obtained for $R_{S}=1.25 \mathrm{~mm}$, defined by Equ. (42), results in:

$$
\sigma_{\text {ref }}=\frac{\eta \mathrm{P}}{2 \pi \mathrm{a}_{\mathrm{p}} \mathrm{t}_{0}}
$$

Using the dimensions $a_{p}=2 \mathrm{~mm}$ and $t_{0}=0.5 \mathrm{~mm}$ results in the relationship:

$$
\sigma_{\text {ref }}=\frac{\eta \mathrm{P}}{6.28}
$$

The variation of $\eta$ with $\Delta$ (Fig. 38) has been used to obtain the variations of $\sigma_{\text {ref }} / \mathrm{P}$ with $t$, shown in Fig. 40, from which it can be seen that for the vast majority of the test period, $\sigma_{\text {ref }} / \mathbf{P}$

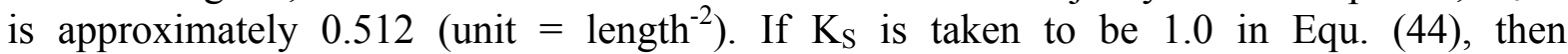
$\sigma_{m} \approx 0.528 \mathrm{P}$, which is very close to the value of $0.512 \mathrm{P}$ (obtained for $\sigma_{\text {ref }}$ ), over the vast majority of the period. It should be noted that the reference stress method results in a $\sigma_{\text {ref }} / P$ value which is the same as the value which has been proposed to be used to relate the SPT creep behaviour to the corresponding uniaxial test stress. The reference stress approach described in this paper therefore supports the stress proposed [10] for use in interpreting SPT data.

The detailed FE analyses carried out using a large deformation, "ductile", Norton material model and a "damage mechanics" material model show that the variation of $\mathrm{P} / \sigma_{\mathrm{m}}$ with $\Delta$ for both models are practically the same (see Figs. 32(a) and (b)). These $\mathrm{P} / \sigma_{\mathrm{m}}$ versus $\Delta$ variations are also very similar to the approximate, analytical solutions based on Chakrabarty's model and that derived in section 2.3 (see Figs. 23, 24(b), 25(b) and 39). These results also support the stress proposed [10] for use in interpreting SPT deformation versus time data.

The choice of the appropriate rupture reference stress, $\sigma_{\text {ref }}^{R}$, defined by Equs. (37) and (38), depends on whether the material is taken to be ductile or brittle. If the material is ductile the conversion ratio, $\sigma_{r e f}^{R} / \sigma_{r e f}$, is a function of the stress concentration factor, SCF, i.e.

$$
\sigma_{r e f}^{R} / \sigma_{r e f}=(1+0.13(S C F-1))
$$

If the material is brittle, the conversion ratio also requires an estimate of the stress index, $n$, i.e., the conversion ratio is given by:

$$
\sigma_{r e f}^{R} / \sigma_{r e f}=\left(1+\frac{1}{n}(S C F-1)\right)
$$


It is usually possible to estimate the n-value, but for a SPT specimen, the choice of an appropriate SCF is not easy. If $\mathrm{K}_{\mathrm{S}}$ (Equ. (44)) is taken to be 1.0, the value of SCF, in Equs. (37) and (38) can be estimated from Equs. (44) and (37) or Equs. (44) and (38), for ductile and brittle materials, respectively. For both ductile and brittle materials, the SCF is predicted to be 1.0. This is consistent with the fact that the membrane stress at positions B and C (Fig. 4) are the same (see Fig. 23, for example) and do not vary across the wall thickness to any significant extent; indicating that the stress concentration factor is approximately 1.0, i.e. $\sigma_{r e f}^{R} \approx \sigma_{r e f}$.

The multiaxial stress version of the damage equation (Equ. (27)) is:

$$
\dot{\omega}=\frac{M \sigma_{r}{ }^{x}}{(1-\omega)^{\phi}}
$$

where

$$
\sigma_{r}=\alpha \sigma_{1}+(1-\alpha) \sigma_{e q}
$$

and $\alpha$ is the multiaxiality material dependent constant. It should be noted that other alternative definitions for $\sigma_{r}$ could be used but the overall effect would be similar.

Throughout the conical section and hemispherical end section of the SPT specimen, the stress field is essentially biaxial. The value of $\sigma_{\text {eq }}$ can range from $0.866 \sigma_{1}$ to $\sigma_{1}$ for $0<\sigma_{2}<\sigma_{1}$ (with $\sigma_{3}=0$ ) and this will vary from position to position. Hence, when incorporated with $\alpha$ in Equ. (50) and used in Equ. (49) to obtain the damage rate, the creep deformation rate and failure time will be influenced by the multiaxial creep damage behaviour of the material. This phenomenon has been observed in experimental tests and the need for the inclusion of the $\mathrm{K}_{\mathrm{S}}$ parameter in Equ. (3) may, in part, be a reflection of this multiaxiality effect on damage rates. Further work on this aspect is currently in progress.

\subsection{Converting SPT Displacements to Corresponding Uniaxial Creep Strains}

The most commonly used creep constitutive equation is the Norton equation, i.e.,

$$
\dot{\varepsilon}_{\text {min }}^{\mathrm{c}}=\mathrm{B} \sigma^{\mathrm{n}}
$$

which relates the minimum strain rate (in the secondary creep region, see Fig 41) to the applied stress. Equ. (51) implies that a straight line, with gradient " $n$ ", would be obtained if $\log \left(\dot{\varepsilon}_{\text {min }}^{c}\right)$ is plotted against $\log (\sigma)$, see Fig 42 .

For the ductile model described in section 2.4.1, the strain is related to time via Equ. (25), from which it can be shown that the variation of strain rate with strain is given by:-

$$
\dot{\varepsilon}=\left(1+\varepsilon^{\prime}\right)^{n} B \sigma^{n}
$$

This equation implies that for a plot of $\log (\dot{\varepsilon})$ versus $\log (\sigma)$ at any specific strain value, $\varepsilon$ ' say, the gradient would be $n$, i.e. the same gradient as that associated with the minimum strain rates. However, the B-value (see Equ. (51)) in Equ. (52) is replaced by $B^{\prime}=(1+\varepsilon)^{n} B$. 
Fig. 17 shows some typical results for a "ductile", Norton equation, for which $\mathrm{B}=1.88 \mathrm{e}-29$ and $\mathrm{n}=10.147$.

If the gradients at a series of fixed strain levels (e.g. $\varepsilon$ ' in Fig. 41) are plotted against $\sigma$ (log$\log$ scales), approximately straight line fits are obtained for materials obeying a number of other creep constitutive equations; see Figs. 18(a) and 18(b) for the Murakami and Liu damage model with constants applicable to 316 stainless steel at $600^{\circ} \mathrm{C}$ and $\mathrm{P} 91$ at $650^{\circ} \mathrm{C}$. Similar results for a Kachanov damage equation are shown in Figs. 19(a) and 19(b) from which it can be seen that approximately straight line fits are obtained again at each strain level. However, it can be seen that, unlike the "ductile" Norton model (Fig. 17), the gradients are not all the same and equal to that for the minimum strain rate.

Typical experimental SPT data [11] is shown in Fig. 3(c), from which it can be seen that the minimum displacement rate occurs when the punch displacement is about $1.5 \mathrm{~mm}$ or more. The FE results presented in Figs. 21 and 30 for two material behaviour models also indicate that the minimum displacement rate occurs when the punch displacement is about $1.5 \mathrm{~mm}$. When the punch displacement is about $1.5 \mathrm{~mm}$, the general and peak strain levels in a SPT are more than 15\% and 30\%, respectively; this can be seen from Figs. 12(a), 22, 24(a) and 25(a). When compared with the strain levels which exist when the minimum strain rate occurs in a uniaxial creep test, i.e. $1 \%$ to $3 \%$, as indicated in Fig. 1(b), the strain levels in a SPT test, at the minimum deflection rate position, are extremely high. Nevertheless, when the minimum displacement rate is plotted against the load using log - log scales, reasonably good straight line fits occur (see Figs. 26, 28 and 34), as is the case for the $\log \left(\dot{\varepsilon}_{\min }\right)$ versus $\log (\sigma)$ plots obtained from uniaxial creep test data (see Fig. 42, for example). Also, the gradients obtained at given strain levels, within the tertiary range, for a large deformation, Norton creep model, are equal to the respective stress exponents; this is the case for the displacement rates in small punch tests at fixed displacement levels as well, see Fig. 29. The gradients obtained from the results obtained with the FE analyses using the damage material model did not correspond to the n-value, except at the lower displacements (see Fig. 35); in general the gradients were between the $\mathrm{n}$ and $\chi$ values.

The fact that the $\log (\dot{\Delta})$ versus $\log (\mathrm{P})$ plots are straight lines even though the strain levels are too high for secondary creep to be occurring is because for a given strain level, in the tertiary range, the $\log (\dot{\varepsilon})$ versus $\log (\sigma)$ plots produce approximately straight line relationships for many materials. Plots of $\log (\dot{\varepsilon})$ versus $\log (\sigma)$ for a range of constant strain values, in the tertiary range, are given in Figs. 17, 18 and 19 for three material behaviour models, i.e. Norton (large deformation), Kachanov and Lui and Murakami [20].

Attempts are usually made to relate the displacement rate in a SPT, in particular the "minimum displacement rate", to the secondary creep region in a uniaxial creep test. However, it is clear from the detailed FE analyses and the Chakrabarty [13] and simple (section 2.3) models that the strain levels in the region of the minimum displacement rate are far too high to be related to secondary creep behaviour. However, as indicated in this section, for some practical materials the $\log (\dot{\varepsilon})$ versus $\log (\sigma)$ data, at fixed strain levels in the tertiary range, produce plots with gradients which are approximately equal to those which are obtained using the minimum strain rates. For other materials, the n-values obtained do not necessarily correlate with those of the minimum rates in uniaxial creep data; the same is true of the gradients obtained from SPT data. This can be explained by the fact that the $\beta$-value continuously decreases (see Fig. 38) as the test proceeds, and hence $\beta$ decreases as $\Delta$ 
increases. Therefore, Equ. (40) indicates that $\dot{\varepsilon}\left(\sigma_{r e f}\right)=\dot{\Delta} / \beta a_{p}$ produces an increasing $\dot{\varepsilon}\left(\sigma_{\text {ref }}\right)$ because $\beta$ decreases. Therefore, even for a region in which $\dot{\Delta}$ is practically constant, the predicted $\dot{\varepsilon}\left(\sigma_{\text {ref }}\right)$ increases, indicating that tertiary creep is occurring. This is a mathematical form of the argument which follows from the fact that the general and peak strain levels, when the minimum deformation rate is achieved, are far too high for the material to be still in the secondary region. However, integration of the experimental $\Delta$ versus time data, using Equ. (40) with the instantaneous values of $\sigma_{r e f}\left(=\eta \sigma_{\text {nom }}\right)$ and $\mathrm{D}\left(=\beta \mathrm{a}_{\mathrm{p}}\right)$ should allow the $\varepsilon^{c}$ versus time data, corresponding to uniaxial data, to be obtained, for the $\sigma_{\text {ref }}$ history (increasing with the increase of $\eta$, in the constant $\dot{\Delta}$ region, Fig. 38) experienced by the SPT material. Further work is being carried out on this aspect of the SPT data interpretation project.

\section{CONCLUSION}

(a) Reference parameters, $\eta$ and $\beta$, which relate the test conditions (load and specimen dimensions) and test results (deformation versus time and failure time) to corresponding uniaxial stress, uniaxial creep strain versus time and uniaxial rupture time, have been established for a typical geometry $\left(\mathrm{a}_{\mathrm{p}}=2.0 \mathrm{~mm}, \mathrm{R}_{\mathrm{S}}=1.25 \mathrm{~mm}\right.$ and $\left.\mathrm{t}_{0}=0.5 \mathrm{~mm}\right)$. The variations of $\eta$ and $\beta$ with $\Delta$ are given in Fig. 38.

(b) For the majority of an SP test duration, see Fig. 40, the reference stress is related to the applied load, $\mathrm{P}$, via the relationship $\sigma_{\text {ref }}=0.512 \mathrm{P}$; where $\mathrm{P}$ has units of $\mathrm{N}$ and $\sigma_{\text {ref }}$ has units of MPa. This is an appropriate stress to relate the SPT load and geometry to a corresponding stress for uniaxial creep and creep rupture data if the material is creep ductile. This is similar to the value recommended in the proposed code of practice [10]. For creep brittle materials the conversion factor $(0.512)$ may need to be modified.

(c) The minimum displacement rate in a SPT relates to the strain rate at some position within the tertiary creep region, i.e. not directly to the minimum strain rate in a uniaxial creep test. However, the strain rate related to the minimum displacement rate can be determined by using equ (40) with $D=\beta a_{p}$ and $\beta$ is obtained from Fig. 38. The minimum creep strain rate obtained from a uniaxial creep test is approximately related to the creep strain rate at a strain of $\varepsilon^{\prime}$ in the tertiary region, for a ductile material, via the relationship $\dot{\varepsilon}\left(\varepsilon=\varepsilon^{\prime}\right) / \dot{\varepsilon}_{\text {min }}\left(1+\varepsilon^{\prime}\right)^{\mathrm{n}}$, see equation (52). At the minimum displacement rate position in a SPT, $\varepsilon^{\prime}$ can be estimated from one of the relationships between $\varepsilon$ and $\Delta$ (e.g. equation (1)), Fig. 9, Fig 22(b), Fig $24(\mathrm{a})$, etc) and hence the strain rate obtained using equation (40) can be converted to the corresponding minimum creep strain rate using equation (52), i.e., $\dot{\varepsilon}_{\min }=\dot{\varepsilon}\left(\varepsilon=\varepsilon^{\prime}\right) /\left(1+\varepsilon^{\prime}\right)^{\mathrm{n}}$. If a series of tests are performed with different load levels (hence different $\sigma_{\text {ref }}$ values) and the $\log \left(\dot{\varepsilon}_{\text {min }}\right)$, calculated as indicated above, is plotted against $\log \left(\sigma_{\text {ref }}\right)$, this will correlated with the data obtained from uniaxial tests, provided the material is "ductile". For a brittle material, the gradient obtained from the SPT data may not be exactly the same as that obtained for minimum uniaxial creep strain rate data.

\section{ACKNOWLEDGEMENTS}


We would like to acknowledge the support of EPSRC through the Supergen 2 programme (GR/S86334/01 and EP/F029748) and the following companies; Alstom Power Ltd., Corus, E.ON Engineering Ltd., Doosan Babcock Energy Ltd., National Physical Laboratory, QinetiQ, Rolls-Royce plc, RWE npower, Sermatech Ltd. and Siemens Industrial Turbomachinery Ltd. for their valuable contributions to the project.

\section{REFERENCES}

1. Penny R. K. and Marriott D. L. Design for Creep. Chapman \& Hall ( $2^{\text {nd }}$ Edition $), 1995$.

2. Brett S. J. (2007). Service Experience with a retrofit modified 9Cr (Grade 91) steel header, EPRI - $5^{\text {th }}$ Int. Conf. on Advances in Materials Technology for Fossil Power Plants, 2007, Marco Island, Florida.

3. Askins M. C. and Marchant K. D. (1987). Estimating the remanent life of boiler pressure parts, EPRI Contract RP2253-1, Part 2, Miniature specimen creep testing in tension, CEGB Report., TPRD/3099/R86, CEGB, UK.

4. Hyde, T. H., Sun, W., Becker, A. A. and Williams, J. A. (2004) Creep behaviour and failure assessment of new and fully repaired P91 pipe welds at $923 \mathrm{~K}$. Proc. Instn Mech. Engrs. Vol. 218, Part L: J. of Materials: Design \& Applications, 211-222.

5. Hyde T. H., Sun W. and Williams J. A. (2007) The requirements for and the use of miniature test specimens to provide mechanical and creep properties of materials: - a review. International Materials Reviews 52 (4), 213-255.

6. Hyde T. H., Sun W. and Becker A. A. (1996) Analysis of the impression creep test method using a rectangular indenter for determining the creep properties in welds, Int. J. Mech. Sci. 38, 1089-1102.

7. Parker J. D. and James J. D. (1994) Creep behaviour of miniature disc specimens of low alloy steel, ASME, PVP 279, Developments in a Progressing Technology, 167-172.

8. Hyde, T. H. and Sun, W. (2009) A novel, high sensitivity, small specimen creep test. $J$. of Strain Analysis 44 (2), 171-185.

9. British Standard BS 4A 4-13, Specification for test pieces for tensile and creep testing, BSI, London, UK. BS EN 10291:20, Metallic materials uniaxial testing in tension, BSI, London, UK.

10. CEN CWA 15627 Workshop Agreement: Small punch test method for metallic materials (Part A). December 2006, European Committee for Standardisation.

11. Sturm R., Jenjo M., Ule B. and Solar, M. Small-punch testing of smart weld materials, Proc. of the $2^{\text {nd }}$ Int. Conf. on Structural Integrity of High Temperature Welds, November 2003, IOM ${ }^{3}$ Communications, London, pp. 269-278.

12. Yang Z. and Wang Z-W. (2003). Relationship between strain and central deflection in small punch creep specimens. Int. J. Press. Vess. \& Piping 80, 397-404.

13. Chakrabarty J. (1970). A theory of stretch forming over hemispherical punch heads. Int. J. Mech. Sci. 12, 315-325.

14. Purmensky J. and Matocha K. Latest developments in SPT. VITKOVICE Research \& Development Ltd., Czech Republic, June 2007.

15. Li Y. Z. (2007) Determination of Norton creep law and rupture time dependence from small punch test. Proc. of $3^{\text {rd }}$ Int. Conf. on Integrity of High Temp. Welds, April 2007 , IoM Communications, London, pp. 433-449.

16. Hayhurst D. R. Creep rupture under multi-axial states of stress. J. Mech. Phys. Solids 20, 381-390 (1972).

17. ABAQUS User Manual, version 6.3. Hibbitt, Karlsson \& Sorensen, Inc, 2002. 
18. MacKenzie A. C. (1968). On the use of a single uniaxial test to estimate deformation

19. R5 Assessment procedure for the high temperature response of structures. British Energy, Issue 3, 2003.

20. Liu, Y. and Murakami, S. (1998) Damage localization of conventional creep damage models and propsition of a new model for creep damage analysis. JSME International Journal 41 (1), 57-65. 


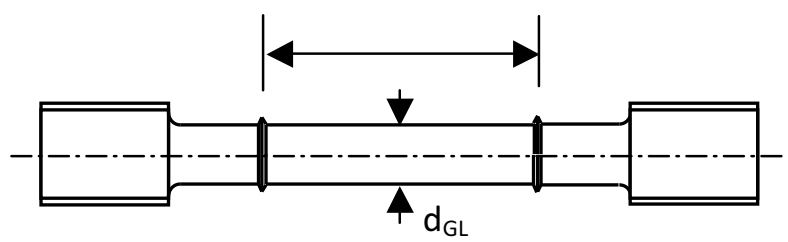

(a)

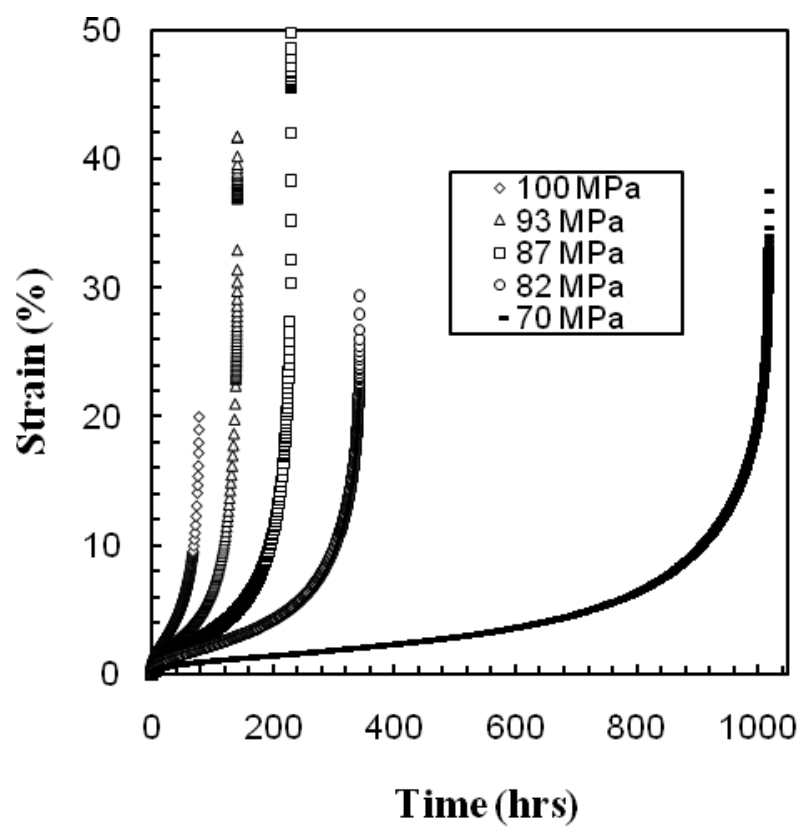

(b)

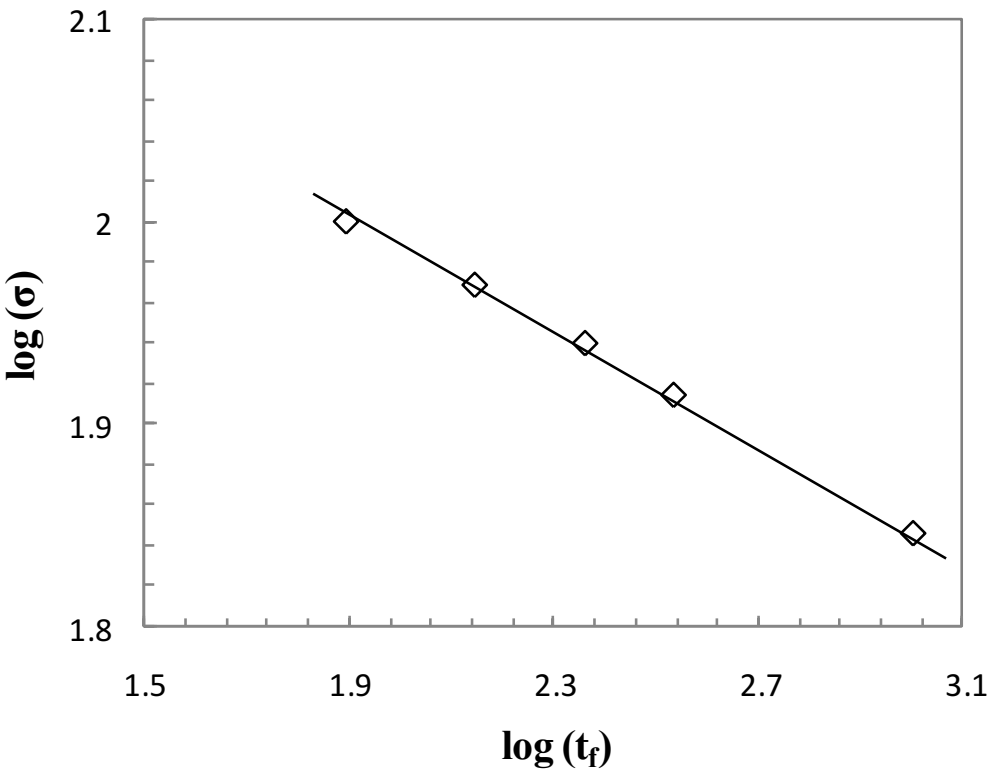


Fig. 1 (a) Typical conventional creep test specimen (GL $\left.\approx 50 \mathrm{~mm}, \mathrm{~d}_{\mathrm{GL}} \mathrm{d}_{\mathrm{GL}} \approx 10 \mathrm{~mm}\right)$; (b) Uniaxial creep strain curves for a P91 steel at $650^{\circ} \mathrm{C}$; (c) Creep rupture data for a P91 steel at $650^{\circ} \mathrm{C}$.

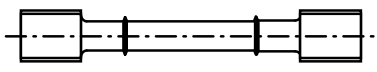

(a)

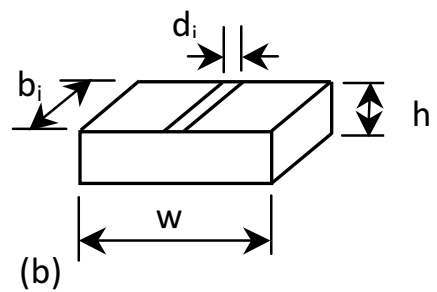

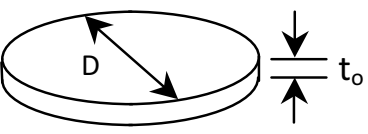

(c)

Fig. 2 Commonly used small specimens: (a) conventional sub - size uniaxial specimen; (b) impression creep specimen, and (c) small punch specimen.

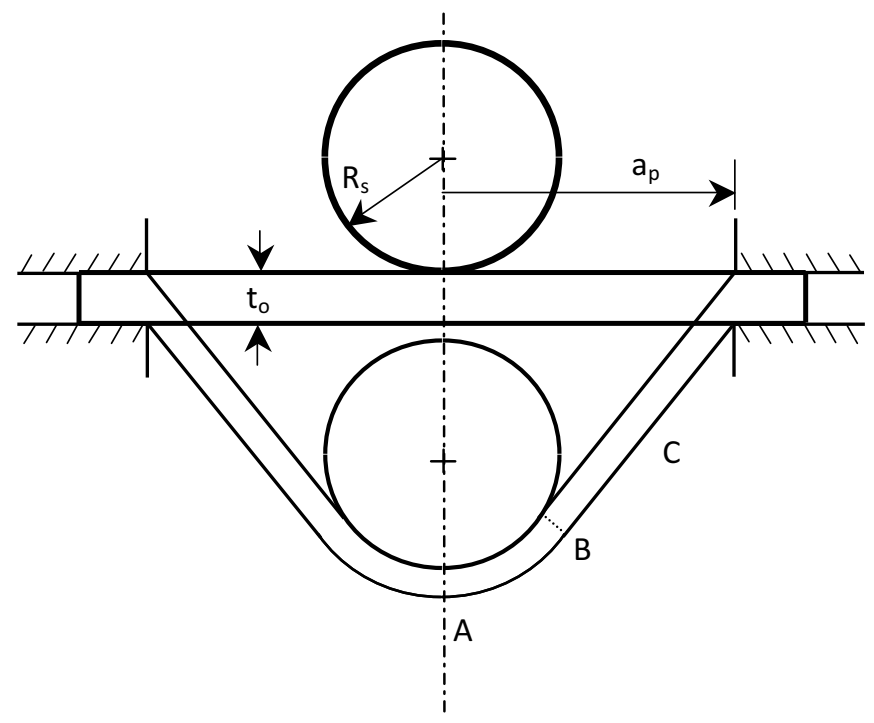

Fig. 3(a) Schematic diagram of typical SPT setup. 


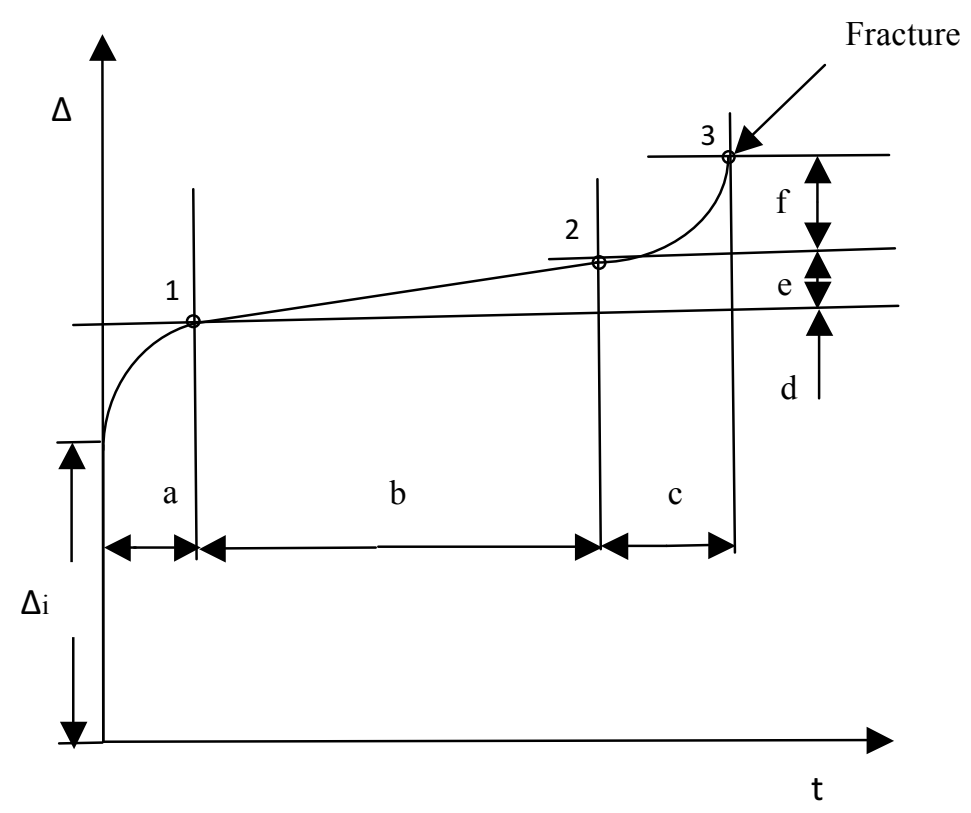

Fig. 3(b) Schematic representation of displacement versus time curve from SPT showing different deformation regions(where $\Delta_{\mathrm{i}}$ is the instantaneous elastic and plastic deformation):

a) reducing deformation rate; b) approximately constant deformation rate; c) increasing deformation rate; d) deformation occurring during reducing deformation rate; e) deformation occurring during "constant" deformation rate, and f) deformation occurring during increasing deformation rate.

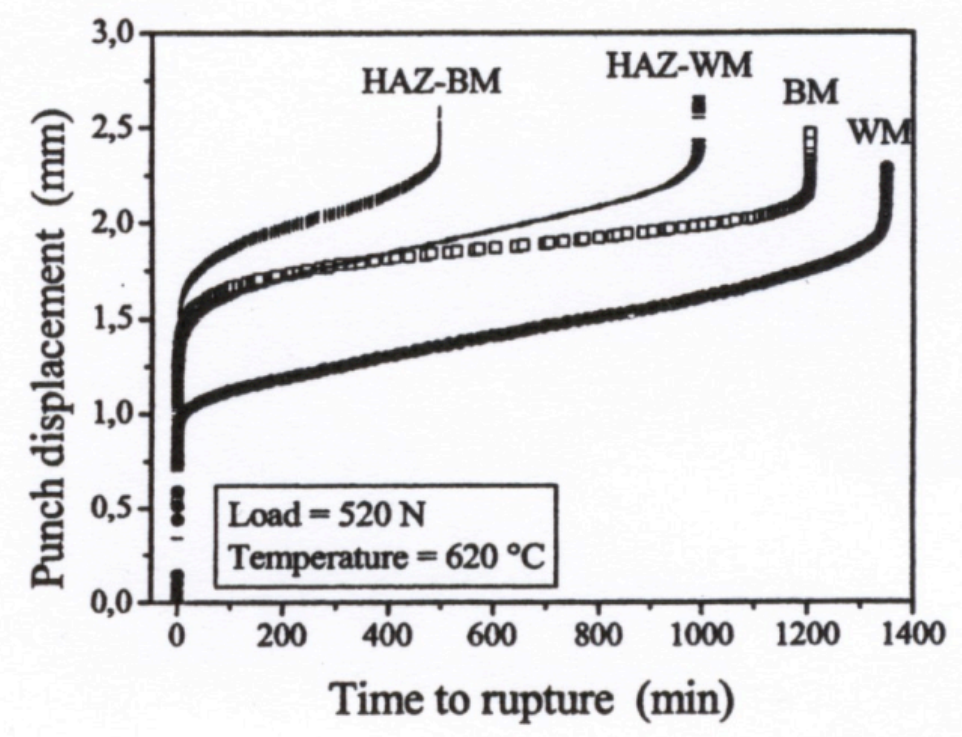


$R_{s} a_{p}$

A

$t_{0} \quad$ Fig. $\beta(c)$ Typical small punch test curves for different zones of a P91 weldment [11].

$\mathrm{t}$

$\mathrm{BM}, \mathrm{HAZ}_{\mathbf{p}}$ and $\mathrm{WM}$ are the base material, heat-affected zone and weld metal, respectively.

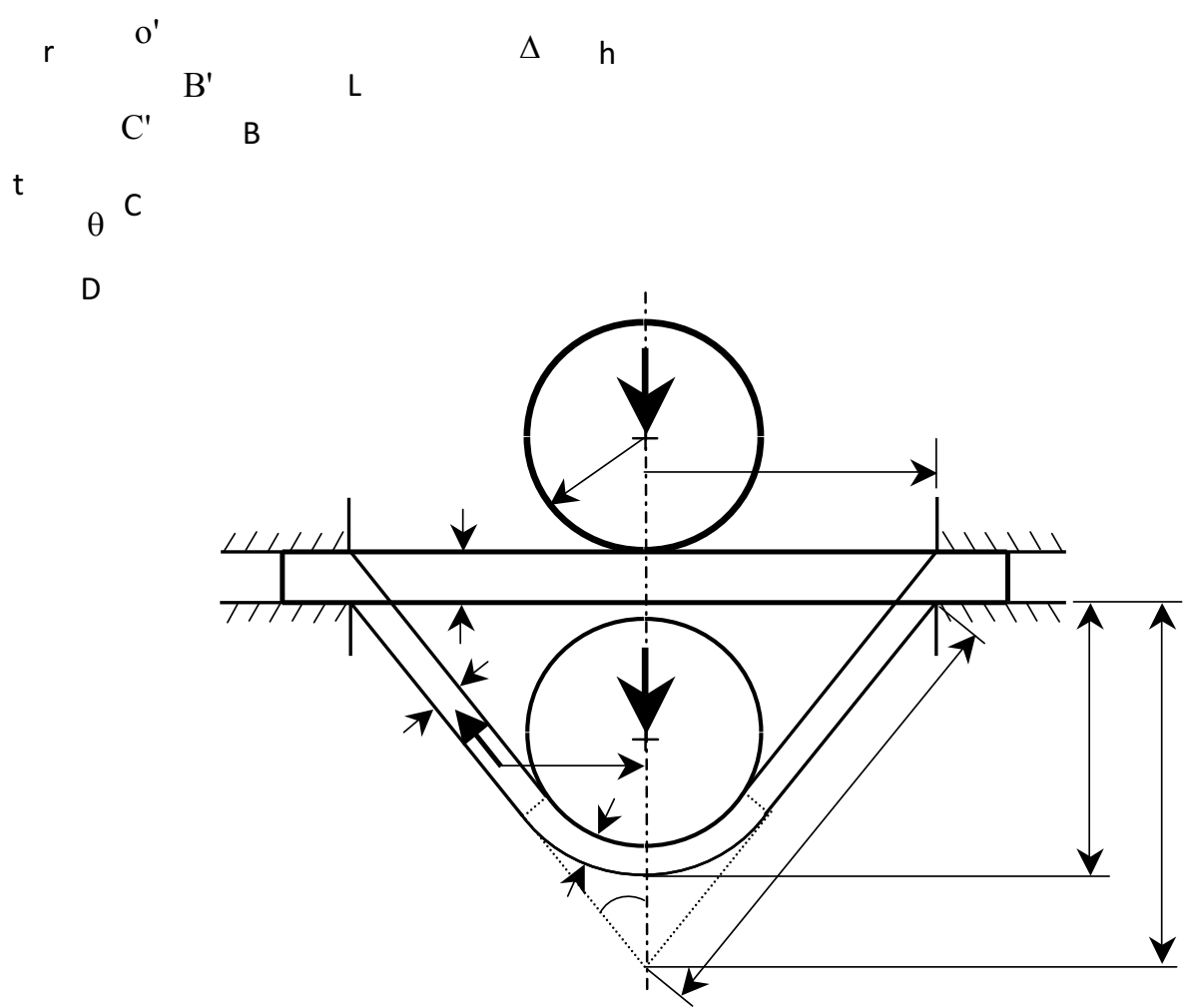

Fig. 4 Initial and deformed (assumed constant thickness) shape of the SPT specimen.

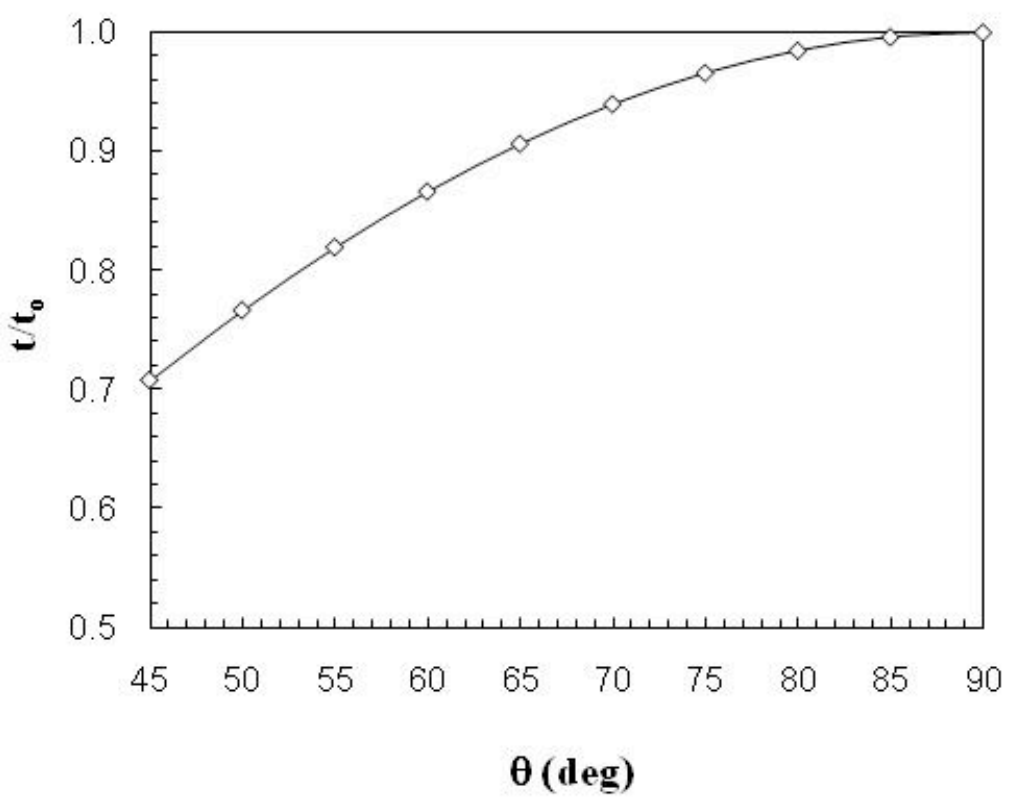


Fig. 5 Variation of $\mathrm{t} / \mathrm{t}_{\mathrm{o}}$ with $\theta$.

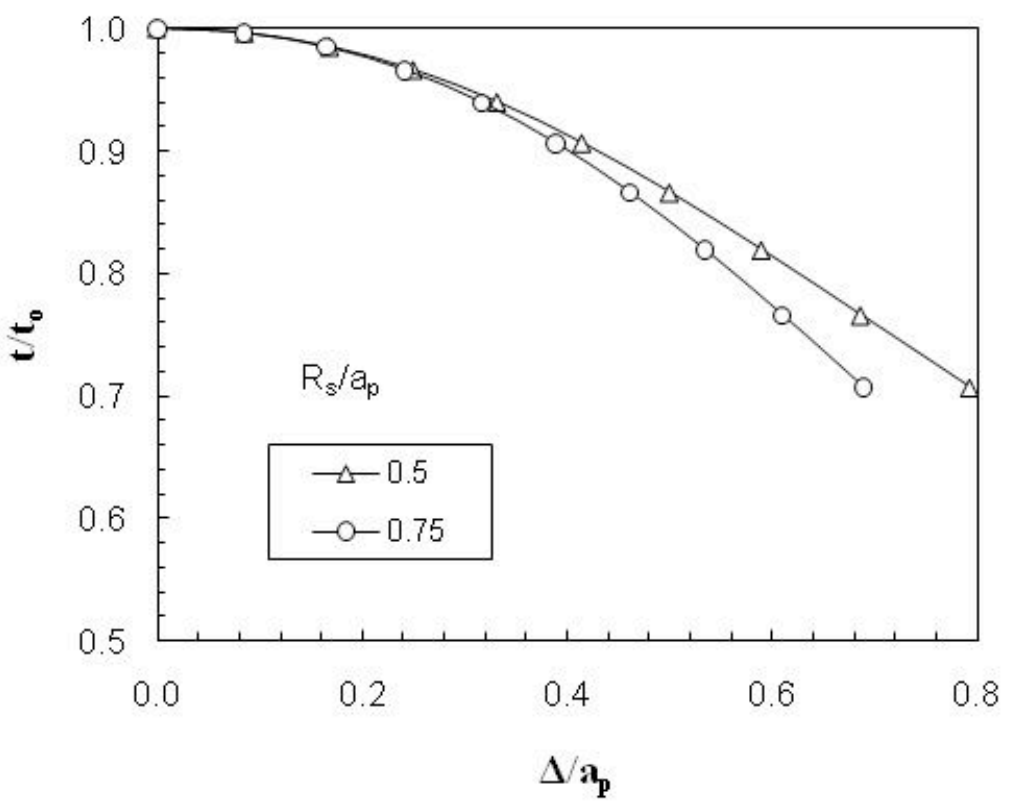

Fig. 6 Variations of $\mathrm{t} / \mathrm{t}_{\mathrm{o}}$ with $\Delta / \mathrm{a}_{\mathrm{p}}$.

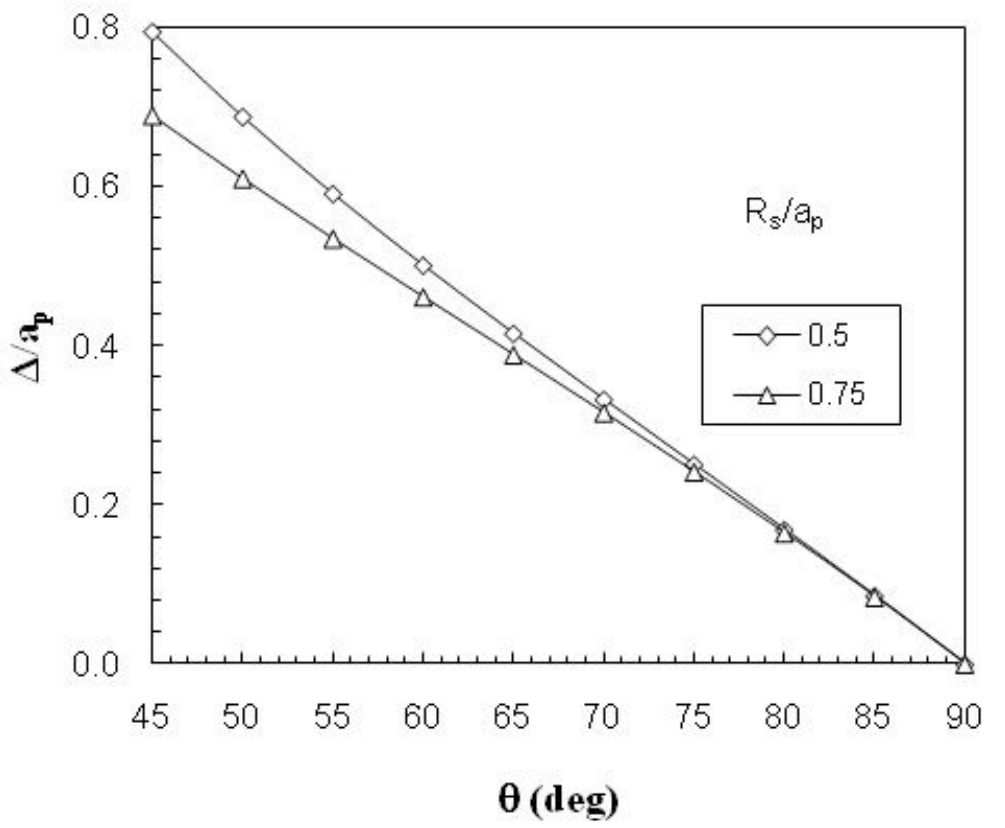


Fig. 7 Variations of $\Delta / a_{p}$ with $\theta$.

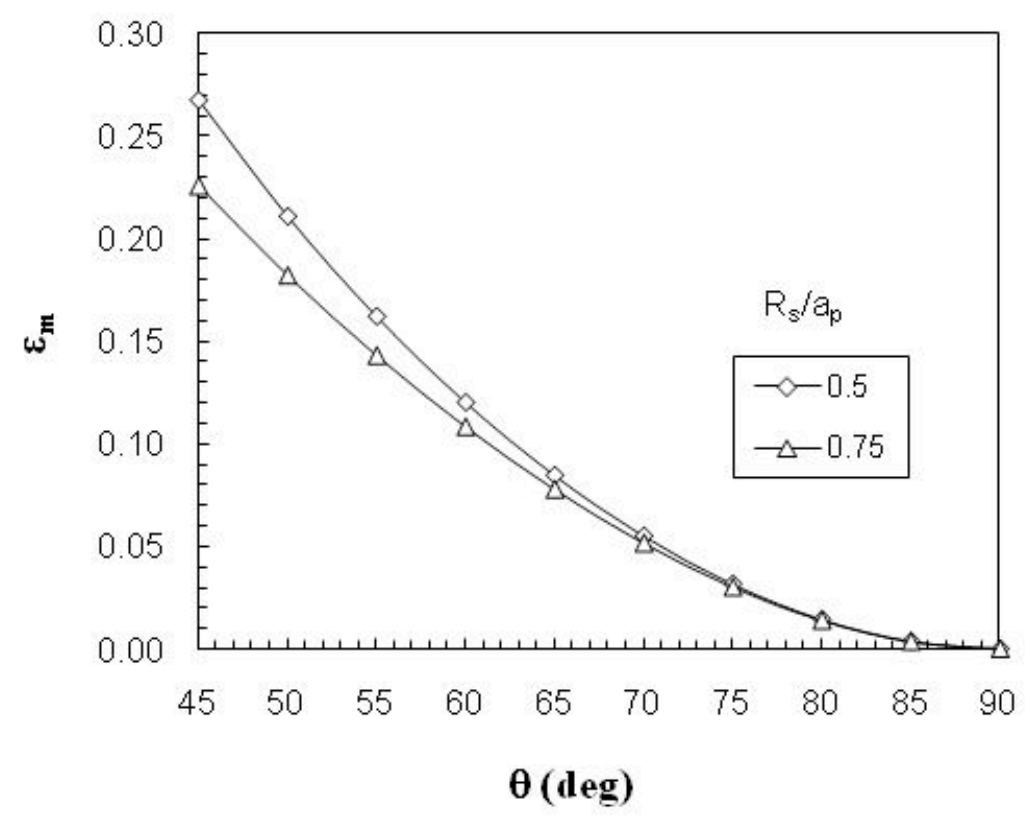

Fig. 8 Variations of $\varepsilon_{\mathrm{m}}$ with $\theta$.

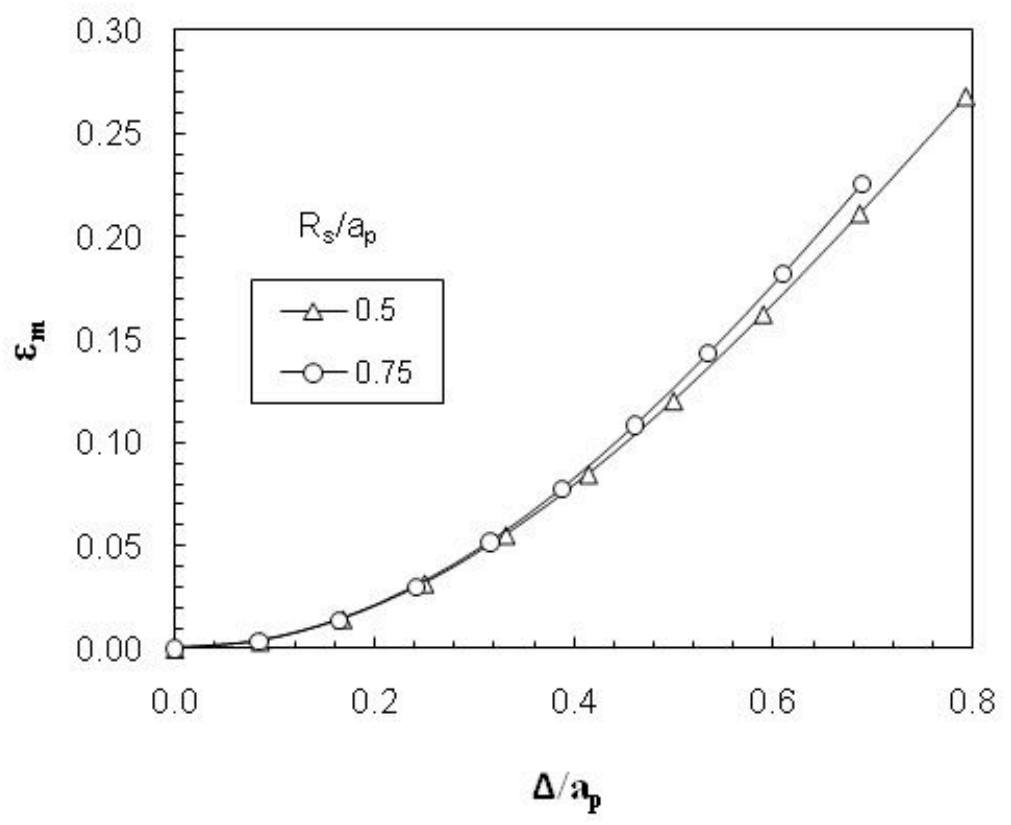

Fig. 9 Variations of $\varepsilon_{\mathrm{m}}$ with $\Delta / \mathrm{a}_{\mathrm{p}}$. 


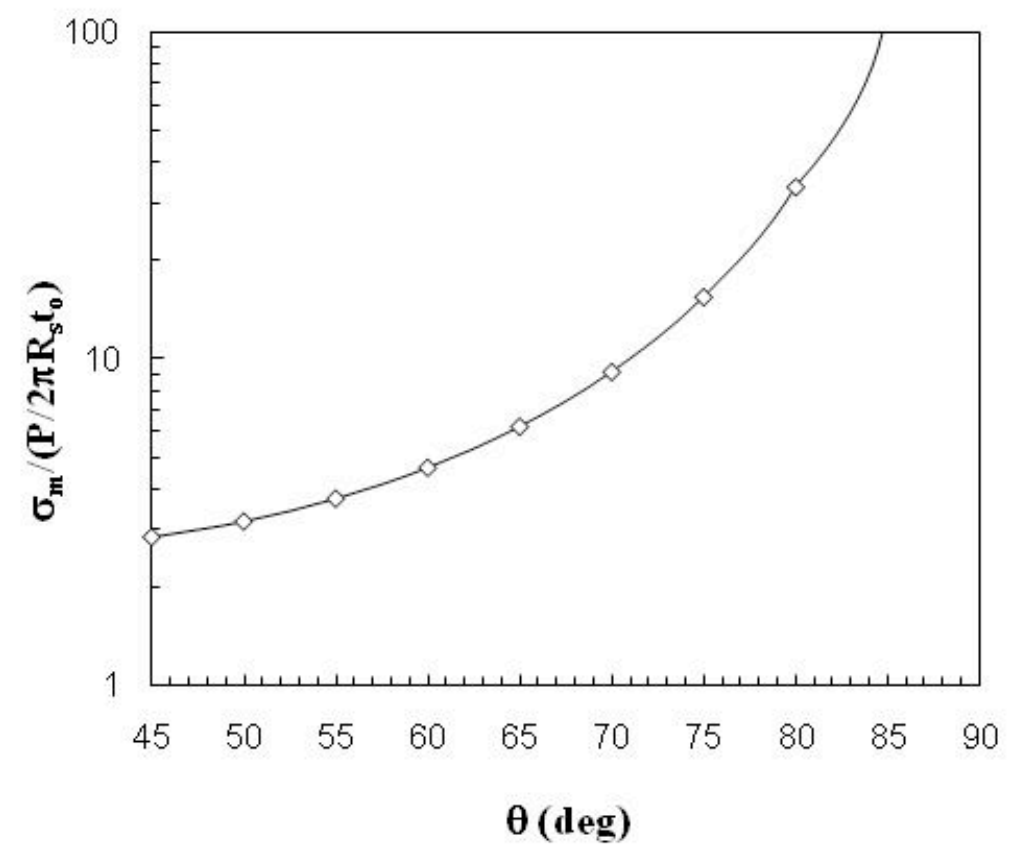

Fig. 10 Variation of $\sigma_{\mathrm{m}} /\left(\mathrm{P} / 2 \pi \mathrm{R}_{\mathrm{s}} \mathrm{t}_{\mathrm{o}}\right)$ with $\theta$.

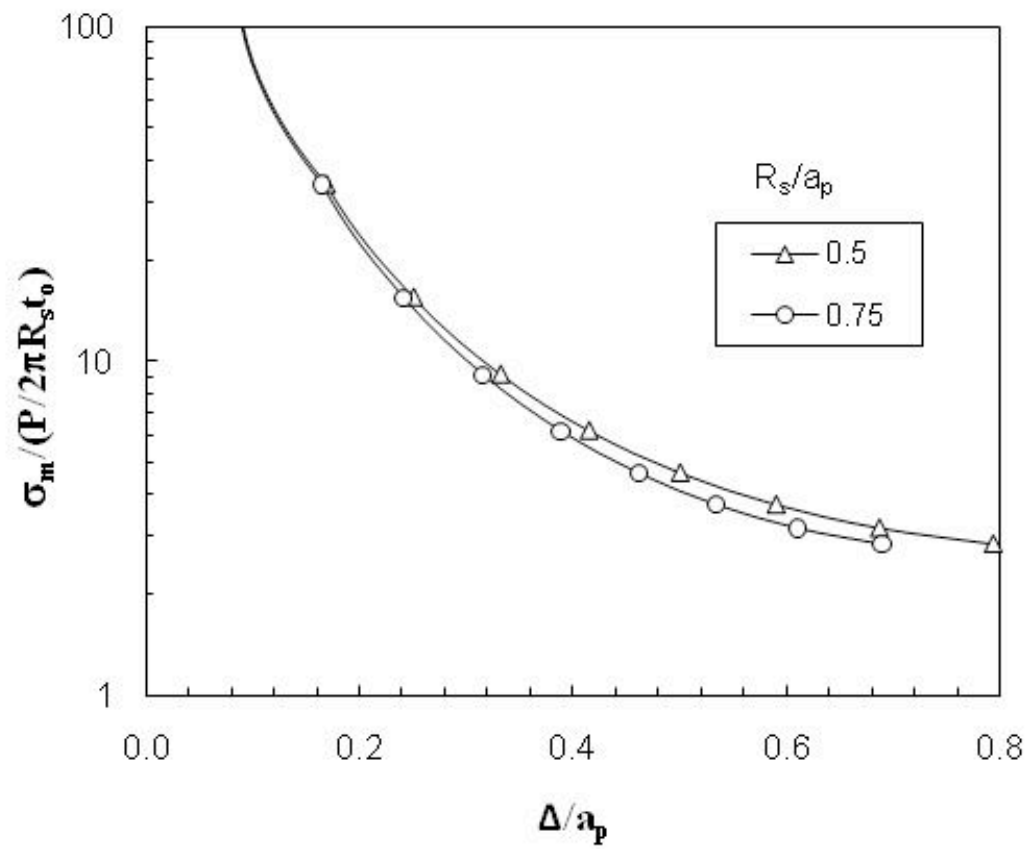

Fig. 11 Variations of $\sigma_{\mathrm{m}} /\left(\mathrm{P} / 2 \pi \mathrm{R}_{\mathrm{s}} \mathrm{t}_{\mathrm{o}}\right)$ with $\Delta / \mathrm{a}_{\mathrm{p}}$ 


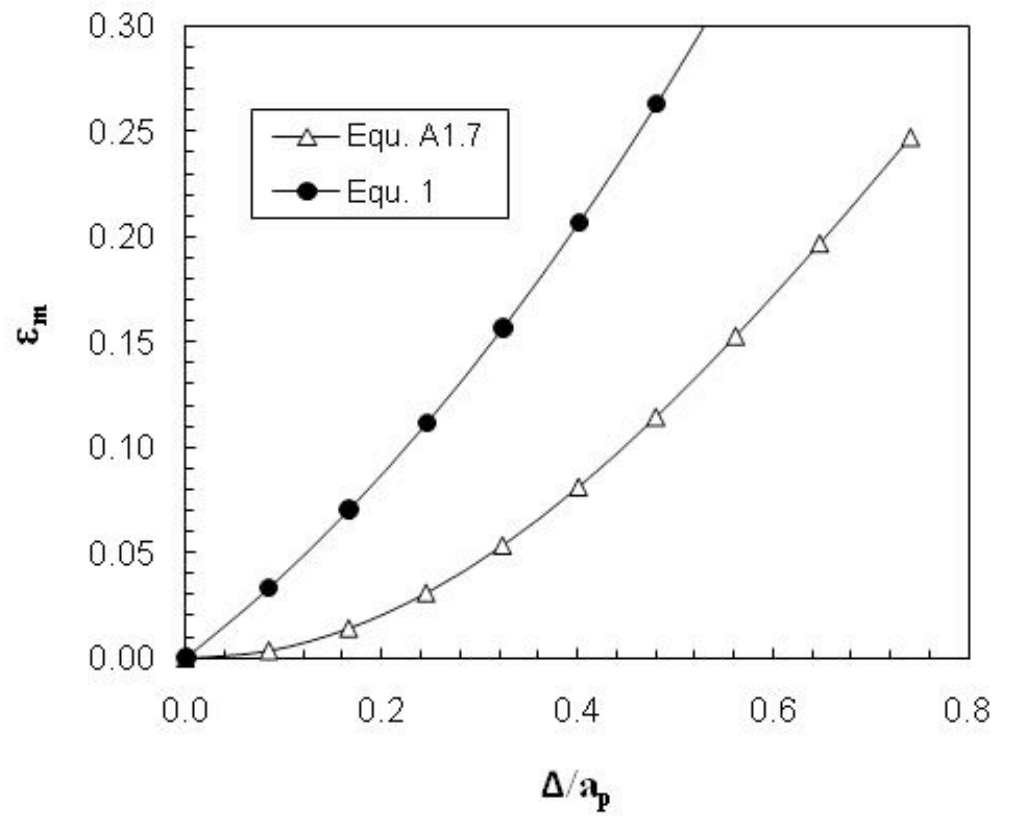

Fig. 12(a) Variations of $\varepsilon_{\mathrm{m}}$ with $\Delta / \mathrm{a}_{\mathrm{p}}$ for $\mathrm{a}_{\mathrm{p}}=2 \mathrm{~mm}$ and $\mathrm{R}_{\mathrm{s}}=1.25 \mathrm{~mm}$.

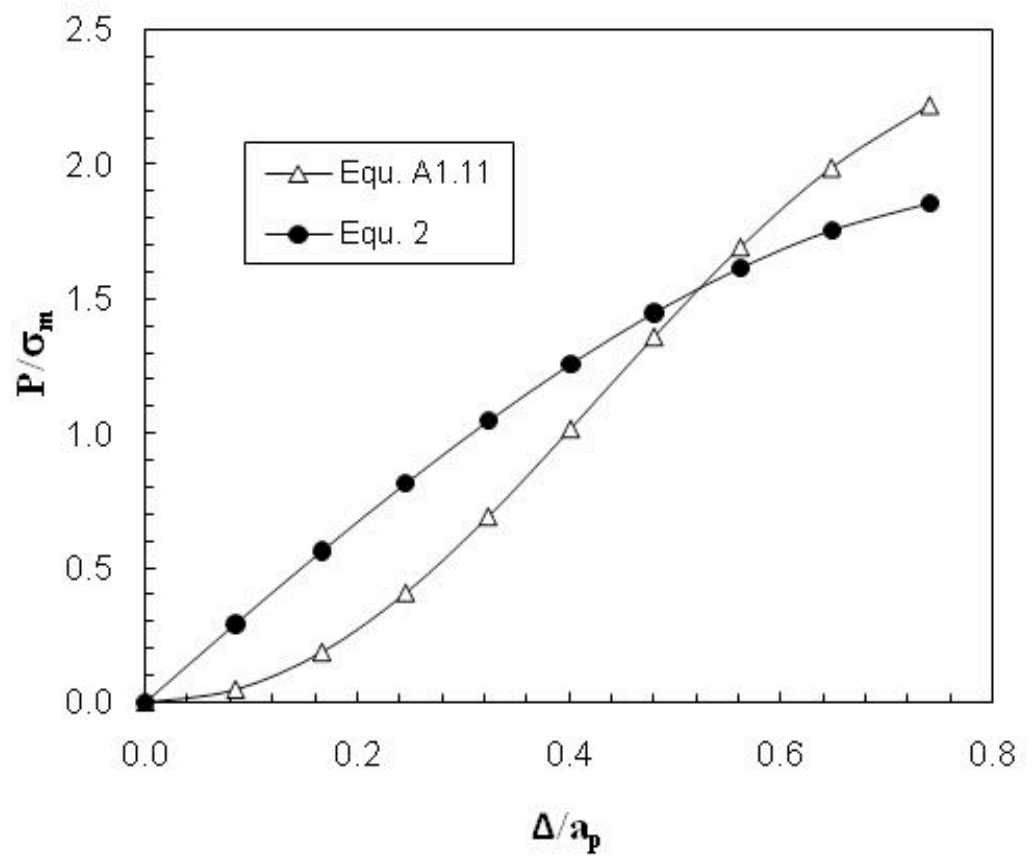

Fig. 12(b) Variations of $\mathrm{P} / \sigma_{\mathrm{m}}$ with $\Delta / \mathrm{a}_{\mathrm{p}}$, for $\mathrm{a}_{\mathrm{p}}=2 \mathrm{~mm}, \mathrm{R}_{\mathrm{s}}=1.25 \mathrm{~mm}$ and $\mathrm{t}_{\mathrm{o}}=0.5 \mathrm{~mm}$. 


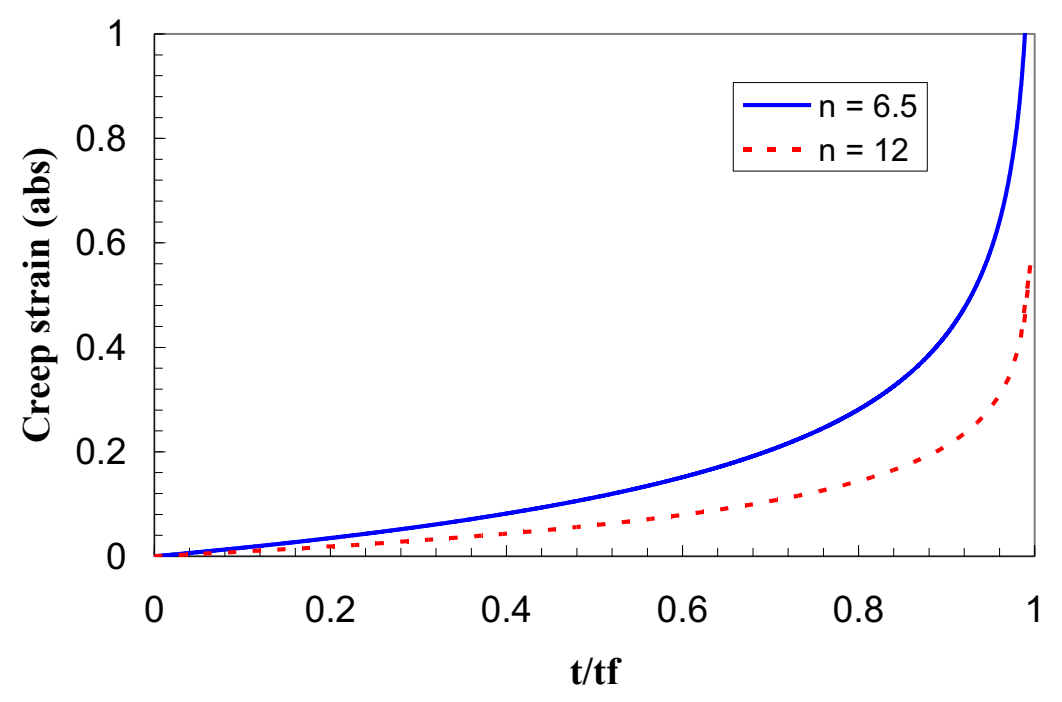

Fig 13 Creep strain data for a ductile (Norton creep law) failure model

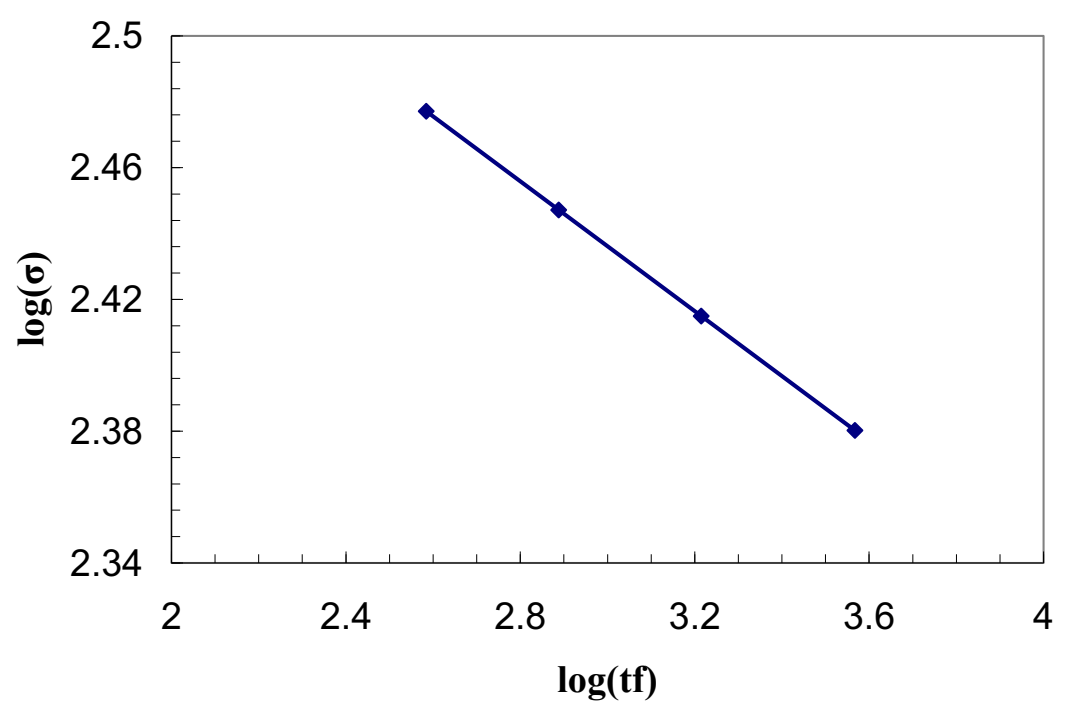

Fig 14 Creep rupture data for a ductile (Norton creep law) failure model, based on constants for 316 stainless steel at $600^{\circ} \mathrm{C}($ gradient $=-1 / \mathrm{n})$ 


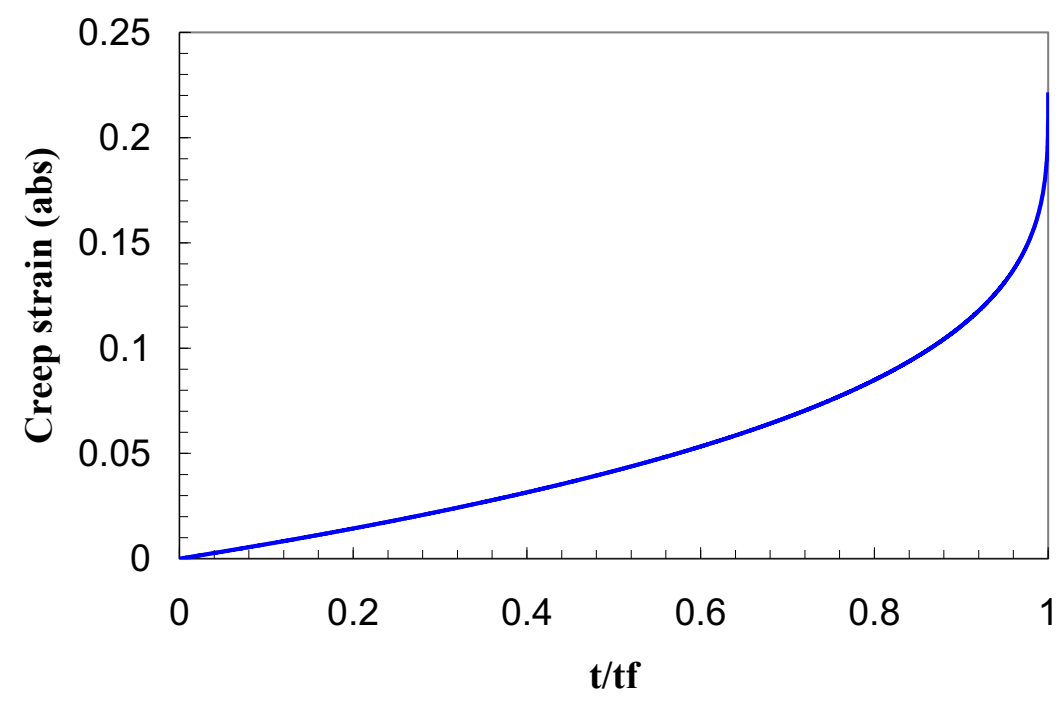

Fig 15 Creep strain data for a brittle (Kachanov damage) failure model, using constants for 316 stainless steel at $600^{\circ} \mathrm{C}$

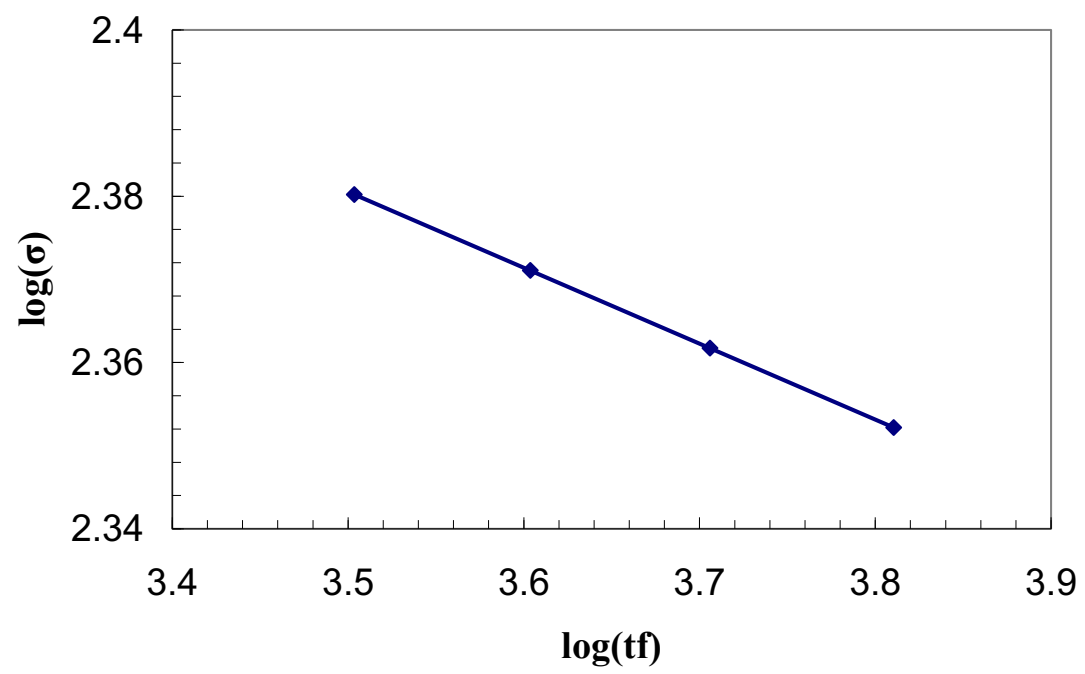

Fig 16 Creep rupture data for a brittle (Kachanov damage) failure model using constants for 316 stainless steel at $600^{\circ} \mathrm{C}($ gradient $=-1 / \chi)$ 


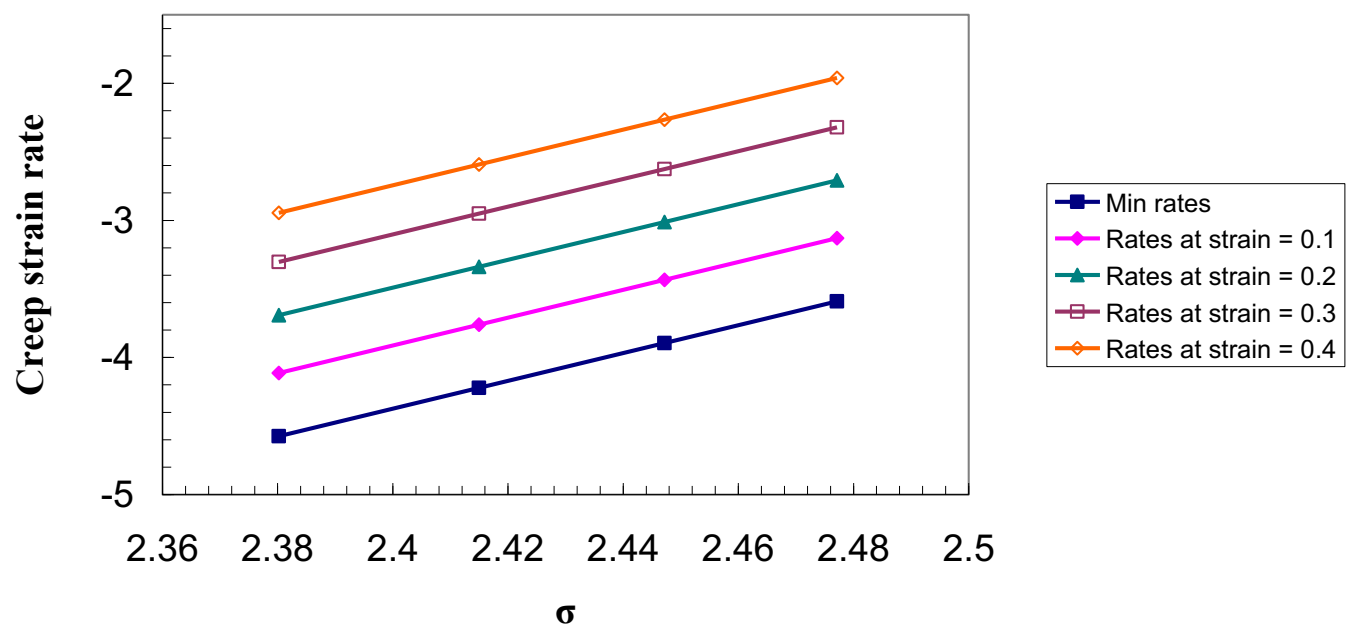

Fig 17 Variations of creep strain rate with $\sigma$ on a log-log scale for a material obeying a "ductile" Norton model (for 316 stainless steel at $600^{\circ} \mathrm{C}$ )

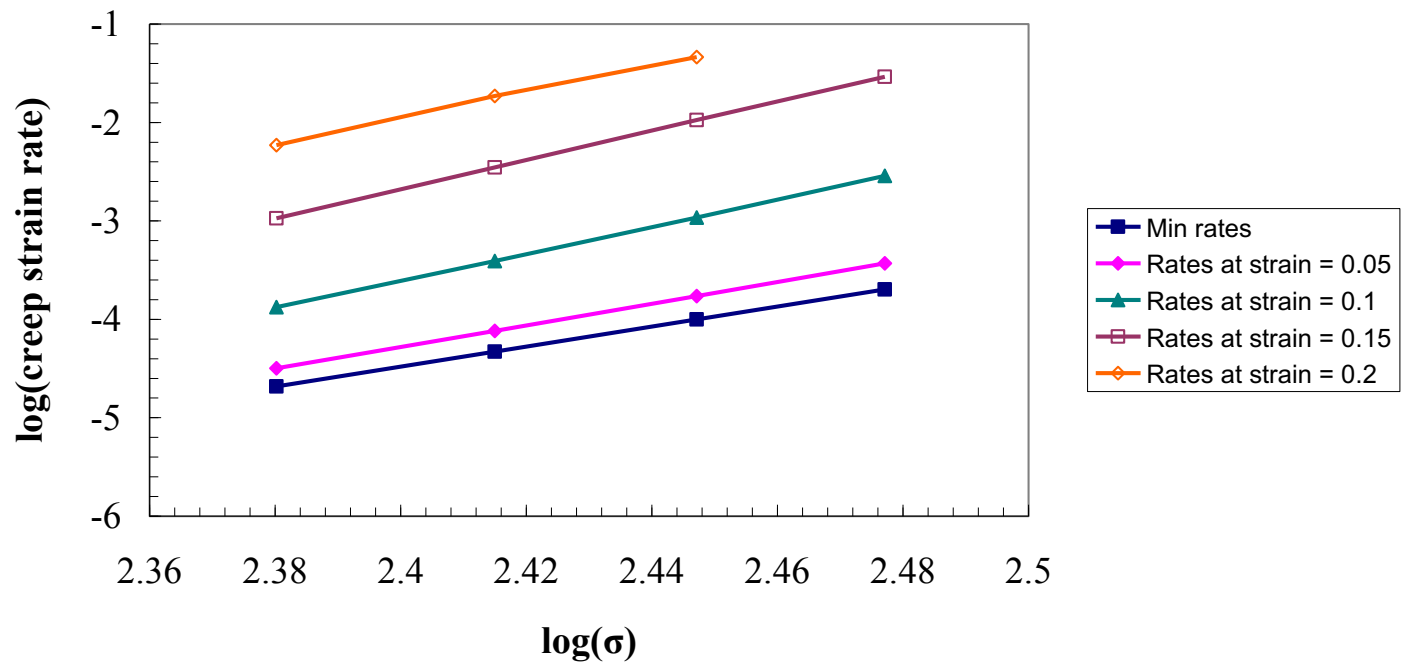

Fig 18(a) Creep strain rate vs. $\sigma$ on a log-log scale using the Liu and Murakami damage model (for 316 stainless steel at $600^{\circ} \mathrm{C}$ ) 


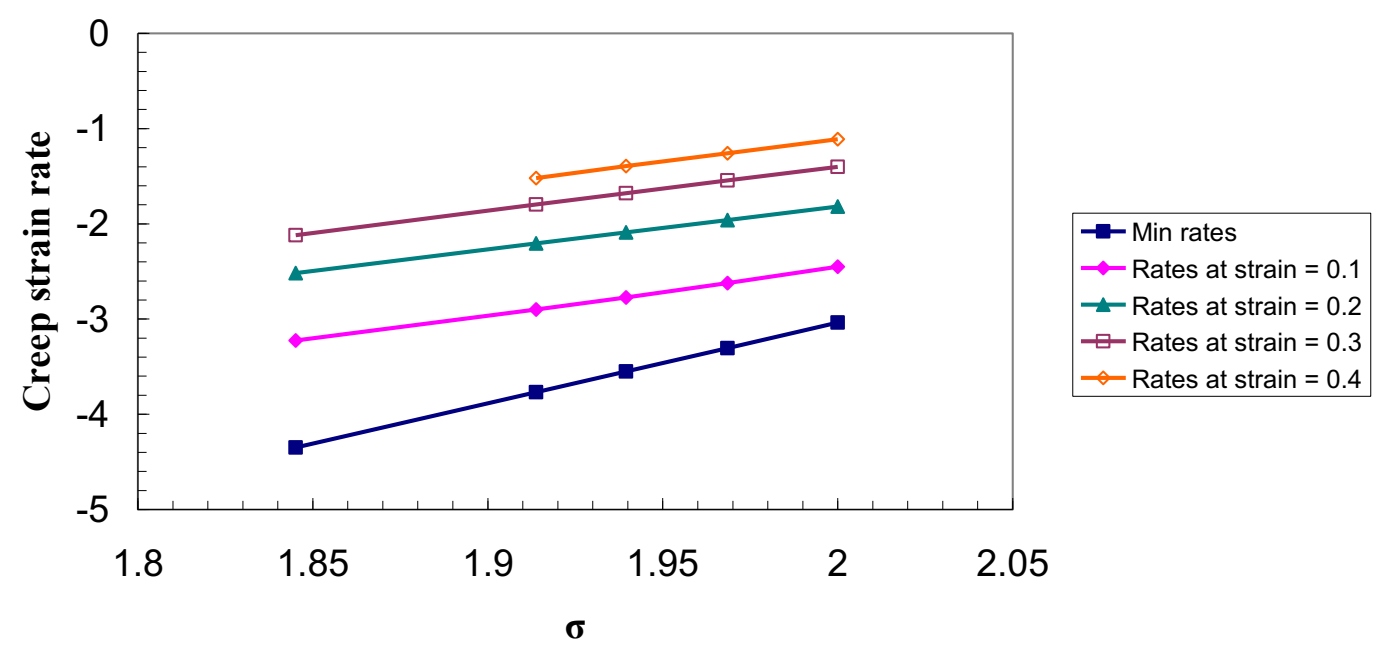

Fig 18(b) Creep strain rate vs. $\sigma$ on a log-log scale using the Liu and Murakami [20] damage model (for P91 steel at $650^{\circ} \mathrm{C}$ )

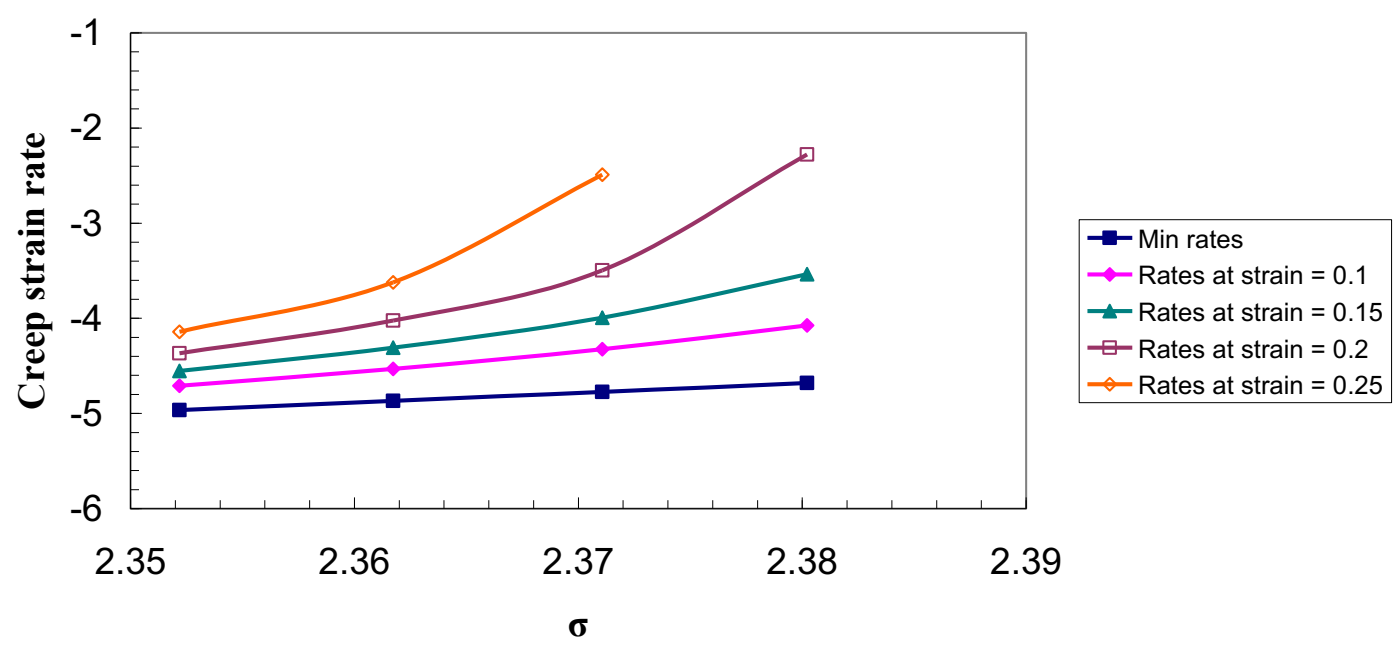

Fig 19(a) Creep strain rate vs. $\sigma$ on a log-log scale using the Kachanov damage model (for 316 stainless steel at $600^{\circ} \mathrm{C}$ ) 


\section{upper}

clamp

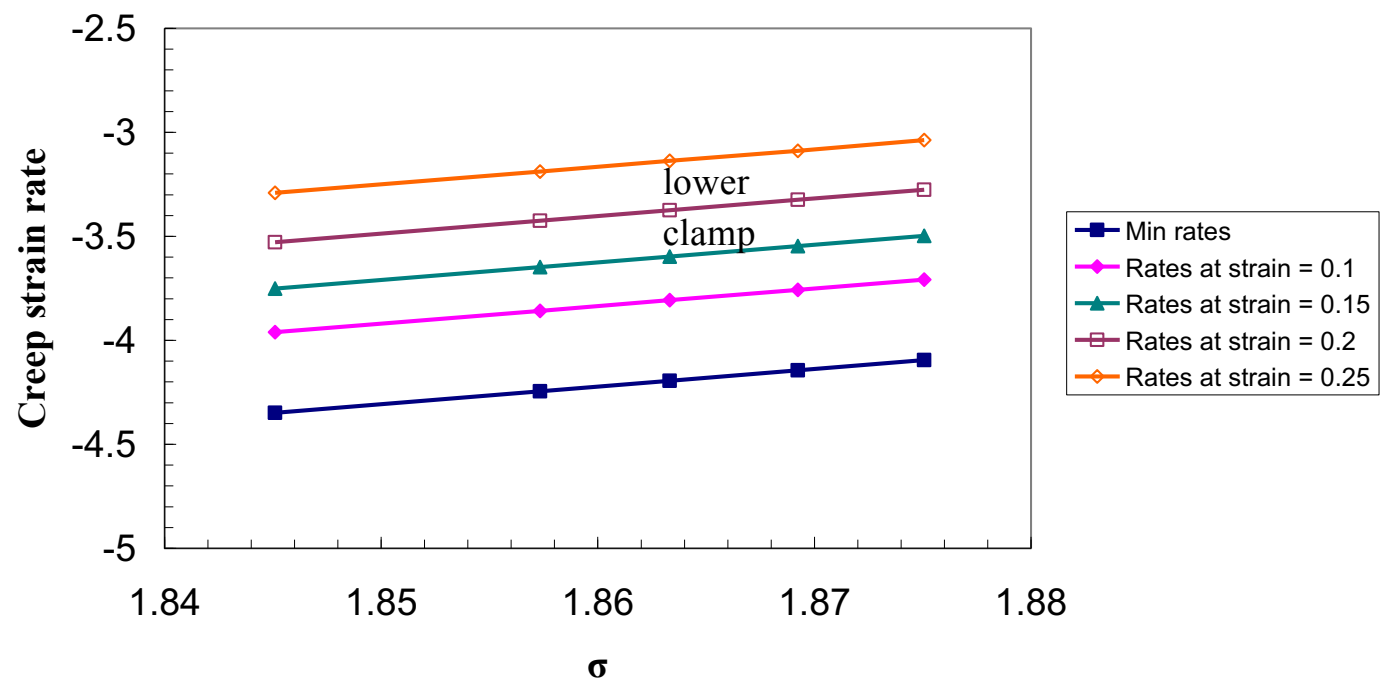

Fig 19(b) Creep strain rate vs. $\sigma$ on a log-log scale using the Kachanov damage model (for P91 steel at $650^{\circ} \mathrm{C}$ )

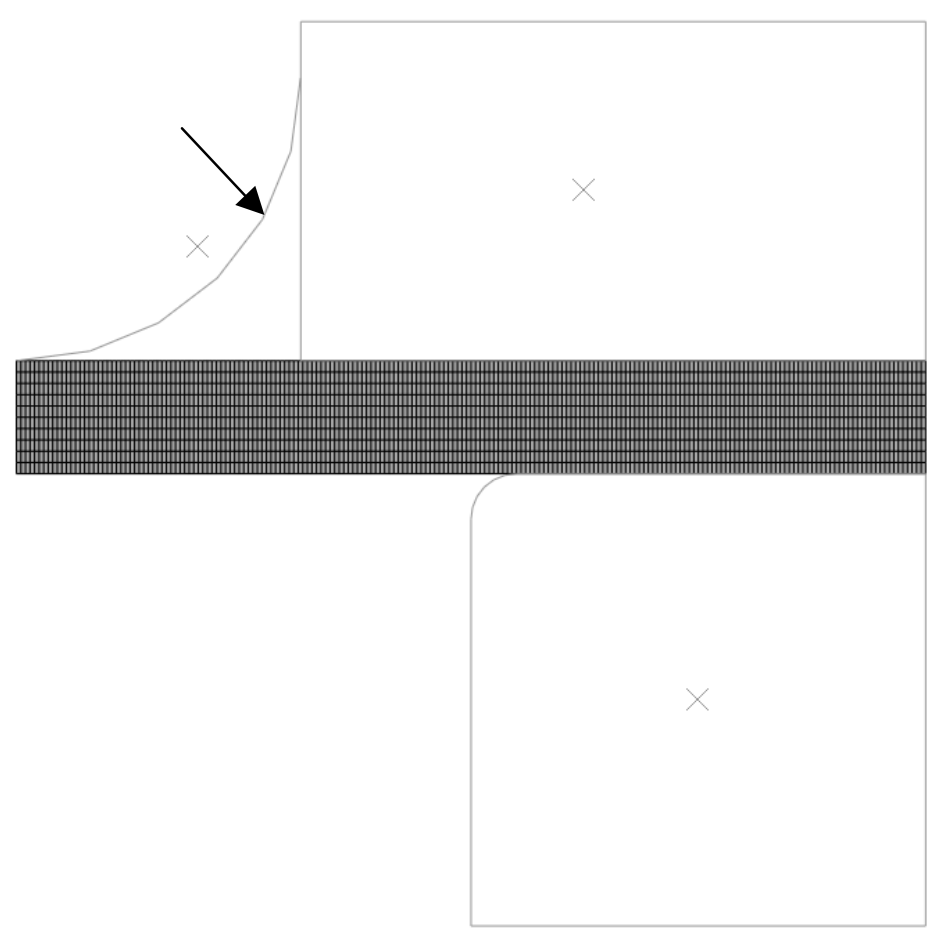

Fig. 20 FE model used for the SPT analyses. 


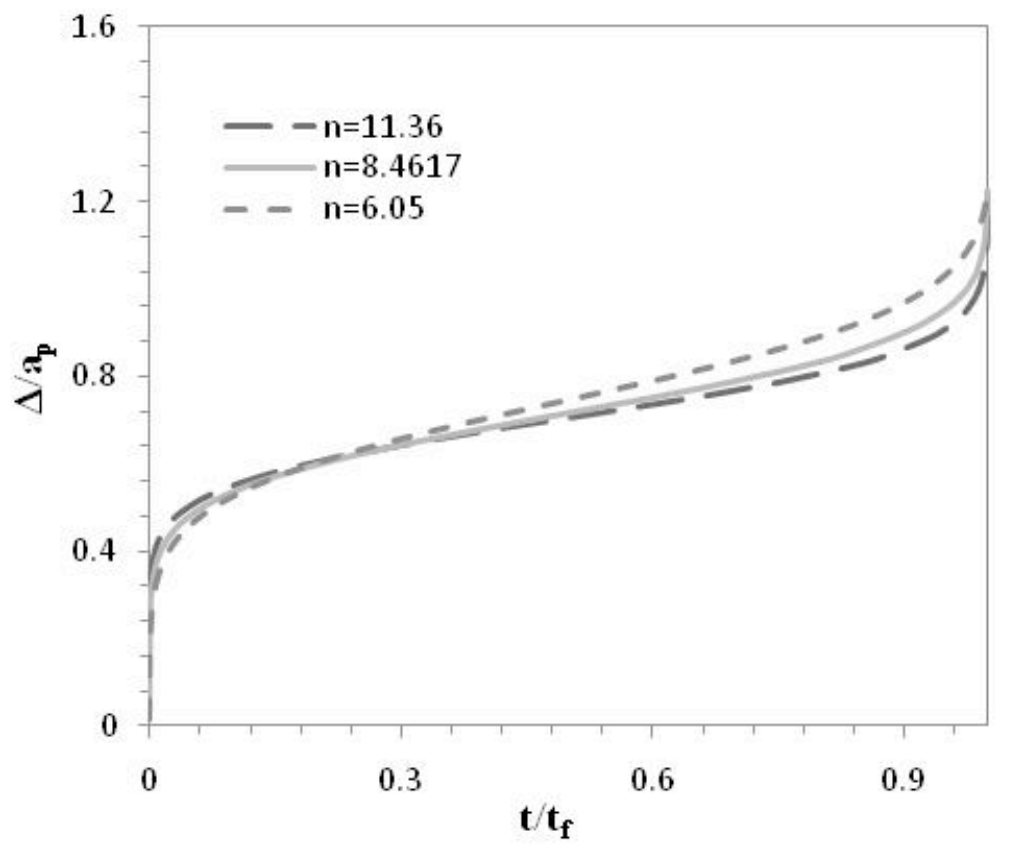

Fig. $21 \Delta$ versus $\mathrm{t}_{\mathrm{f}}$ for Norton law creep behaviour with $\mathrm{n}=6.05,8.4617,11.36$.

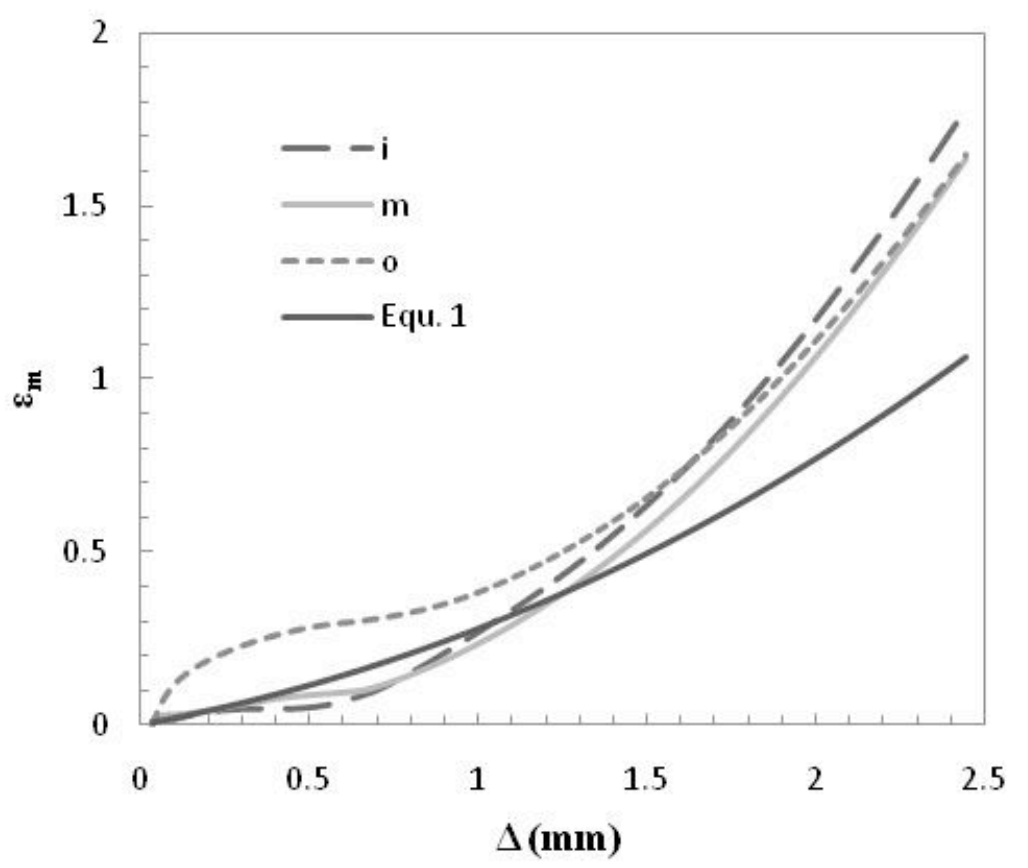

(a) Position A; $\mathrm{n}=6.05$ 


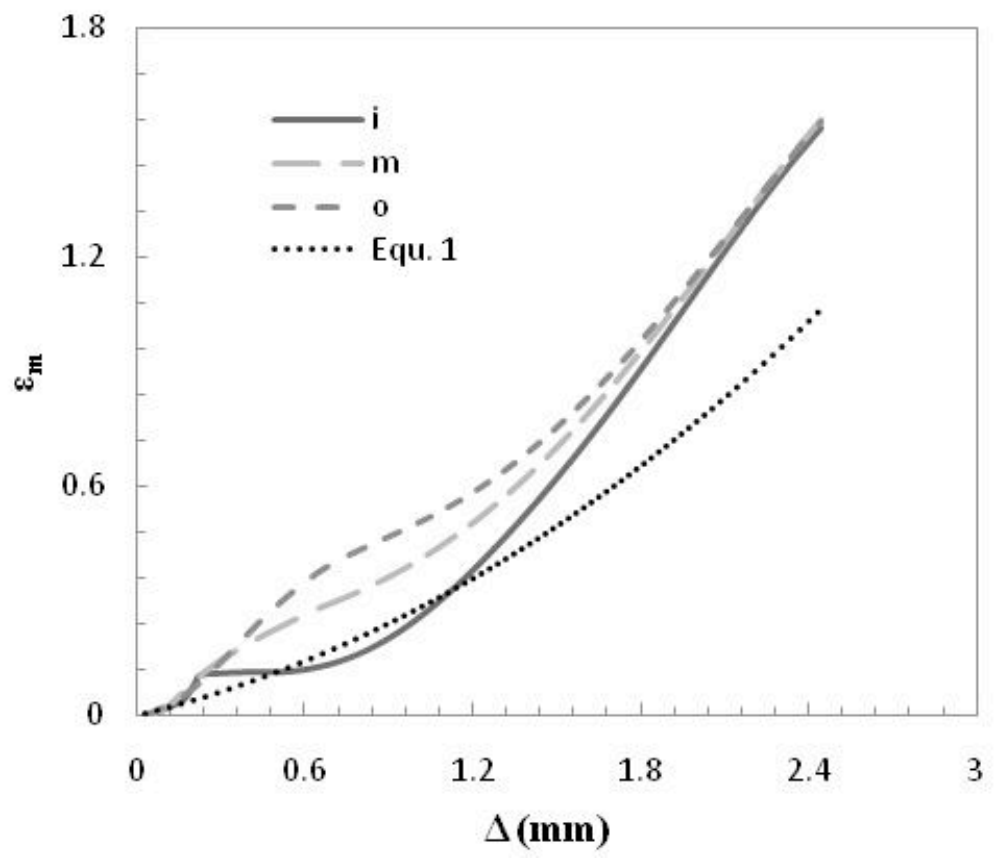

(b) Position B; $\mathrm{n}=6.05$

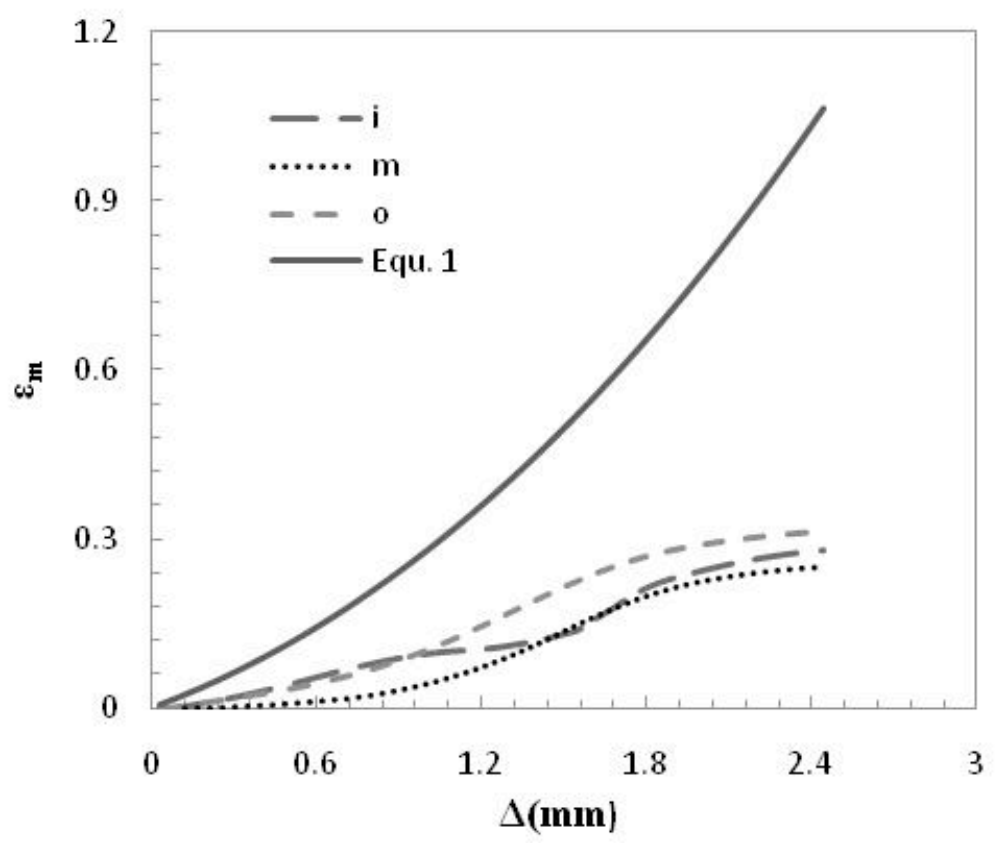

(c) Position $C ; n=6.05$

Fig. $22 \varepsilon_{\mathrm{m}}$ versus $\Delta$ at inside, i, middle, $\mathrm{m}$, and outside, o. 


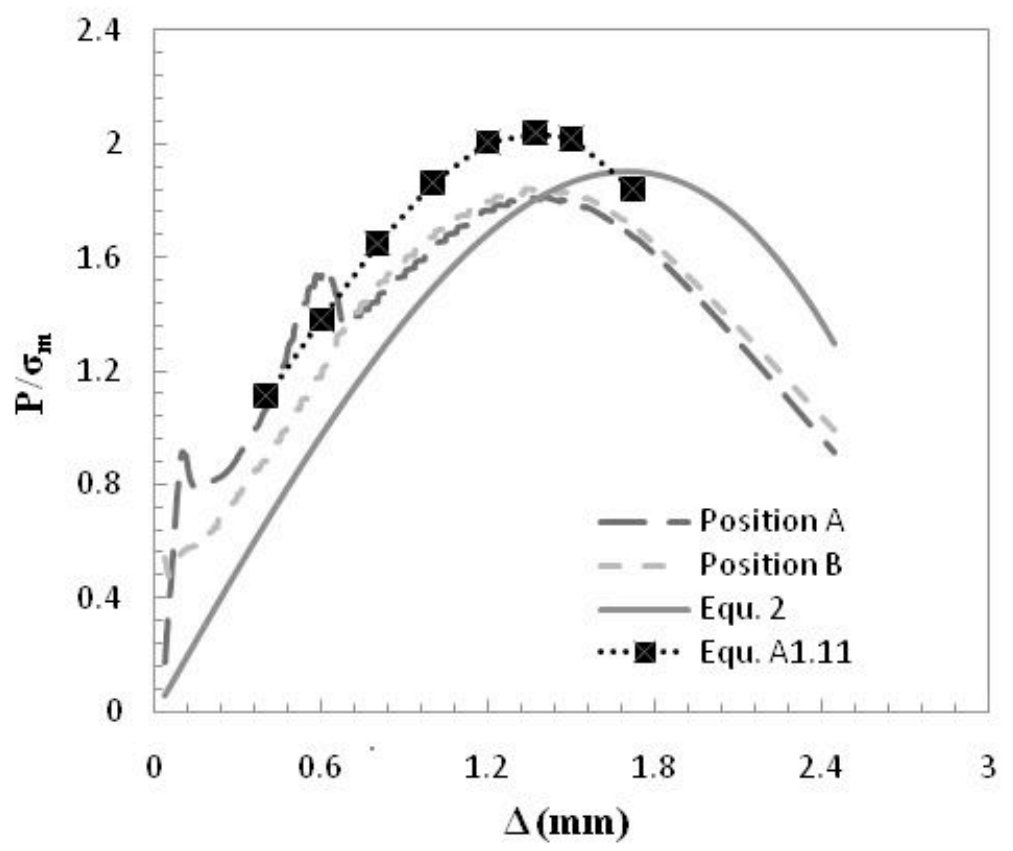

Fig. 23 Variation of $\mathrm{P} / \sigma_{\mathrm{m}}$ with $\Delta$ (middle, $\left.\mathrm{m}\right) ; \mathrm{n}=6.05$

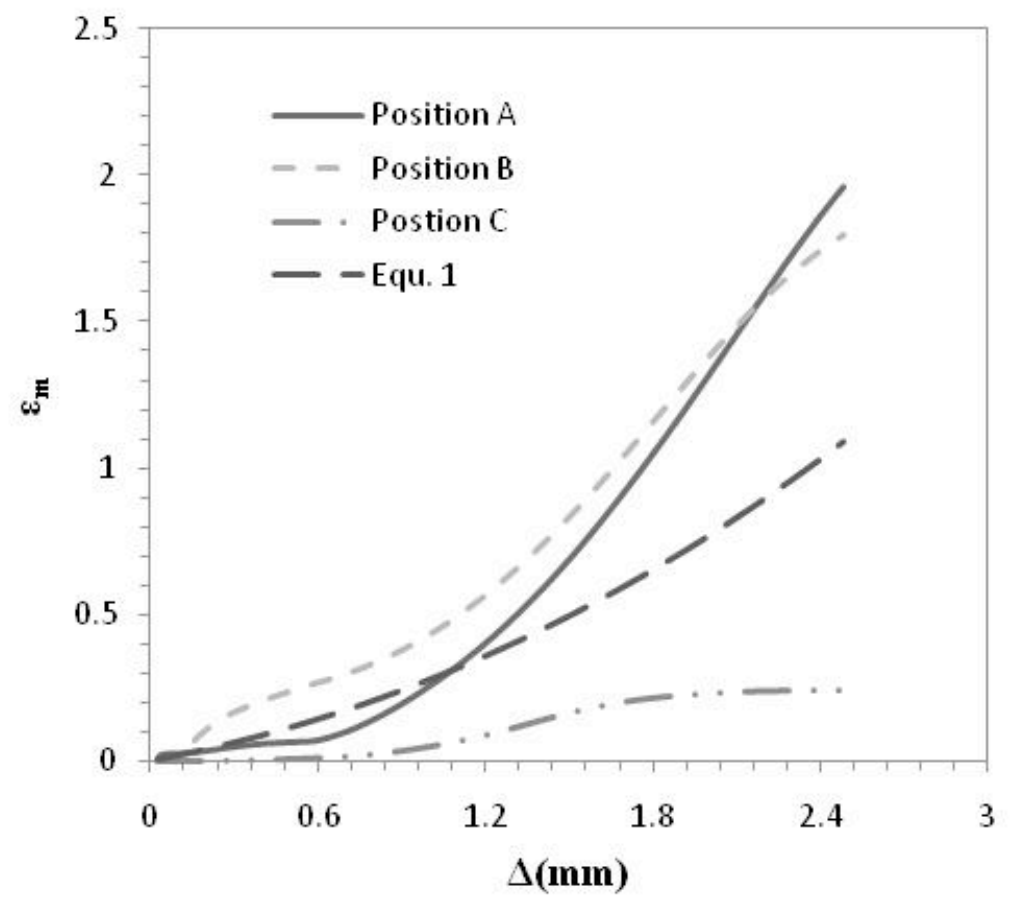

Fig. 24(a) $\varepsilon_{\mathrm{m}}$ (middle, $\mathrm{m}$ ) versus $\Delta$ at three positions; $\mathrm{n}=8.4617$. 


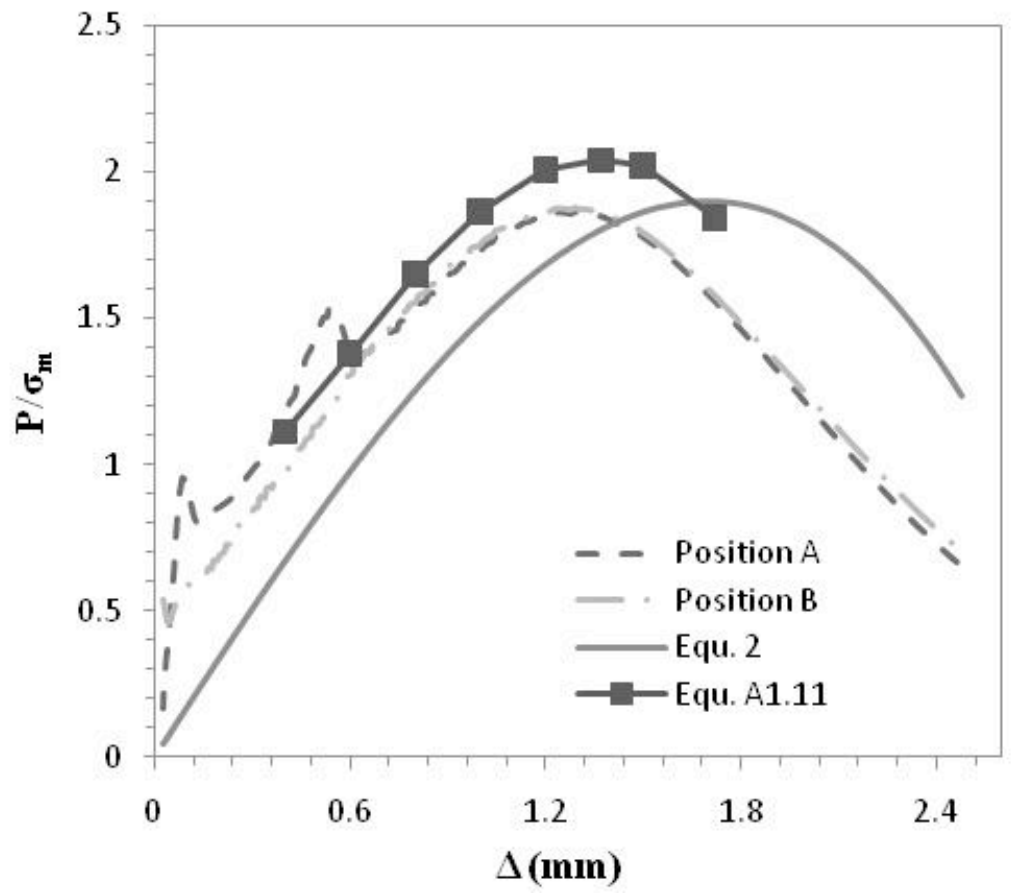

Fig. 24(b) Variation of $\mathrm{P} / \sigma_{\mathrm{m}}$ with $\Delta ; \mathrm{n}=8.4617$.

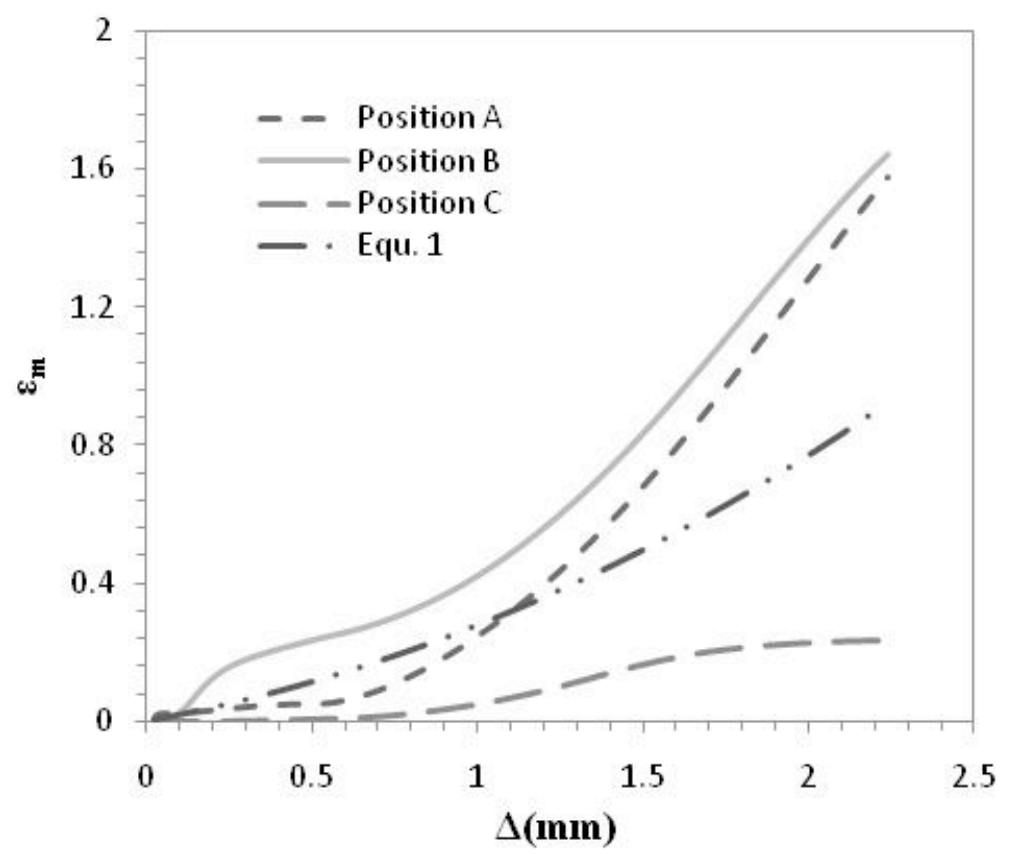

Fig 25(a) $\varepsilon_{\mathrm{m}}$ (middle, $\mathrm{m}$ ) versus $\Delta$ at three positions; $\mathrm{n}=11.36$. 


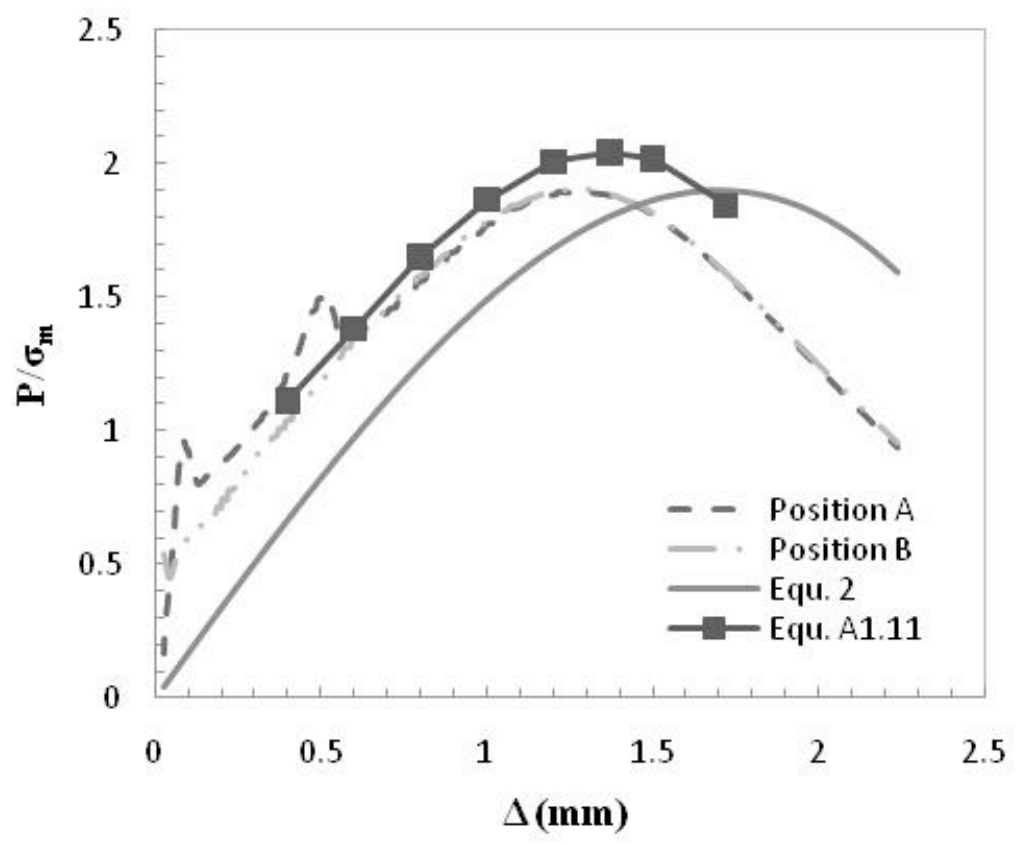

Fig. 25(b) Variation of $\mathrm{P} / \sigma_{\mathrm{m}}$ with $\Delta ; \mathrm{n}=11.36$.

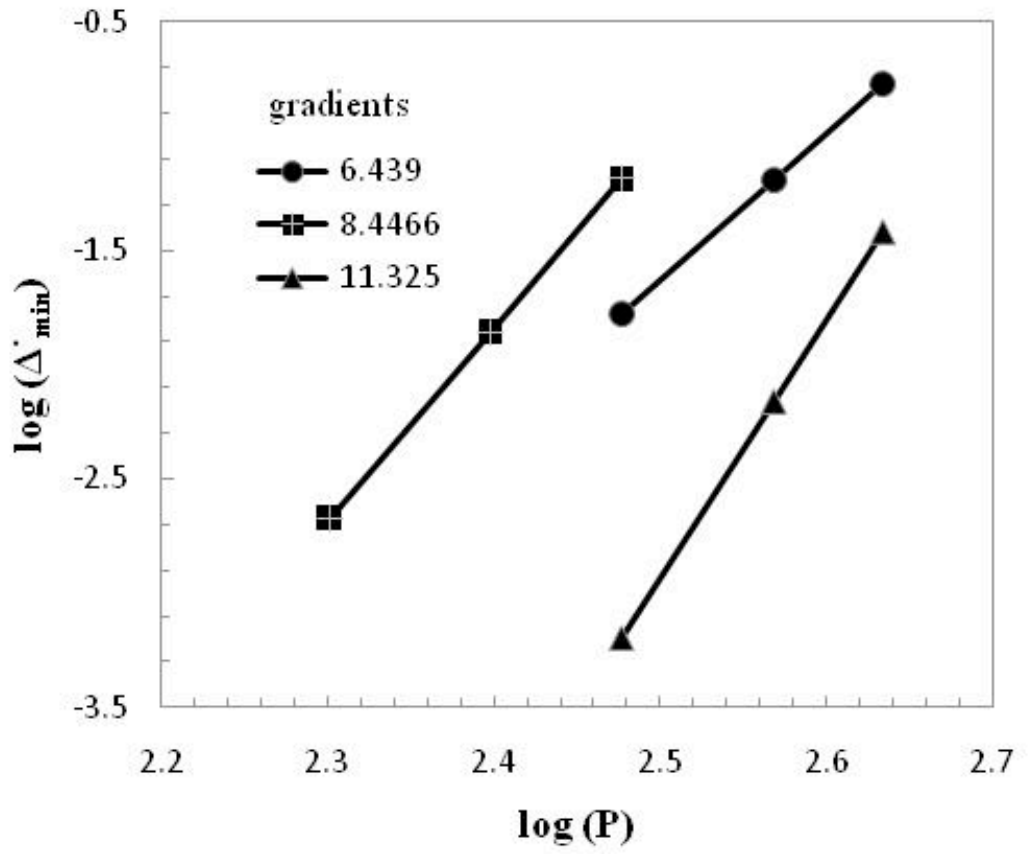

Fig. 26 FE predictions of $\log \left(\dot{\Delta}_{\dot{\Delta}_{\text {min }}}\right)$ versus $\log (\mathrm{P})$ based on Norton`s law $(\mathrm{n}=6.05 ; B=1.88 \mathrm{e}-18, \mathrm{n}=8.4617 ; \mathrm{B}=1.09 \mathrm{e}-20, \mathrm{n}=11.36 ; \mathrm{B}=5.38 \mathrm{e}-29)$. 


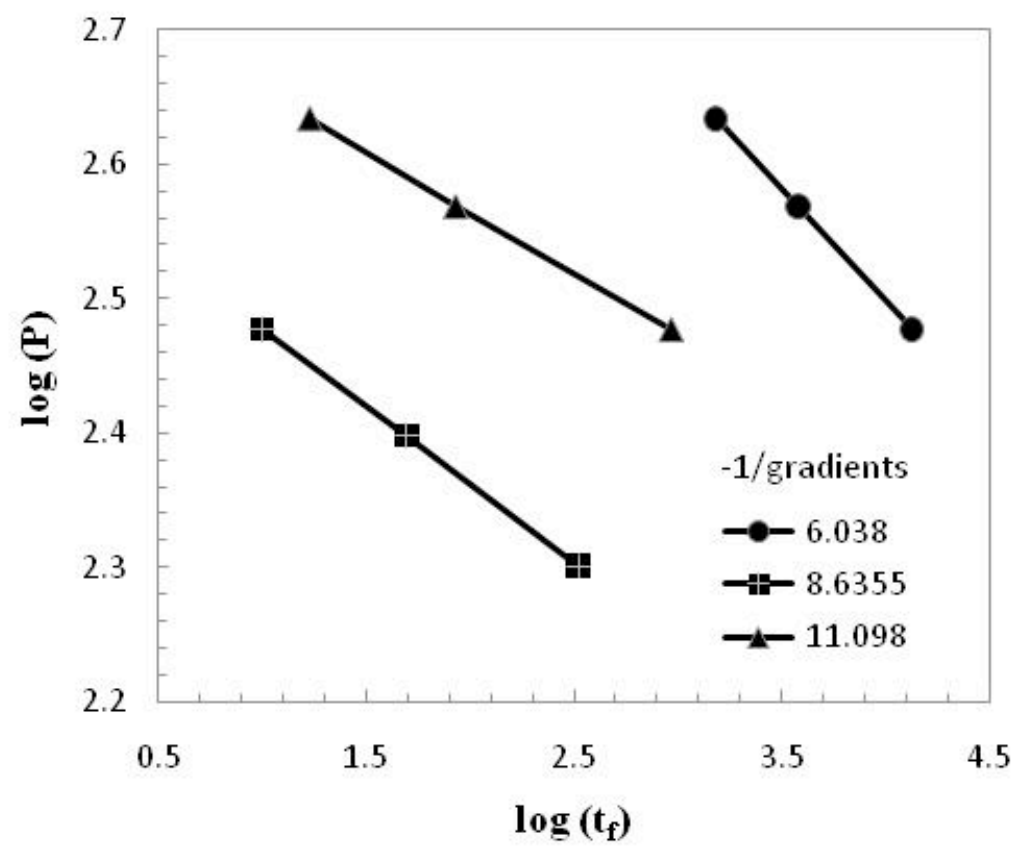

Fig. 27 FE predictions of $\log (\mathrm{P})$ versus $\log \left(\mathrm{t}_{\mathrm{f}}\right)$ based on Norton`s law $(\mathrm{n}=6.05 ; \mathrm{n}=8.4617 ; \mathrm{n}=11.36)$.

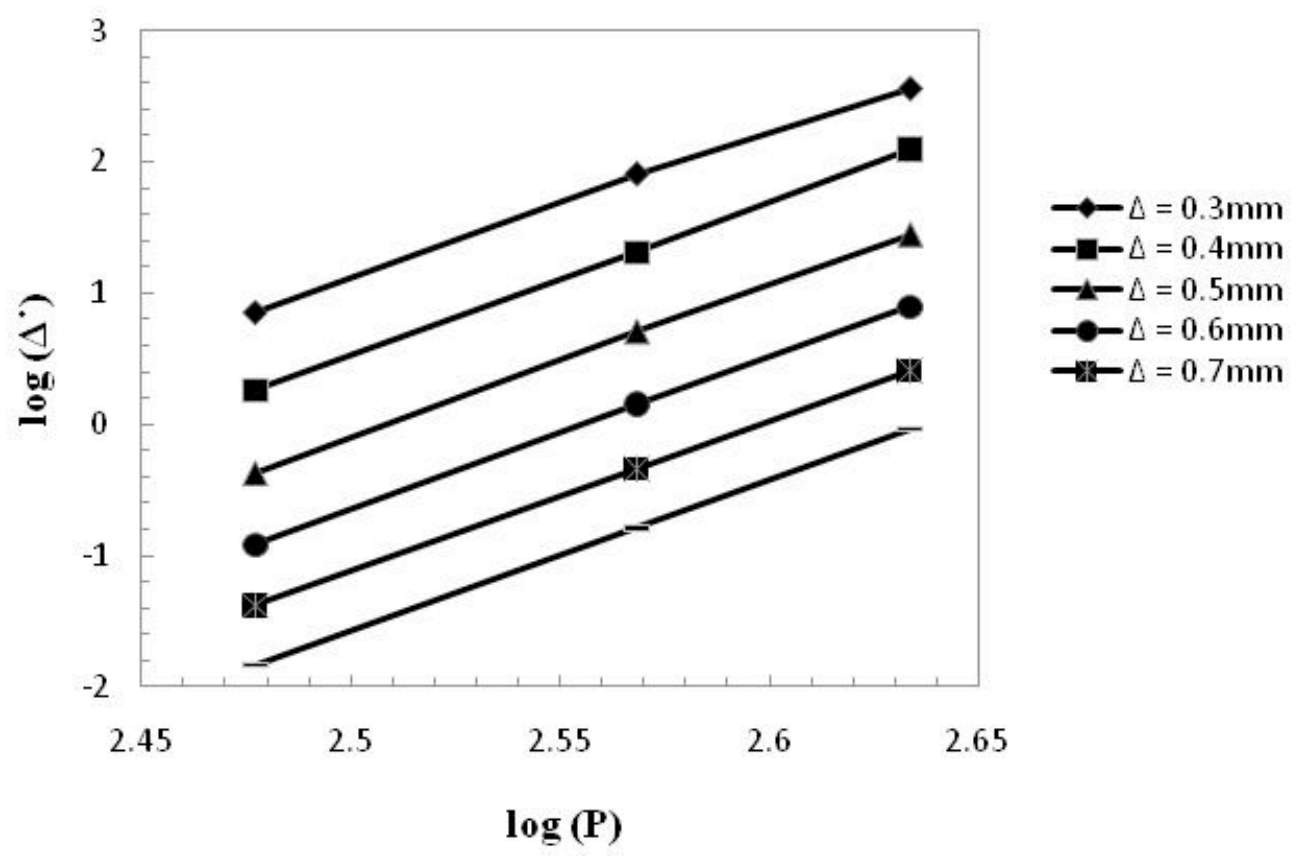

Fig. $28 \log (\dot{\Delta})$ versus $\log (\mathrm{P})$ for different displacements $(\mathrm{n}=11.36 ; \mathrm{B}=5.38 \mathrm{e}-29)$. 


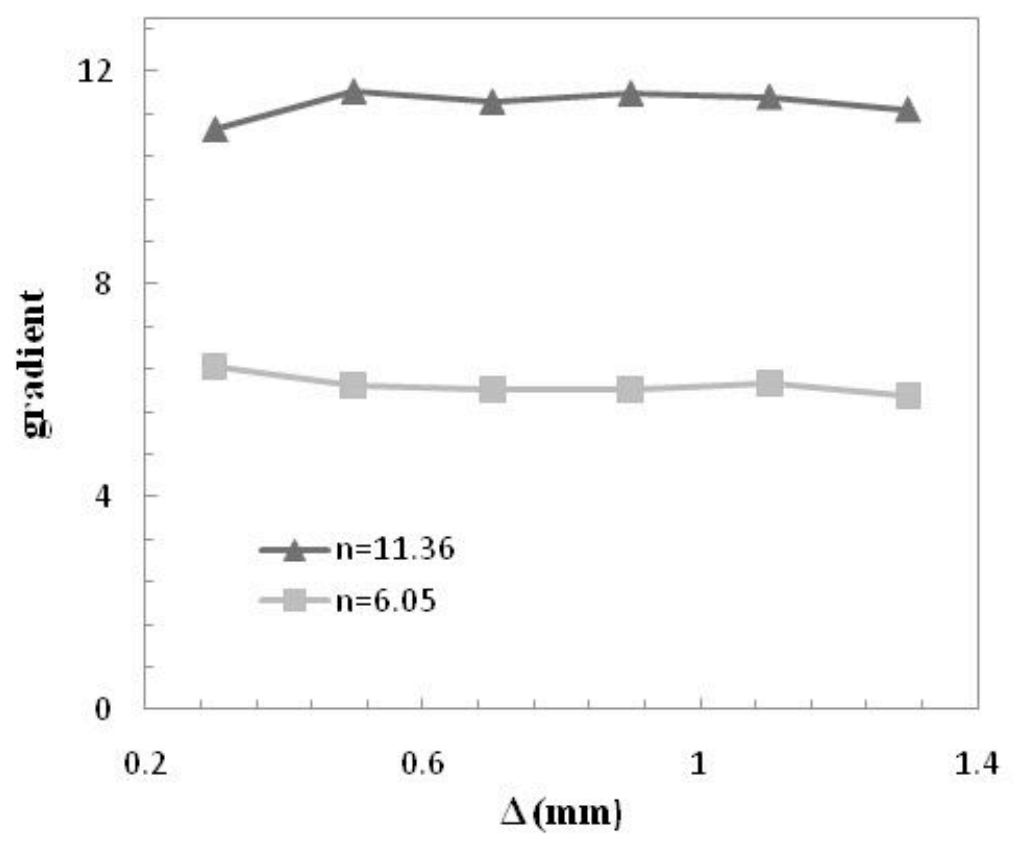

Fig. 29 Variation of gradient $($ of $\log (\dot{\Delta})$ versus $\log (\mathrm{P}))$ with $\Delta$.

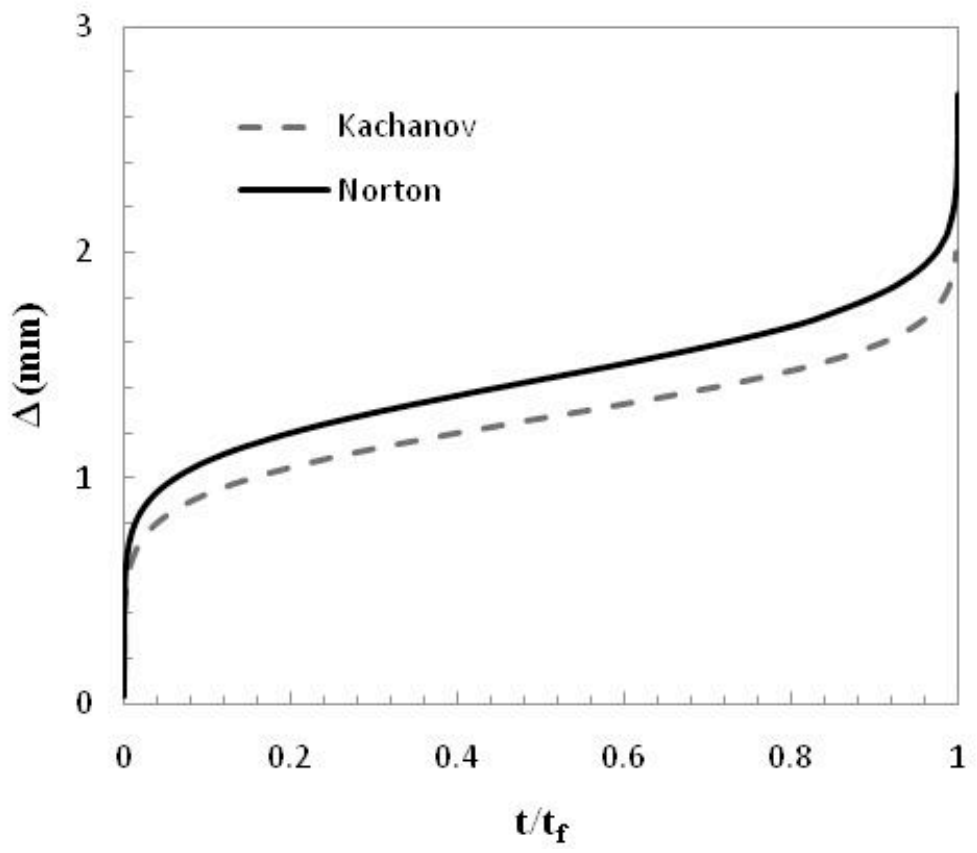

Fig. 30 Comparison of $\Delta$ versus $\mathrm{t} / \mathrm{t}_{\mathrm{f}}$ for both Kachanov damage model and Norton`s law. 


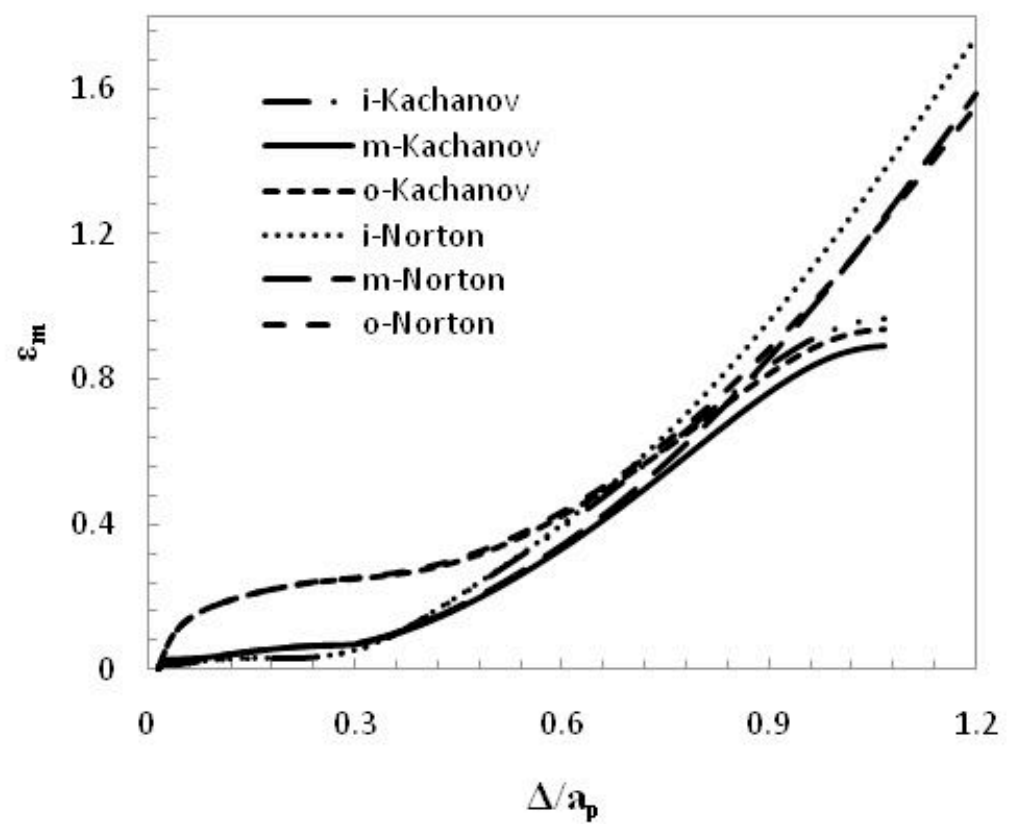

(a) Position $\mathrm{A}$

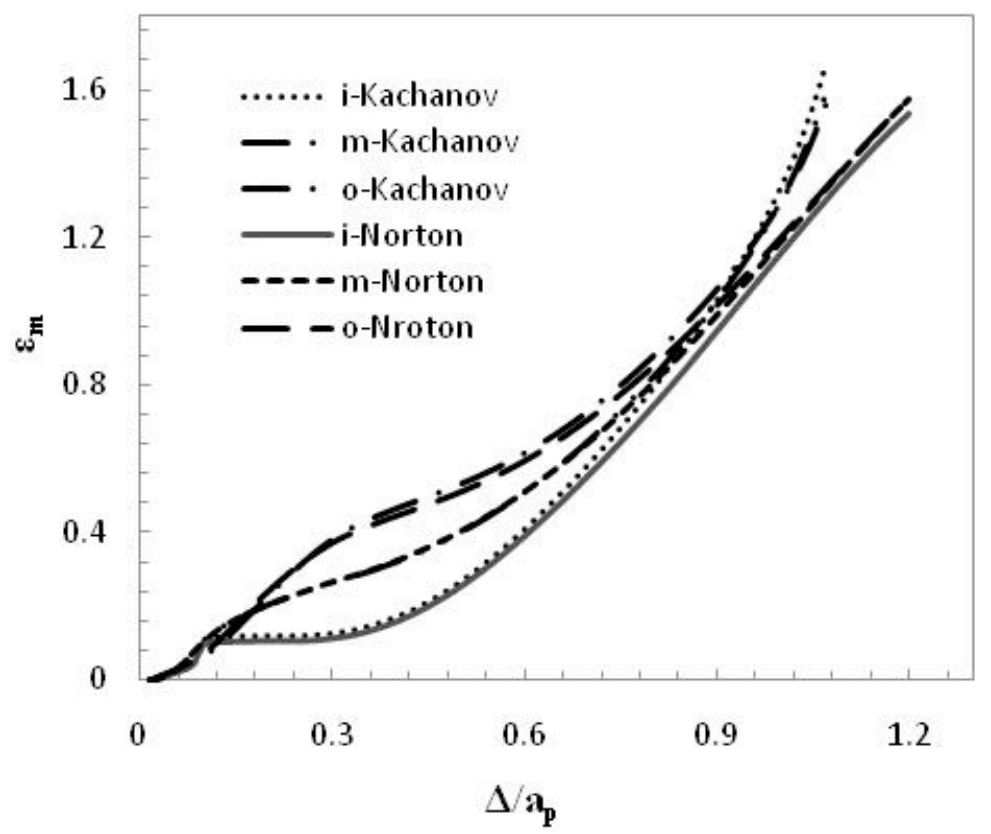

(b) Position B 


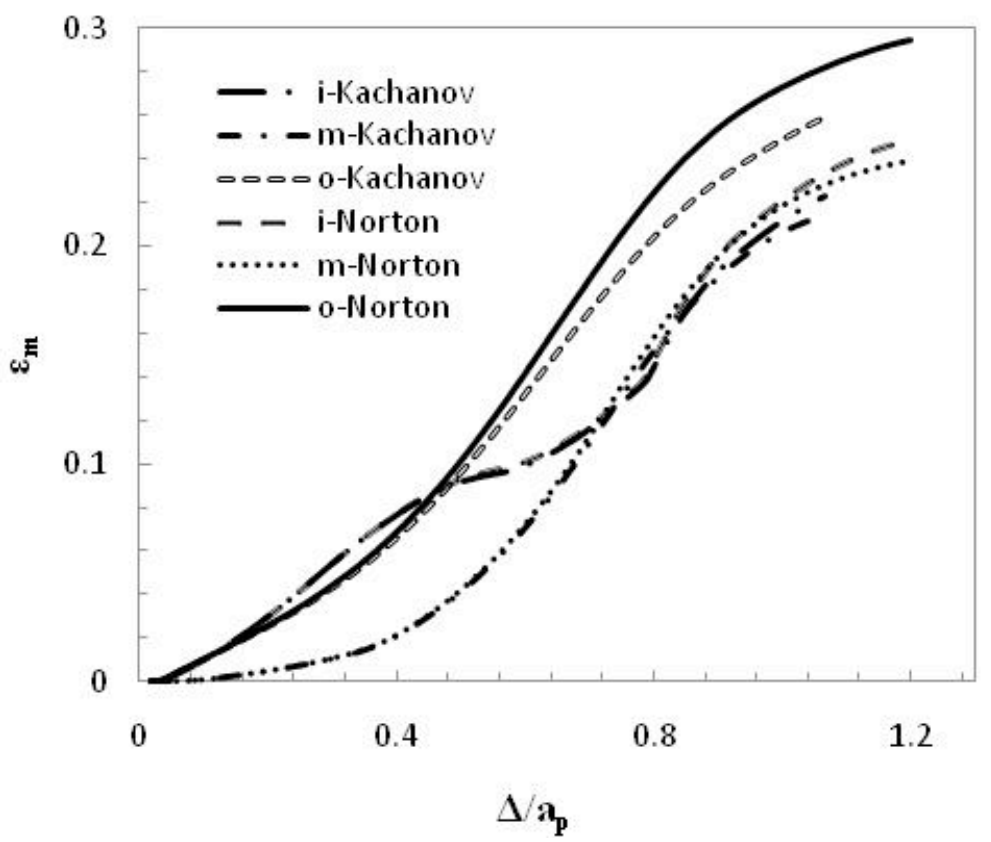

(c) Position C

Fig. $31 \varepsilon_{\mathrm{m}}$ versus $\Delta$ at inside, i, middle, $\mathrm{m}$, and outside, o, for both Kachanov damage model and Norton`s law.

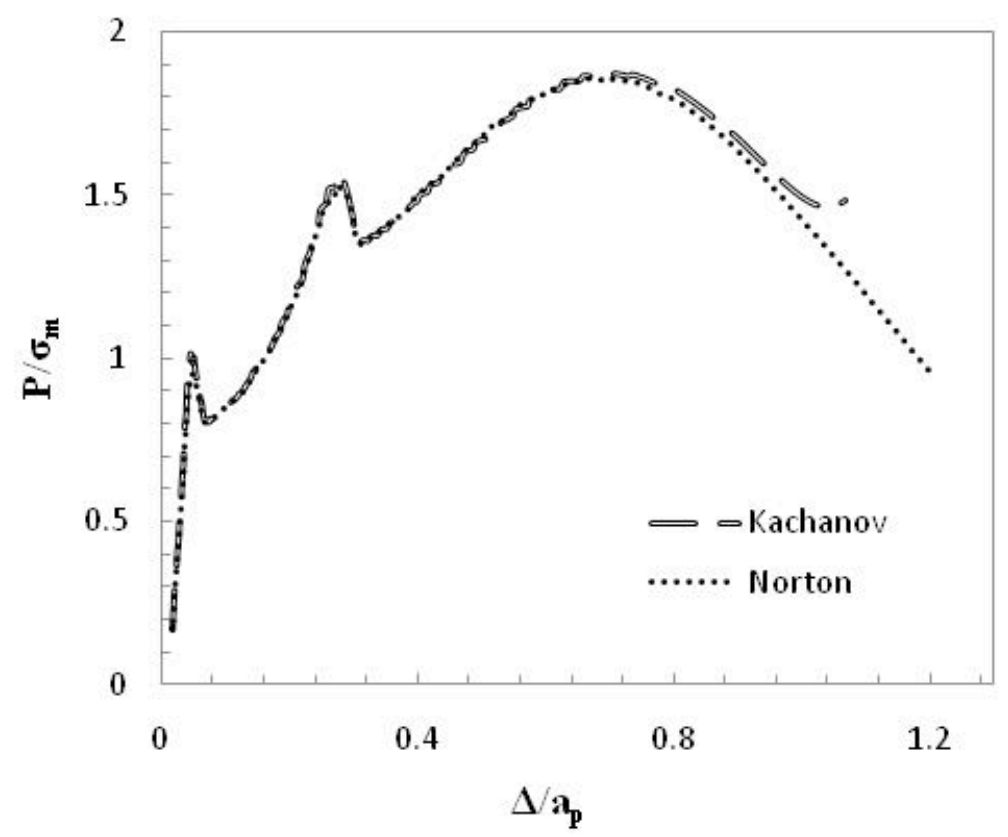

(a) Position $\mathrm{A}$ 


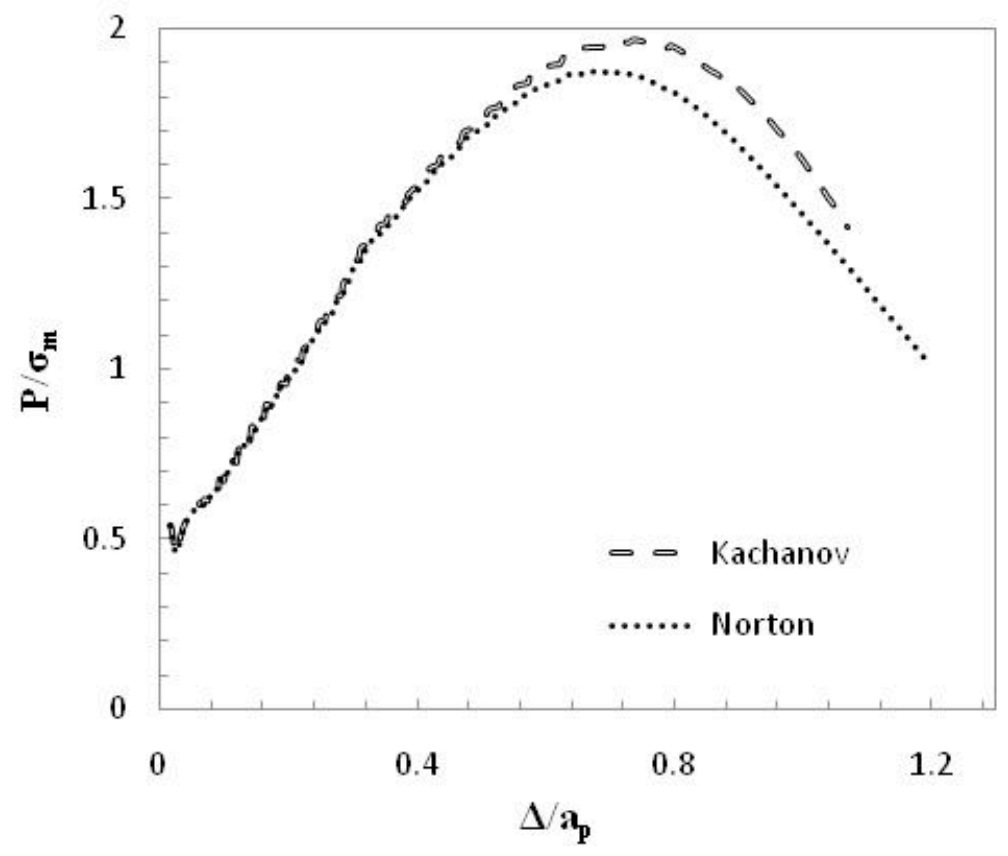

(b) Position B

Fig. 32 Variation of $\mathrm{P} / \sigma_{\mathrm{m}}$ with $\Delta / \mathrm{a}_{\mathrm{p}}($ middle, $\mathrm{m}$ ) for both Kachanov and Norton models.

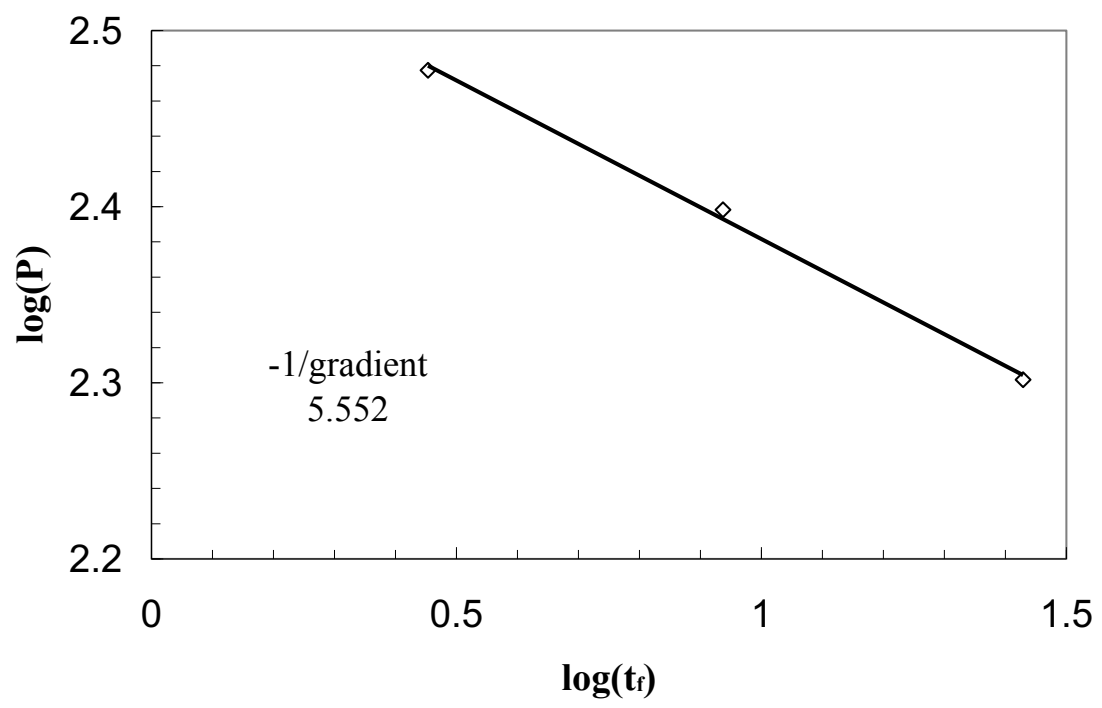

Fig. 33 FE predictions of $\log (\mathrm{P})$ versus $\log \left(\mathrm{t}_{\mathrm{f}}\right)$ based on Kachanov damage model. 


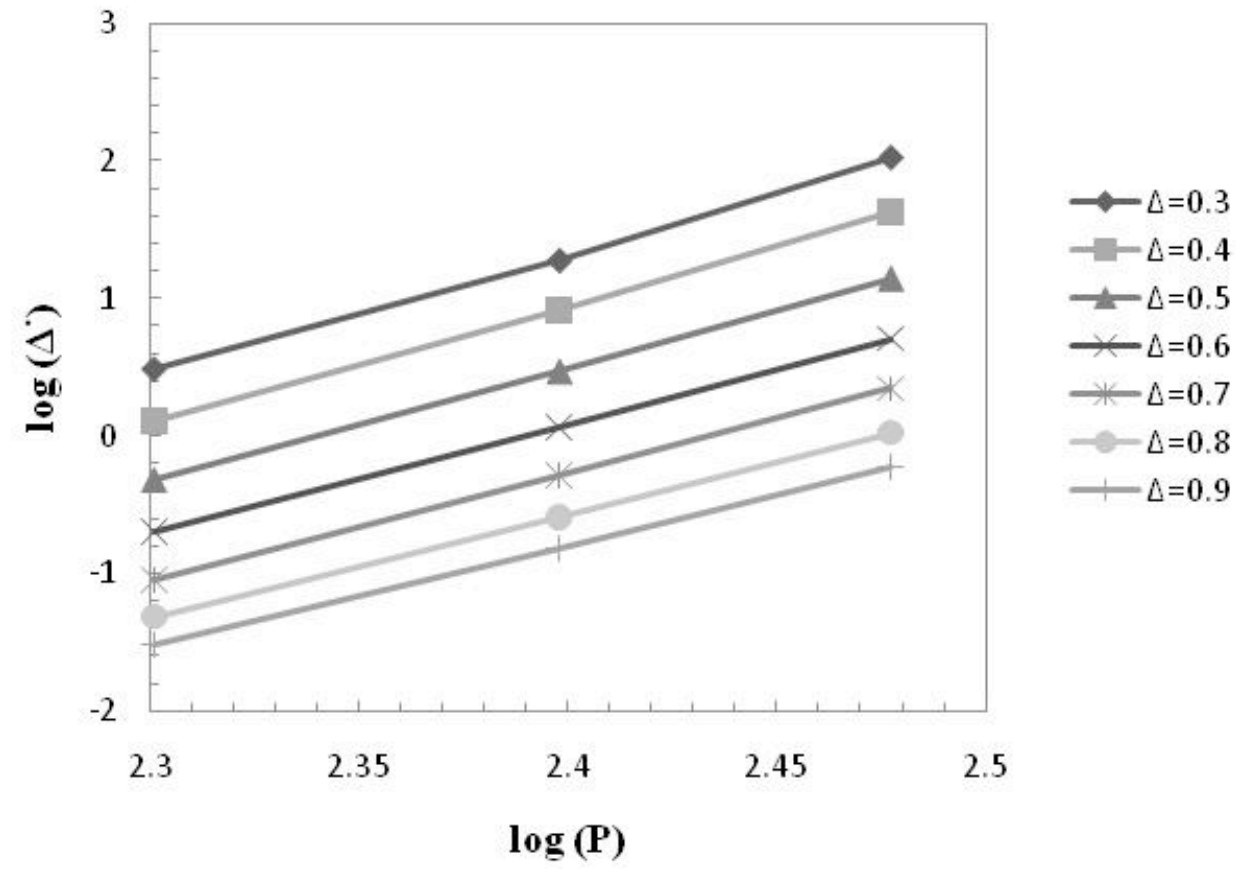

Fig. 34 FE predictions of $\log (\dot{\Delta})$ versus $\log (P)$ based on Kachanov damage model for different $\Delta$ values.

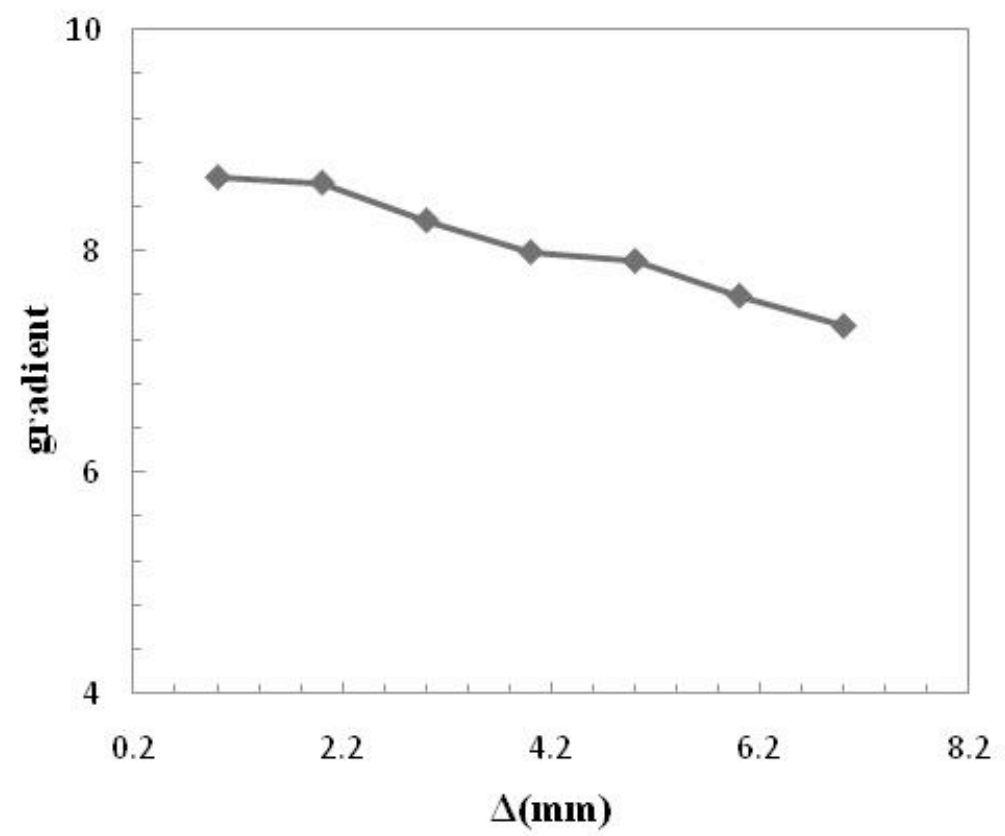

Fig. 35 Variation of the gradient for $\log (\dot{\Delta})$ versus $\log (\mathrm{P})$ with $\Delta$ for Kachanov model.(n $=$ $8.4617, \chi=6.789)$ 


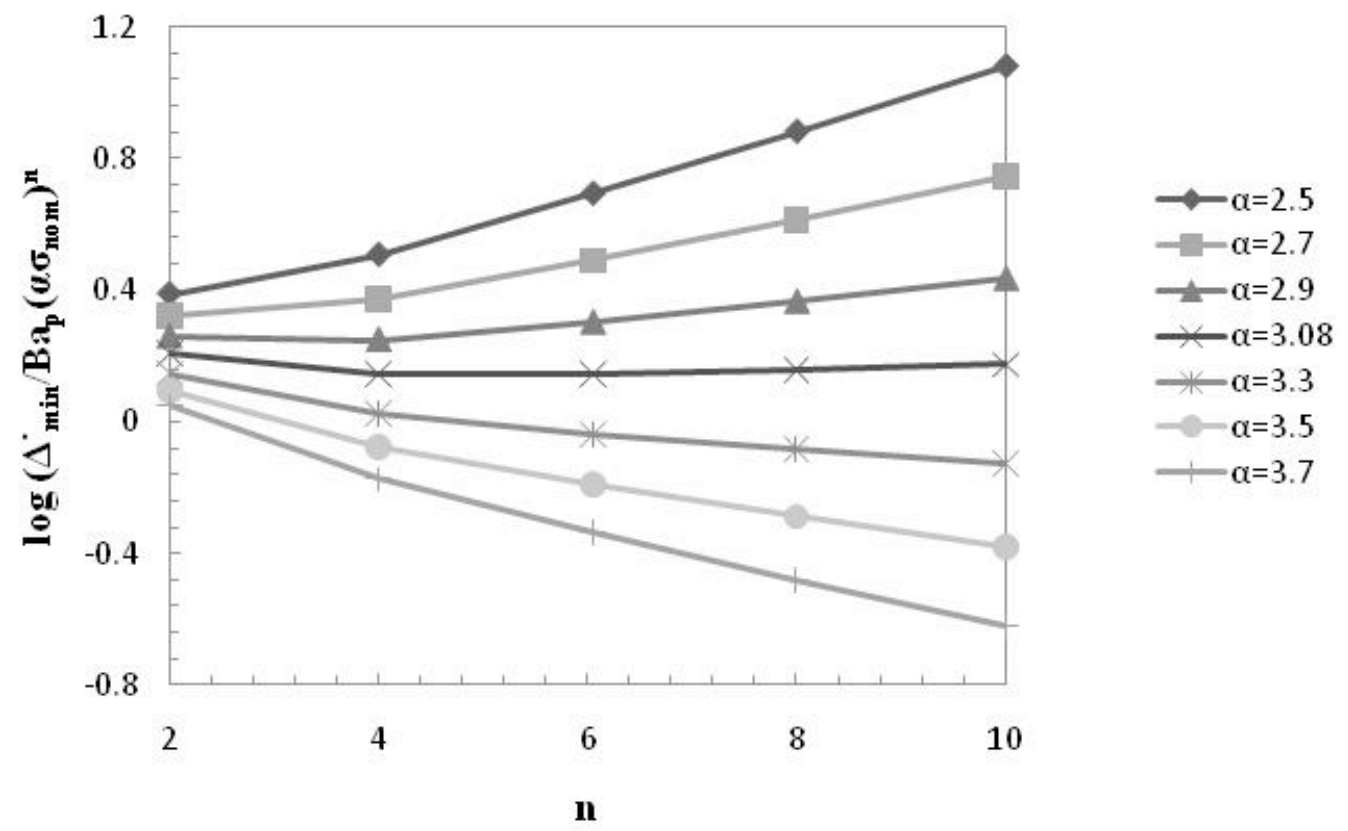

Fig. 36 Variations of $\log \left[\left(\dot{\Delta}_{\text {min }}\right) / \mathrm{Ba}_{\mathrm{p}}\left(\alpha \sigma_{\text {nom }}\right)^{\mathrm{n}}\right\rfloor$ with $\mathrm{n}$ for various $\alpha$-values.

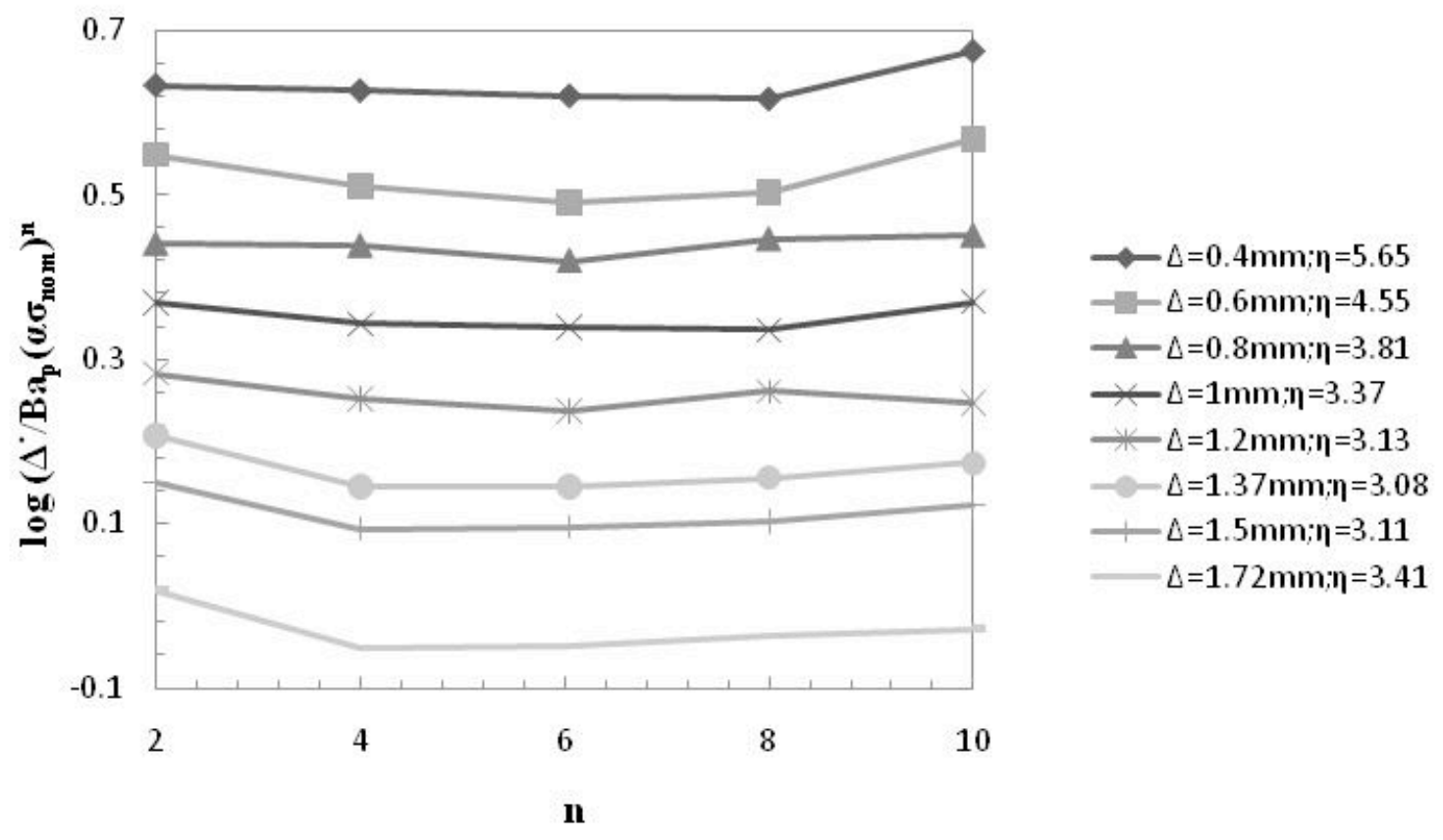

Fig. 37 Variations of $\log \left(\dot{\Delta} \dot{\Delta} / \mathrm{Ba}_{\mathrm{p}}\left(\eta \sigma_{\mathrm{nom}}\right)^{\mathrm{n}}\right)$ with $\mathrm{n}$ for various of $\Delta$-values for the $\alpha$-values which produce approximately horizontal lines (N.B. for this condition $\alpha=\eta$ ). 


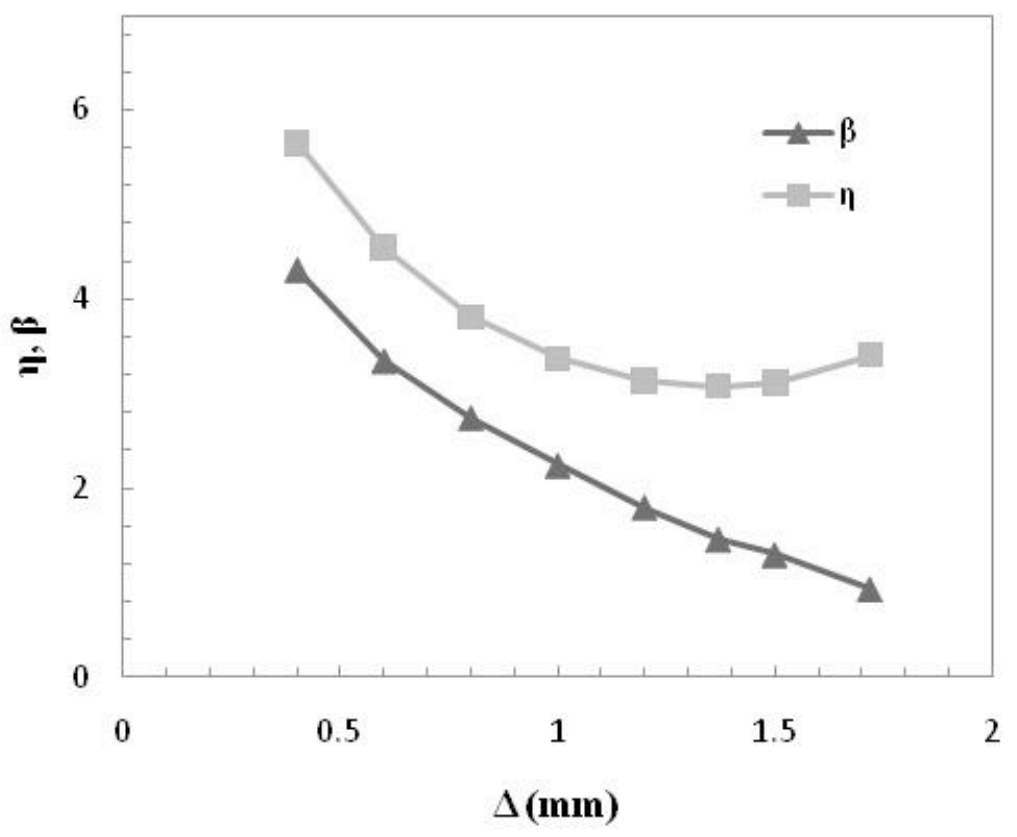

Fig. 38 Variation of reference parameters $(\alpha$ and $\beta)$ with $\Delta$.

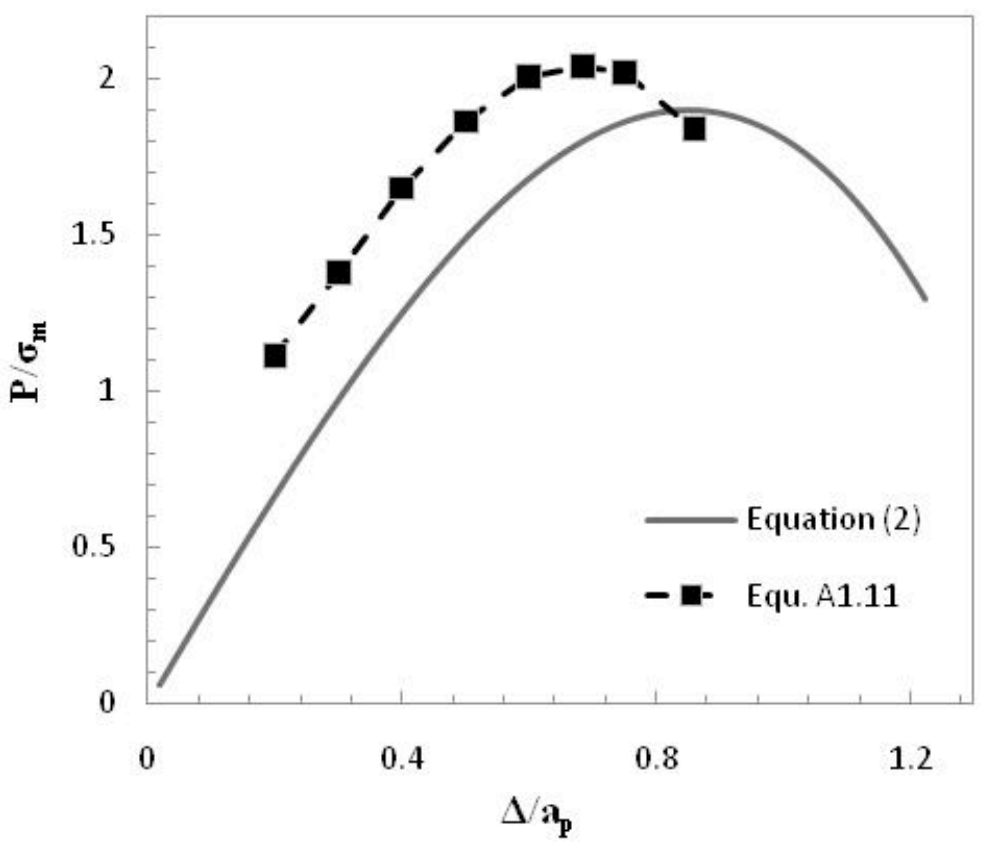

Fig. 39 Variation of $\mathrm{P} / \sigma_{\mathrm{m}}$ with $\Delta / \mathrm{a}_{\mathrm{p}}$ 


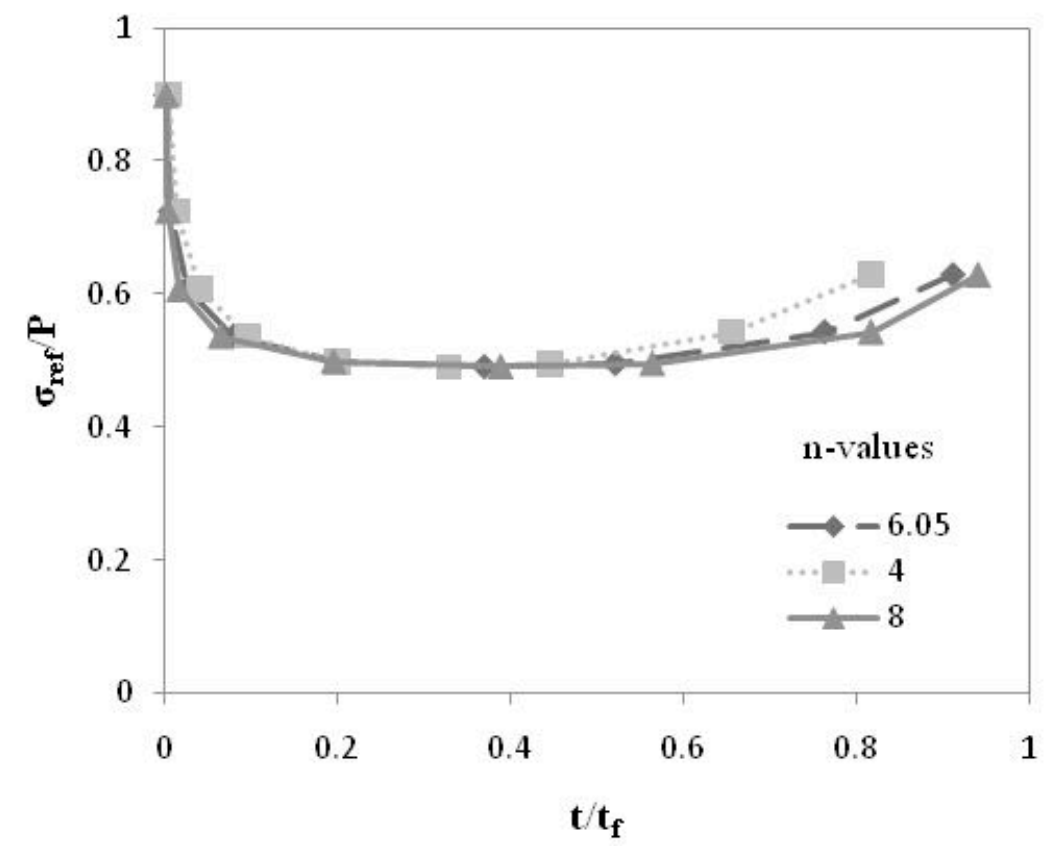

Fig. 40 Variations of $\sigma_{\text {ref }} / \mathrm{P}$ with $\mathrm{t} / \mathrm{t}_{\mathrm{f}}$, for different $\mathrm{n}$-values.

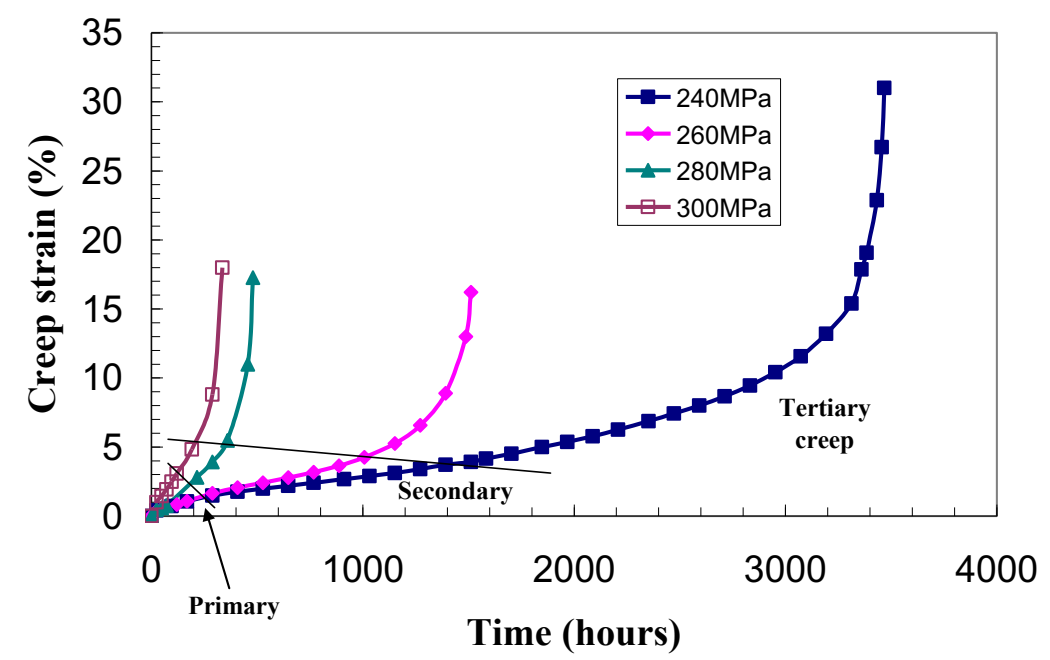

Fig. 41 Typical creep curves showing the primary, secondary and tertiary regions (for 316 stainless steel at $600^{\circ} \mathrm{C}$ ) 


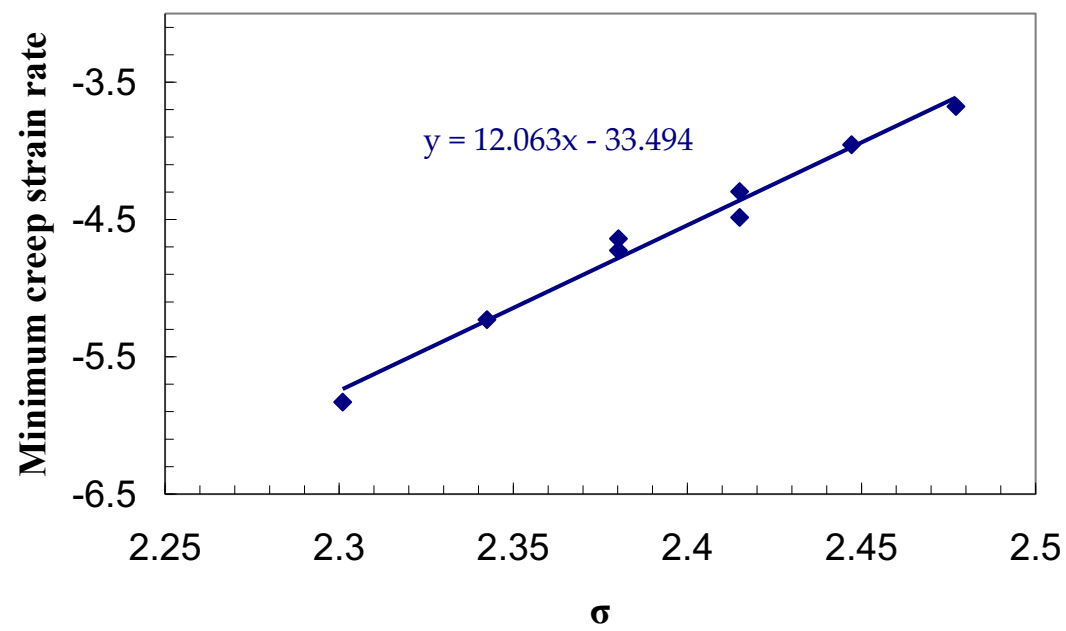

Fig. 42 Linear fit to minimum creep strain rate vs. $\sigma$ on a $\log$-log scale for a material obeying Norton's creep law (for 316 stainless steel at $600^{\circ} \mathrm{C}$ ) 